\title{
Athens Journal of Sciences
}

(ATINNER)

\section{Volume 6, Issue 4, December 2019}

\section{Articles}

Front Pages

VEBIL YILDIRIM

Centrifugal Force-Induced Elastic Field for a Stress-Free Annulus Made of Functionally Graded Polar Orthotropic Material from Circular Plates to Rings

HUSSIEN MOTAWEH \& MARWA NABIL

Porous Silica for Removing Organic Impurities from Wastewater

THOMAS FEHLMANN \& EBERHARD KRANICH

Testing Artificial Intelligence by Customers' Needs

MICHAEL OGBEIDE \& JOSEPH OSEMWENKHAE

Some Improvements in Nonparametric Multivariate Kernel Density Estimation 


\section{Mission}

ATINER is a World Non-Profit Association of Academics and Researchers based in Athens. ATINER is an independent Association with a Mission to become a forum where Academics and Researchers from all over the world can meet in Athens, exchange ideas on their research and discuss future developments in their disciplines, as well as engage with professionals from other fields. Athens was chosen because of its long history of academic gatherings, which go back thousands of years to Plato's Academy and Aristotle's Lyceum. Both these historic places are within walking distance from ATINER's downtown offices. Since antiquity, Athens was an open city. In the words of Pericles, Athens"... is open to the world, we never expel a foreigner from learning or seeing". ("Pericles' Funeral Oration", in Thucydides, The History of the Peloponnesian War). It is ATINER's mission to revive the glory of Ancient Athens by inviting the World Academic Community to the city, to learn from each other in an environment of freedom and respect for other people's opinions and beliefs. After all, the free expression of one's opinion formed the basis for the development of democracy, and Athens was its cradle. As it turned out, the Golden Age of Athens was in fact, the Golden Age of the Western Civilization. Education and (Re)searching for the 'truth' are the pillars of any free (democratic) society. This is the reason why Education and Research are the two core words in ATINER's name. 
The Athens Journal of Sciences

ISSN NUMBER: 2241-8466- DOI: 10.30958/ajs

Volume 6, Issue 4, December 2019

Download the entire issue ( $\underline{\mathrm{PDF}})$

Front Pages

i-viii

Centrifugal Force-Induced Elastic Field for a Stress-

231

Free Annulus Made of Functionally Graded Polar

Orthotropic Material from Circular Plates to Rings

Vebil Yildirn

Porous Silica for Removing Organic Impurities from

253

Wastewater

Hussien Motaweh \& Marwa Nabil

Testing Artificial Intelligence by Customers' Needs

Thomas Fehlmann \& Eberhard Kranich

Some Improvements in Nonparametric Multivariate

Kernel Density Estimation

Michael Ogbeide \& Joseph Osemwenkhae 


\section{Athens Journal of Sciences Editorial and Reviewers' Board}

\section{Editors}

- Dr. Nicolas Abatzoglou, Head, Environment Unit, ATINER; Professor, Department of Chemical \& Biotechnological Engineering, Université de Sherbrooke, Canada; Chair Pfizer, Processes and Analytical Technologies in Pharmaceutical Engineering; Director of GRTP-C \& P (Groupe de recherches sur les technologies et procédés de conversion et pharmaceutiques); Fellow of Canadian Academy of Engineering.

- Dr. Christopher Janetopoulos, Head, Biology Unit, ATINER \& Associate Professor, University of the Sciences, USA.(Biology)

- Dr. Ethel Petrou, Academic Member, ATINER \& Professor and Chair, Department of Physics, Erie Community College-South, State University of New York, USA.

- Dr. Ellene Tratras Contis, Head, Chemistry Unit, ATINER \& Professor of Chemistry, Eastern Michigan University, USA.(Chemistry)

\section{Editorial Board}

- Dr. Colin Scanes, Academic Member, ATINER \& Emeritus Professor, University of Wisconsin Milwaukee, USA.

- Dr. Dimitris Argyropoulos, Professor, North Carolina State University, USA.

- Dr. Cecil Stushnoff, Emeritus Professor, Colorado State University, USA.

- Dr. Hikmat Said Hasan Hilal, Academic Member, ATINER \& Professor, Department of Chemistry, An-Najah N. University, Palestine.

- Dr. Jean Paris, Professor, Polytechnique Montreal, Canada.

- Dr. Shiro Kobayashi, Academic Member, ATINER \& Distinguished Professor, Kyoto Institute of Technology, Kyoto University, Japan.

- Dr. Jose R. Peralta-Videa, Academic Member, ATINER \& Research Specialist and Adjunct Professor, Department of Chemistry, The University of Texas at El Paso, USA.

- Dr. Jean-Pierre Bazureau, Academic Member, ATINER \& Professor, Institute of Chemical Sciences of Rennes ICSR, University of Rennes 1, France.

- Dr. Mohammed Salah Aida, Professor, Taibah University, Saudi Arabia.

- Dr. Zagabathuni Venkata Panchakshari Murthy, Academic Member, ATINER \& Professor/Head, Department of Chemical Engineering, Sardar Vallabhbhai National Institute of Technology, India.

- Dr. Alexander A. Kamnev, Professor, Institute of Biochemistry and Physiology of Plants and Microorganisms, Russian Academy of Sciences, Russia.

- Dr. Carlos Nunez, Professor, Physics Department, University of Wales Swansea, UK.

- Dr. Anastasios Koulaouzidis, Academic Member, ATINER \& Associate Specialist and Honorary Clinical Fellow of the UoE, The Royal Infirmary of Edinburgh, The University of Edinburgh, UK.

- Dr. Francisco Lopez-Munoz, Professor, Camilo Jose Cela University, Spain.

- Dr. Panagiotis Petratos, Professor, California State University-Stanislaus, USA.

- Dr. Yiannis Papadopoulos, Professor of Computer Science, Leader of Dependable Systems Research Group, University of Hull, UK.

- Dr. Joseph M. Shostell, Professor and Department Head, Math, Sciences \& Technology Department, University of Minnesota Crookston, USA.

- Dr. Ibrahim A. Hassan, Professor of Environmental Biology, Faculty of Science, Alexandria University, Egypt \& Centre of Excellence in Environmental Studies, King Abdulaziz University, Saudi Arabia.

- Dr. Laurence G. Rahme, Associate Professor, Department of Surgery, Microbiology and Immunobiology, Harvard Medical School, Boston, Massachusetts \& Director of Molecular Surgical Laboratory, Burns Unit, Department of Surgery, Massachusetts General Hospital, USA.

- Dr. Stefano Falcinelli, Academic Member, ATINER \& Associate Professor, Department of Civil and Environmental Engineering University of Perugia, Italy.

- Dr. Mitra Esfandiarei, Academic Member, ATINER \& Assistant Professor, Midwestern University, USA

- Dr. Athina Meli, Academic Member, Academic Member, ATINER, Visiting Scientist and Research Scholar, University of Gent \& University of Liege, Belgium and Ronin Institute Montclair, USA.

- Vice President of Publications: Dr Zoe Boutsioli

- General Managing Editor of all ATINER's Publications: Ms. Afrodete Papanikou

- ICT Managing Editor of all ATINER's Publications: Mr. Kostas Spyropoulos

- Managing Editor of this Journal: Ms. Olga Gkounta ( $\underline{\text { bio }})$

\section{Reviewers' Board}

Click Here 


\section{President's Message}

All ATINER's publications including the e-journals are open access without any costs (submission, processing, publishing, open access paid by authors, open access paid by readers etc.) and are independent of the presentations made at any of the many small events (conferences, symposiums, forums, colloquiums, courses, roundtable discussions) organized by ATINER throughout the year. The intellectual property rights of the submitted papers remain with the author.

Before you submit, please make sure your paper meets some basic academic standards, which include proper English. Some articles will be selected from the numerous papers that have been presented at the various annual international academic conferences organized by the different divisions and units of the Athens Institute for Education and Research.

The plethora of papers presented every year will enable the editorial board of each journal to select the best ones, and in so doing, to produce a quality academic journal. In addition to papers presented, ATINER encourages the independent submission of papers to be evaluated for publication.

The current issue of the Athens Journal of Sciences (AJS) is the fourth issue of the sixth volume (2019). The reader will notice some changes compared with the previous volumes, which I hope is an improvement. An effort has been made to include papers which extent to different fields of the Natural and Formal Sciences.

Gregory T. Papanikos, President

Athens Institute for Education and Research 


\title{
Athens Institute for Education and Research
}

\section{A World Association of Academics and Researchers}

\author{
$8^{\text {th }}$ Annual International Conference on Chemistry \\ 20-23 July 2020, Athens, Greece
}

The Chemistry Unit of ATINER, will hold its $8^{\text {th }}$ Annual International Conference on Chemistry, 20-23 July 2020, Athens, Greece sponsored by the Athens Journal of Sciences. The aim of the conference is to bring together academics and researchers of all areas of chemistry and other related disciplines. You may participate as stream organizer, presenter of one paper, chair a session or observer. Please submit a proposal using the form available (https://www.atiner.gr/2020/FORMCHE.doc).

Academic Members Responsible for the Conference

- Dr. Ellene Tratras Contis, Head, Chemistry Unit, ATINER \& Professor of Chemistry, Eastern Michigan University, USA.

- Dr. Nicolas Abatzoglou, Head, Environment Unit, ATINER \& Professor, Department of Chemical \& Biotechnological Engineering, University of Sherbrook, Canada, Chair Pfizer, PAT in Pharmaceutical Engineering, Director GREEN-TPV and GRTP-C \& Pwelcomes.

\section{Important Dates}

- Abstract Submission: 16 December 2019

- Acceptance of Abstract: 4 Weeks after Submission

- Submission of Paper: 22 June 2020

\section{Social and Educational Program}

The Social Program Emphasizes the Educational Aspect of the Academic Meetings of Atiner.

- Greek Night Entertainment (This is the official dinner of the conference)

- Athens Sightseeing: Old and New-An Educational Urban Walk

- Social Dinner

- Mycenae Visit

- Exploration of the Aegean Islands

- Delphi Visit

- Ancient Corinth and Cape Sounion

\section{Conference Fees}

Conference fees vary from $400 €$ to $2000 €$ Details can be found at: https://www.atiner.gr/2019fees 


\section{Athens Institute for Education and Research}

A World Association of Academics and Researchers

\section{$8^{\text {th }}$ Annual International Conference on Physics 20-23 July 2020, Athens, Greece}

The Physics Unit of ATINER, will hold its $7^{\text {th }}$ Annual International Conference on Physics, 20-23 July 2020, Athens, Greece sponsored by the Athens Journal of Sciences. The aim of the conference is to bring together academics and researchers of all areas of physics and other related disciplines. You may participate as stream organizer, presenter of one paper, chair a session or observer. Please submit a proposal using the form available (https://www.atiner.gr/2020/FORM-PHY.doc).

\section{Important Dates}

- Abstract Submission: 16 December 2019

- Acceptance of Abstract: 4 Weeks after Submission

- Submission of Paper: 22 June 2020

\section{Academic Member Responsible for the Conference}

- Dr. Ethel Petrou, Academic Member, ATINER \& Professor and Chair, Department of Physics, Erie Community College-South, State University of New York, USA.

- Dr. Bala Maheswaran, Head, Electrical Engineering Unit, ATINER \& Professor, Northeastern University, USA.

\section{Social and Educational Program}

The Social Program Emphasizes the Educational Aspect of the Academic Meetings of Atiner.

- Greek Night Entertainment (This is the official dinner of the conference)

- Athens Sightseeing: Old and New-An Educational Urban Walk

- Social Dinner

- Mycenae Visit

- Exploration of the Aegean Islands

- Delphi Visit

- Ancient Corinth and Cape Sounion

More information can be found here: https://www.atiner.gr/social-program

\section{Conference Fees}

Conference fees vary from $400 €$ to $2000 €$

Details can be found at: https://www.atiner.gr /2019fees 





\title{
Centrifugal Force-Induced Elastic Field for a Stress-Free Annulus Made of Functionally Graded Polar Orthotropic Material from Circular Plates to Rings
}

\author{
By Vebil Yıldırım*
}

\begin{abstract}
Formation of a new kind of advanced material type from polar orthotropic materials obeying certain functional material grading rules has gained a great importance lately. In this study, a circular annulus rotating at a constant angular velocity and made of such kind of advanced materials having the same inhomogeneity index for both elasticity moduli and material density is studied analytically. Governing equation in terms of radial displacement is derived from the elasticity theory under axisymmetric conditions and plane stress assumption for such structures. After deriving closed-form solutions, effect of the aspect ratio (inner radius/outer radius) of a rotating circular annulus with uniform thickness on the dimensionless elastic field is investigated. It is observed that both the aspect ratio and inhomogeneity index of a simple power-law material grading rule have significant impacts on the linear elastic response arising out of rotation of the annulus at a constant angular velocity.
\end{abstract}

Keywords: Rotating discs, circular annulus, elasticity solution, functionally graded, polar orthotropic.

\section{Introduction}

Around 1970s, composite materials obtained by combining two or more materials at the macro-scale appeared in many engineering applications such as aircraft structures, automobile, transportation, marine, and building structures due to their high strength to weight and stiffness to weight ratios, high corrosion resistance, thermal and acoustic insulation properties, improved fatigue life, and good design practice than metallic structures (Gopalakrishnan et al. 2008, Campbell 2010). The fiber (reinforcement) and the matrix are two main constituents of a typical composite material. The reinforcement should be harder, stronger, and stiffer than the matrix. The smaller the diameter of the fiber is, the higher its strength. However the cost of the composite structure increases with decreasing diameter. The continuous phase of a composite material is called the matrix, which may be a polymer, metal, or ceramic. As a matrix material, polymers have low strength and stiffness as well as ductile while ceramics have high strength and stiffness but are brittle. As is well known, metals have moderate strength and stiffness together with considerably high ductility.

Composite materials are classified as fibrous composites, particulate composites and laminated composites. The fibrous composites, in which the matrix material has low stiffness, density and strength compared to the fibers or whiskers dispersed in a matrix. Carbon, graphite, E-glass etc. are commonly used for fibers while a polymeric material epoxy is used for the matrix material. Suspension of particles of one or more materials in a matrix of different material

*Professor, University of Çukurova, Turkey. 
forms a particulate composite. In a particulate composite both the matrix and particle materials may be metallic or non-metallic. Particulate composites tend to be much weaker and less stiff than continuous fiber composites, but they are usually much less expensive. The laminated composites consists of a number of laminas (plies) stacked together to form a composite structure. Each lamina contains fibers bounded by a matrix material are oriented in the same direction where the maximum strength is required. The most commonly used matrix material is epoxy resin while carbon, glass, aramid and boron are used for fiber materials. The lay-up in which the plies are stacked at different orientation angles is called a laminate. Unidirectional $\left(0^{\circ}\right)$ laminae are extremely strong and stiff in the $0^{\circ}$ direction. However, they are considerably weak in the $90^{\circ}$ direction. The laminated composites are orthotropic at the lamina level while they exhibit highly anisotropic properties at the laminate level.

From the composite materials, polar orthotropic materials were used to increase the critical speeds of rotating disks (Tang 1969, Murthy and Sherbourne 1970, Reddy and Srinath 1974, Ari-Gur and Stavsky 1981, Jain et al. 1999, 2000, Tütüncü 2000, Liang et al. 2002, Singh and Jain 2004, Çallığlu 2007, Çallığlu et al. 2005, 2006, Koo 2006, 2008, Gupta et al. 2006, Li et al. 2007, Eraslan et al. 2016, Yildırım 2018a-d). Murthy and Sherbourne (1970) presented analytical solutions for rotating anisotropic hollow discs with variable thickness for an annular disc (free-free) and a disc mounted on a circular rigid shaft (fixedfree). Reddy and Srinath (1974) obtained closed-form solutions for stresses and displacement in an anisotropic rotating circular disc of variable thickness and variable density. Çallığlu et al. (2006) investigated analytically the elastic-plastic stress analysis of a curvilinearly orthotropic rotating annular disc for strain hardening material behavior. Eraslan et al. (2016) developed an analytical solution in terms of hypergeometric functions to estimate the mechanical response of nonisothermal, orthotropic, variable thickness disks under a variety of boundary conditions such as rotating annular disks with two free surfaces, stationary annular disks with pressurized inner and free outer surfaces, and free inner and pressurized outer surfaces. Yildırım (2018a) introduced the complementary functions method (CFM) for the initial value problem solutions to the linear elastic analysis of anisotropic rotating uniform discs. The anisotropy effects are considered in this study for free-free, fixed-free, and fixed-guided rotating disks made of a polar orthotropic material.

As a new kind of advanced structural composite materials, functionally graded materials (FGMs) are originated in Japan (Mahamood et al. 2012, Mahamood and Akinlabi 2017). Mahamood and Akinlabi (2017) presented the concept of functionally graded materials as well as their use and different fabrication processes. A FGM consist of at least two constituents which are continuously graded along demanded engineered directions to meet the requirements of the applications. Unlike the classical composites, in a FGM structure inter-laminar failure due to the delamination along the interfaces of continuous and discontinuous plies does not occur. In a laminated composite structure considerable inter-laminar stresses may arise especially at the ends of discontinuous plies. Moreover inter-laminar failure may also occur when the inter- 
laminar stresses are much lower than the in-plane stresses. To sum up, functionally graded materials can withstand very high thermal gradient, can inhibit crack propagation, may provide thermal barrier, and also perfectly meet the requirements for minimizing thermo-mechanical mismatch in metal-ceramic bonding. Due to these impeccable advantages, functionally graded materials have attracted the attention of many researchers and industrial applications having severe operating conditions in the mineral processing industry along with machine, aerospace, energy, nuclear, defense, optoelectronics, dental, orthopedic, and automotive industries. Here some applications of FGMs are highlighted (Mahamood et al. 2012, Mahamood and Akinlabi 2017): linings for wear-resistant, abrasionresistant and impact-resistant, rocket heat shields, rocket engine components, heat exchanger tubes, thermoelectric generators, heat-engine components, plasma facings for fusion reactors, electrically insulating metal/ceramic joints, space plane bodies, teeth and bone replacements, penetration resistant materials used for armour plates and bullet-proof vests, protective coatings on turbine blades in gas turbine engines, graded refractive index materials, magnetic storage media, tribology, sensors, fire retardant doors, energy conversion devices, cutting tool insert coatings, automobile engine components, nuclear reactor components etc.

Low-cost ceramic-metal functionally graded materials are essentially used in FGM applications. They form an isotropic but inhomogeneous structure. In quest of searching more advanced materials, scholars have begun to apply anisotropic materials as functionally graded material constituents to form both anisotropic and inhomogeneous structures. For annular structures made of functionally graded anisotropic and inhomogeneous materials, there may be provided relatively a few studies on the stress and displacement analyses in the available literature (Gurushankar 1975, Mian and Spencer 1998, Durodola and Attia 2000, Chen et al. 2007, Wang and Sudak 2008, Zenkour 2009, Lubarda 2012, Peng and Li 2012, Boga 2016, Kacar and Yıldırım 2017, Zeng et al. 2017; Essa and Argeso 2017).

Gurushankar (1975) obtained closed form solution for the elastic fields in a rotationally symmetric, nonhomogeneous, polar orthotropic, annular disk of varying thickness and density, subjected to thermal loading. The variations of homogeneity, density and thickness are assumed to be hyperbolic in this study. Durodola and Attia (2000) studied with a functionally graded material which was modelled as a non-homogeneous orthotropic material for rotating hollow and uniform solid discs. Chen et al. (2007) studied analytically uniform rotating disc made of exponentially functionally graded materials with transverse isotropy. Lubarda (2012) worked on the elastic response of uniformly pressurized cylindrically anisotropic hollow uniform thin rotating discs. He used the finite difference method and a Fredholm integral equation. Peng and Li (2012) considered a functionally graded hollow polar-orthotropic rotating uniform disk for both power-law material grading rule and arbitrarily varying gradient. They also used Fredholm integral equation in the solution procedure. Kacar and Yildirım (2017) studied analytically the elastic behavior of a stress-free rotating circular uniform disc (a uniform annulus), a rotating uniform disc mounted a rigid shaft at its center, and a rotating disc attached a rigid shaft and guided at outer surface for the same issue for five types of materials. Zeng et al. (2017) considered 
variable thickness rotating discs made of a functionally graded fiber-reinforced material. Recently Essa and Argeso (2017) developed analytical solutions for the analysis of elastic polar orthotropic functionally graded annular disks rotating with constant angular velocity. Traction-free inner and outer surfaces, and annular disks mounted on a circular rigid shaft having traction-free outer surface were studied separately by Essa and Argeso (2017).

In the present study, an investigation of the variations of the elastic fields along the radial coordinate of a rotating circular annulus from the circular hollow plate to the thin rings is aimed. The annulus is assumed to be made of an anisotropic and nonhomogeneous material. To form such a kind of material, two anisotropic materials are gradually graded such that the mixture should obey a simple power material grading pattern. To conduct a parametric study, the same inhomogeneity index for both elasticity moduli and material density are employed. Closed-form solutions are obtained from the governing Navier equation under axisymmetric conditions, small displacements and plane stress assumption in the linear elasticity theory. Then a parametric study is conducted to study the effects of both the aspect ratio (inner radius/outer radius) and the inhomogeneity index of a rotating circular annulus with uniform thickness on the dimensionless elastic field.

\section{Exact Solutions}

Let's consider a disk made of a functionally graded polar orthotropic material. The disk is assumed to be very thin, as seen in Figure 1, so that in the z-direction, the stress and strain components are neglected, and shear stress is zero. By using the infinitesimal theory of elasticity with axisymmetric plain stress conditions, strain- displacement relations are written as follows

$\varepsilon_{r}(r)=u_{r}^{\prime}(r)$

$\varepsilon_{\theta}(r)=\frac{u_{r}(r)}{r}$

Where $u_{r}$ is the radial displacement, $\varepsilon_{r}$ and $\varepsilon_{\theta}$ are the radial and tangential strain components, respectively. The prime symbol is used for the first derivative of the quantity with respect to the radial coordinate. Representing the radial and hoop stresses by $\sigma_{r}$ and $\sigma_{\theta}$, respectively, Hooke's law may be written in the following compact form of

$\sigma_{\mathrm{r}}(r)=C_{11}(r) \varepsilon_{r}(r)+C_{12}(r) \varepsilon_{\theta}(r)$

$\sigma_{\theta}(r)=C_{12}(r) \varepsilon_{r}(r)+C_{22}(r) \varepsilon_{\theta}(r)$

By defining the following ratios

$\lambda_{1}=\frac{C_{12}(r)}{C_{11}(r)}=\lambda_{2} v_{r \theta}$ 
$\lambda_{2}=\frac{C_{22}(r)}{C_{11}(r)}=\frac{E_{\theta}(r)}{E_{r}(r)}$

and

$C_{o}=-\frac{E_{\theta}^{b} v_{r \theta}}{v_{\theta r}\left(v_{r \theta} v_{\theta r}-1\right)}$

material on-axis rigidities $\left(\theta=0^{\circ}\right)$ in Eq. (2) may be written as follows

$$
\begin{aligned}
& C_{11}(\mathrm{r})=\left(\frac{r}{b}\right)^{\beta} \mathrm{C}_{0} \\
& C_{12}(\mathrm{r})=\left(\frac{r}{b}\right)^{\beta} C_{o} \lambda_{1} \\
& C_{22}(\mathrm{r})=\left(\frac{r}{b}\right)^{\beta} C_{o} \lambda_{2}
\end{aligned}
$$

Where Young`s modulus in the $r$ and $\theta$ directions are denoted by $E_{r}(r)$ and $E_{\theta}(r)$, the ratio $\lambda_{2}$ stands for the anisotropy/polar degree of the disc material, $\beta$ is the inhomogeneity index, $b$ is the outer radius and $E_{\theta}^{b}$ shows the reference value of Young's modulus of the mixture material located at the outer surface in the circumferential direction (Figure 1). For isotropic and homogeneous materials: $E=E_{\theta}=E_{r}$. In Equation (5) a simple power material grading rule is used. Poisson`s ratios in Equations (3) and (4), $v_{\theta r}$ and $v_{r \theta}$, which are assumed to be constant along the radial coordinate in the present study, are related by each other as follows

$$
\frac{v_{\theta r}}{E_{\theta}(r)}=\frac{v_{r \theta}}{E_{r}(r)}
$$

Figure 1. A Uniform Circular Annulus Rotating at a Constant Angular Velocity

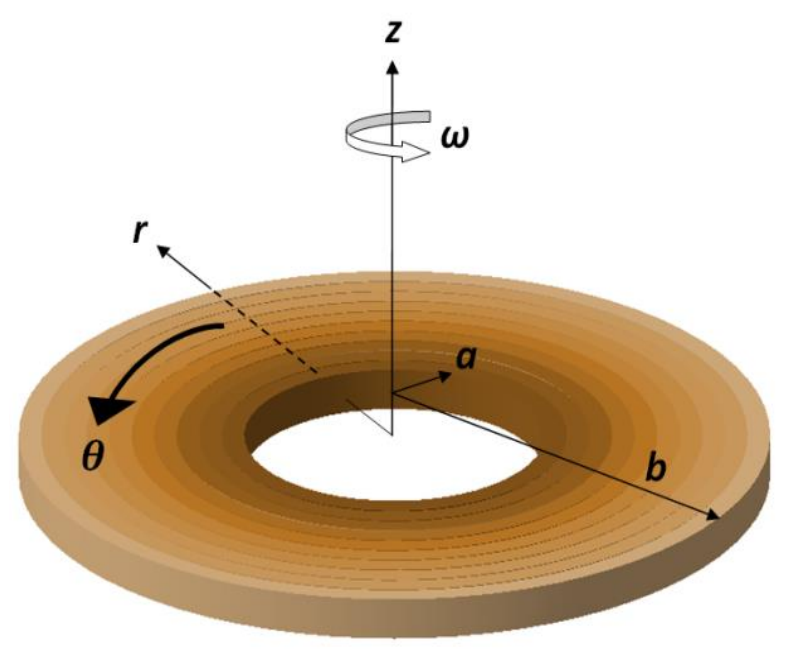


Equilibrium equation with centrifugal force effects is

$\sigma_{r}^{\prime}+\left(\frac{\sigma_{r}-\sigma_{\theta}}{r}\right)+\rho(r) \omega^{2} r=0$

Where $\rho(r)$ denotes the material density, which also radially varies with a simple power material grading rule, and $\omega$ is a constant angular velocity.

$\rho(\mathrm{r})=\left(\frac{r}{b}\right)^{\beta} \rho^{b}$

In the above $\rho^{b}$ stands for the reference value of the density of the mixture material located at the outer surface. Substitution stresses in Equation (2) and the first derivative of the radial stress with respect to the radial coordinate into the equilibrium equation, and then replacing strain components with their counterparts in terms of radial displacements, the following second order Navier differential equation is derived.

$$
u_{r}^{\prime \prime}+\left(\frac{1}{r}+\frac{C_{11}^{\prime}(r)}{C_{11}(r)}\right) u_{r}^{\prime}+\left(-\frac{\lambda_{2}}{r^{2}}+\frac{\lambda_{1}}{r} \frac{C_{11}^{\prime}(r)}{C_{11}(r)}\right) u_{r}=-\frac{\rho(r) \omega^{2} r}{C_{11}(r)}
$$

After implementation of the material grading rule given in Equations (5) and (8) into Equation (9), then Navier equation reduces to the following

$\frac{\left(\beta \lambda_{1}-\lambda_{2}\right)}{r^{2}} u_{r}+\frac{(1+\beta)}{r} u_{r}^{\prime}+u_{r}^{\prime \prime}=-\frac{r \omega^{2} \rho^{b}}{C_{0}}$

This equation is an Euler-Cauchy type differential equation with constant coefficients. General solution of Equation (10) will be in the form of

$u_{r}(\mathrm{r})=r^{\frac{1}{2}(-\beta-\xi)}\left(C_{1}+C_{2} r^{\xi}\right)+r^{3} \Omega$

Where $C_{1}$ and $C_{2}$ are integration constants, and

$$
\begin{aligned}
& \Omega=-\frac{\omega^{2} \rho^{b}}{C_{0}\left(9+3 \beta+\beta \lambda_{1}-\lambda_{2}\right)} \\
& \xi=\sqrt{\beta^{2}-4 \beta \lambda_{1}+4 \lambda_{2}}
\end{aligned}
$$

By using stress-displacement relations for a polar orthotropic material, the radial and hoop stresses may be written in terms of integration constant as follows 


$$
\begin{aligned}
& \sigma_{r}(r)=\frac{1}{2} r^{\frac{1}{2}(-2-\beta-\xi)}\left(-\left(-C_{2} r^{\xi}(-\beta+\xi)+C_{1}(\beta+\xi)-6 r^{\frac{1}{2}(6+\beta+\xi)} \Omega\right) C_{11}\right. \\
& \left.+2\left(C_{1}+C_{2} r^{\xi}+r^{\frac{1}{(}(6+\beta+\xi)} \Omega\right) C_{12}\right) \\
& \sigma_{\theta}(r)=\frac{1}{2} r^{\frac{1}{2}(-2-\beta-\xi)}\left(-\left(-C_{2} r^{\xi}(-\beta+\xi)+C_{1}(\beta+\xi)-6 r^{\frac{1}{2}(6+\beta+\xi)} \Omega\right) C_{12}\right. \\
& \left.+2\left(C_{1}+C_{2} r^{\xi}+r^{\frac{1}{(}(6+\beta+\xi)} \Omega\right) C_{22}\right)
\end{aligned}
$$

By employing stress-free boundary conditions, $\sigma_{r}(a)=0$ and $\sigma_{r}(b)=0$, unknown coefficients in Equations (11) and (13) are found as

$$
\begin{aligned}
C_{1} & =\frac{2\left(\lambda_{1}+3\right) \Omega a^{\xi} b^{\frac{1}{2}(\beta+\xi+6)}-2\left(\lambda_{1}+3\right) \Omega b^{\xi} a^{\frac{1}{2}(\beta+\xi+6)}}{\left(a^{\xi}-b^{\xi}\right)\left(\beta-2 \lambda_{1}+\xi\right)} \\
C_{2} & =\frac{2\left(\lambda_{1}+3\right) \Omega\left(a^{\frac{1}{2}(\beta+\xi+6)}-b^{\frac{1}{2}(\beta+\xi+6)}\right)}{\left(a^{\xi}-b^{\xi}\right)\left(\beta-2 \lambda_{1}-\xi\right)}
\end{aligned}
$$

Substitution of Equation (14) into Equations (11) and (13) gives the explicit form of the radial displacement, the radial stress and the tangential stress as follows, respectively.

$$
\begin{gathered}
u_{r}(\mathrm{r})=\frac{\Omega r^{\frac{1}{2}}(-\beta-\xi)}{\left(a^{\xi}-b^{\xi}\right)\left(\beta-2 \lambda_{1}+\xi\right)\left(-\beta+2 \lambda_{1}+\xi\right)}\left(2\left(\lambda_{1}+3\right) a^{\xi / 2} b^{\xi / 2}(-\beta\right. \\
\left.+2 \lambda_{1}+\xi\right)\left(a^{\xi / 2} b^{\frac{\beta}{2}+3}-a^{\frac{\beta}{2}+3} b^{\xi / 2}\right) \\
-2\left(\lambda_{1}+3\right) r^{\xi}\left(\beta-2 \lambda_{1}+\xi\right)\left(a^{\frac{1}{2}(\beta+\xi+6)}-b^{\frac{1}{2}(\beta+\xi+6)}\right) \\
\left.+\left(a^{\xi}-b^{\xi}\right)\left(\beta-2 \lambda_{1}+\xi\right)\left(-\beta+2 \lambda_{1}+\xi\right) r^{\frac{1}{2}(\beta+\xi+6)}\right) \\
\sigma_{r}(r)=-\frac{1}{a^{\xi}-b^{\xi}}\left(C _ { 0 } ( \lambda _ { 1 } + 3 ) \Omega ( \frac { r } { b } ) ^ { \beta } r ^ { \frac { 1 } { 2 } ( - \beta - \xi - 2 ) } \left(a^{\frac{1}{2}(\beta+\xi+6)}\left(r^{\xi}-b^{\xi}\right)\right.\right. \\
+a^{\xi}\left(b^{\frac{1}{2}(\beta+\xi+6)}-r^{\frac{1}{2}(\beta+\xi+6)}\right)-r^{\xi} b^{\frac{1}{2}(\beta+\xi+6)} \\
\left.\left.+b^{\xi} r^{\frac{1}{2}(\beta+\xi+6)}\right)\right)
\end{gathered}
$$




$$
\begin{aligned}
& \sigma_{\theta}(r) \\
& =\frac{1}{\left(a^{\xi}-b^{\xi}\right)\left(\beta-2 \lambda_{1}-\xi\right)\left(\beta-2 \lambda_{1}+\xi\right)}\left\{C _ { 0 } \Omega ( \frac { r } { b } ) ^ { \beta } r ^ { \frac { 1 } { 2 } ( - \beta - \xi - 2 ) } \left(\lambda _ { 1 } \left(a ^ { \xi / 2 } b ^ { \xi / 2 } \left(2 \lambda_{2}(\beta\right.\right.\right.\right. \\
& -\xi-6)-3(\beta-\xi)(\beta+\xi))\left(a^{\xi / 2} b^{\frac{\beta}{2}+3}-a^{\frac{\beta}{2}+3} b^{\xi / 2}\right) \\
& -r^{\xi}\left(3(\beta-\xi)(\beta+\xi)-2 \lambda_{2}(\beta+\xi-6)\right)\left(a^{\frac{1}{2}(\beta+\xi+6)}-b^{\frac{1}{2}(\beta+\xi+6)}\right) \\
& \left.-\left(a^{\xi}-b^{\xi}\right)\left(-3 \beta^{2}+4 \beta \lambda_{2}+3 \xi^{2}\right) r^{\frac{1}{2}(\beta+\xi+6)}\right) \\
& +\lambda_{2}\left(6(\beta+\xi) r^{\xi}\left(a^{\frac{1}{2}(\beta+\xi+6)}-b^{\frac{1}{2}(\beta+\xi+6)}\right)-6 b^{\xi}(\beta-\xi) a^{\frac{1}{2}(\beta+\xi+6)}\right. \\
& \left.-6 a^{\xi}(\xi-\beta) b^{\frac{1}{2}(\beta+\xi+6)}-\left(\xi^{2}-\beta^{2}\right)\left(a^{\xi}-b^{\xi}\right) r^{\frac{1}{2}(\beta+\xi+6)}\right) \\
& +2 \lambda_{1}^{3}\left(-a^{\frac{1}{2}(\beta+\xi+6)}\left((\beta+\xi) b^{\xi}+(\xi-\beta) r^{\xi}\right)\right. \\
& +a^{\xi}\left((\beta+\xi) b^{\frac{1}{2}(\beta+\xi+6)}+6 r^{\frac{1}{2}(\beta+\xi+6)}\right)+(\xi-\beta) r^{\xi} b^{\frac{1}{2}(\beta+\xi+6)} \\
& \left.-6 b^{\xi} r^{\frac{1}{2}(\beta+\xi+6)}\right) \\
& +\lambda_{1}^{2}\left(a^{\xi / 2} b^{\xi / 2}\left(-(\beta-\xi-6)(\beta+\xi)-4 \lambda_{2}\right)\left(a^{\xi / 2} b^{\frac{\beta}{2}+3}-a^{\frac{\beta}{2}+3} b^{\xi / 2}\right)\right. \\
& -r^{\xi}\left((\beta-\xi)(\beta+\xi-6)+4 \lambda_{2}\right)\left(a^{\frac{1}{2}(\beta+\xi+6)}-b^{\frac{1}{2}(\beta+\xi+6)}\right) \\
& \left.\left.\left.-4\left(3 \beta-\lambda_{2}\right)\left(a^{\xi}-b^{\xi}\right) r^{\frac{1}{2}(\beta+\xi+6)}\right)\right)\right\}
\end{aligned}
$$

\section{Verification of the Formulas}

As a comparative example, a stress-free disc with $a=2 \mathrm{~cm}$, and $b=5 \mathrm{~cm}$ $(a / b=0.4)$ is chosen. The disk is made of an injection molded Nylon 6 composite containing $40 \mathrm{wt} \%$ short glass fiber. Material properties of the disc are given in Table 1.

Table 1. Material Properties

\begin{tabular}{|l|c|c|c|c|}
\hline & $\begin{array}{c}E_{r} \\
(\mathrm{GPa})\end{array}$ & $\begin{array}{c}E_{\theta} \\
(\mathrm{GPa})\end{array}$ & $\rho\left(\frac{\mathrm{kg}}{\mathrm{m}^{3}}\right)$ & $v_{r \theta}$ \\
\hline $\begin{array}{l}\text { An injection molded Nylon 6 composite } \\
\text { containing 40wt\% short glass fiber }\end{array}$ & 12.0 & 20.0 & 1600 & 0.21 \\
\hline
\end{tabular}

Dimensionless elastic stress and displacements are defined as

$\bar{\sigma}_{r}=\frac{\sigma_{\mathrm{r}}}{\rho_{b} \omega^{2} b^{2}}$ 
$\bar{\sigma}_{\theta}=\frac{\sigma_{\theta}}{\rho_{b} \omega^{2} b^{2}}$

$\bar{u}_{r}=\frac{\mathrm{E}_{\theta}}{\rho_{b} \omega^{2} b^{3}} u_{r}$

Comparisons of dimensionless radial displacements, radial and hoop stresses with the open literature for $\beta=-1$ are given in Table 2. A perfect harmony is observed among the results.

Table 2. Comparisons of Dimensionless Radial Displacement, Radial Stress, and Hoop Stress with the Open Literature for $\beta=-1$

\begin{tabular}{|c|c|c|c|c|}
\hline $\mathrm{a} / \mathrm{b}$ & $\begin{array}{c}\text { Exact } \\
\text { (Present Equation [16]) }\end{array}$ & $\begin{array}{c}\text { Exact } \\
\text { (Peng and Li 2012) }\end{array}$ & $\begin{array}{c}\text { Numerical } \\
\text { Peng and Li } \\
\text { 2012) }\end{array}$ & $\begin{array}{c}\text { Numerical } \\
\text { (Boğa 2016) }\end{array}$ \\
\hline & & $\bar{u}_{r}$ & & \\
\hline 0.4 & 0.26783 & 0.2678 & 0.2678 & 0.2678293 \\
\hline 0.5 & 0.255258 & 0.2553 & 0.2554 & 0.2552581 \\
\hline 0.6 & 0.256099 & 0.2561 & 0.2563 & 0.2560991 \\
\hline 0.7 & 0.262237 & 0.2622 & 0.2625 & 0.2622363 \\
\hline 0.8 & 0.268456 & 0.2685 & 0.2686 & 0.2684556 \\
\hline 0.9 & 0.270831 & 0.2708 & 0.2709 & 0.2708311 \\
\hline 1 & 0.26608 & 0.2661 & 0.2661 & 0.2660798 \\
\hline & & $\bar{\sigma}_{r}$ & & \\
\hline 0.4 & 0 & 0 & 0 & 0 \\
\hline 0.5 & 0.177997 & 0.1780 & 0.1781 & 0.1779964 \\
\hline 0.6 & 0.21002 & 0.2100 & 0.2099 & 0.2100199 \\
\hline 0.7 & 0.185223 & 0.1852 & 0.1856 & 0.1852227 \\
\hline 0.8 & 0.134617 & 0.1346 & 0.1349 & 0.1346162 \\
\hline 0.9 & 0.0709175 & 0.0709 & 0.0711 & 0.07091725 \\
\hline 1 & 0 & 0 & 0 & 0 \\
\hline & & $\bar{\sigma}_{\theta}$ & & \\
\hline 0.4 & 1.67393 & 1.6739 & 1.6739 & 1.673933 \\
\hline 0.5 & 1.08333 & 1.0833 & 1.0825 & 1.083331 \\
\hline 0.6 & 0.784894 & 0.7849 & 0.7839 & 0.7848933 \\
\hline 0.7 & 0.600005 & 0.6000 & 0.6000 & 0.6000040 \\
\hline 0.8 & 0.466578 & 0.4666 & 0.4663 & 0.466577 \\
\hline 0.9 & 0.359181 & 0.3592 & 0.3596 & 0.3591804 \\
\hline 1 & 0.26608 & 0.2661 & 0.2661 & 0.2660798 \\
\hline & & & & \\
\hline & & & & \\
\hline & & & & \\
\hline
\end{tabular}


Table 3. Variation of Elastic Fields with the Inhomogeneity Index and $(a / b)$

\begin{tabular}{|c|c|c|c|c|c|c|c|}
\hline$a / b$ & $\beta=-5$ & $\beta=-3$ & $\beta=-1$ & $\beta=0$ & $\beta=1$ & $\beta=3$ & $\beta=5$ \\
\hline \multicolumn{7}{|c|}{$\beta$} & $\bar{u}_{r}$ \\
\hline 0.4 & 0.133642 & 0.180766 & 0.26783 & 0.329539 & 0.401457 & 0.558106 & 0.701461 \\
\hline 0.5 & 0.126625 & 0.171941 & 0.255258 & 0.314079 & 0.382424 & 0.530565 & 0.665171 \\
\hline 0.6 & 0.126949 & 0.173079 & 0.256099 & 0.31383 & 0.380229 & 0.52205 & 0.64858 \\
\hline 0.7 & 0.132142 & 0.179552 & 0.262237 & 0.318607 & 0.382669 & 0.517389 & 0.635578 \\
\hline 0.8 & 0.139548 & 0.187396 & 0.268456 & 0.322817 & 0.384034 & 0.511388 & 0.621949 \\
\hline 0.9 & 0.145661 & 0.192619 & 0.270831 & 0.322827 & 0.38112 & 0.501804 & 0.606124 \\
\hline 1 & 0.145648 & 0.190927 & 0.26608 & 0.31596 & 0.371837 & 0.487428 & 0.58728 \\
\hline & & & $\bar{\sigma}_{r}$ & & & \\
\hline 0.4 & 0. & & 0. & 0. & 0. & 0. \\
\hline 0.5 & 1.23574 & 0.470408 & 0.177997 & 0.106551 & 0.0618906 & 0.0188078 & 0.00504674 \\
\hline 0.6 & 0.879664 & 0.437232 & 0.21002 & 0.140871 & 0.0916517 & 0.0352044 & 0.0121716 \\
\hline 0.7 & 0.516414 & 0.316927 & 0.185223 & 0.136928 & 0.0984123 & 0.0467708 & 0.0205031 \\
\hline 0.8 & 0.267712 & 0.194997 & 0.134617 & 0.108397 & 0.0851786 & 0.0491921 & 0.0268568 \\
\hline 0.9 & 0.105838 & 0.0888756 & 0.0709175 & 0.0616511 & 0.0525424 & 0.0363096 & 0.0242649 \\
\hline 1 & 0. & 0. & 0. & 0. & 0. & 0. & 0. \\
\hline \multicolumn{7}{|c|}{} & \multicolumn{7}{|c|}{$\bar{\sigma}_{\theta}$} \\
\hline 0.4 & 32.6275 & 7.06116 & 1.67393 & 0.823848 & 0.401457 & 0.089297 & 0.0179574 \\
\hline 0.5 & 8.5365 & 2.9157 & 1.08333 & 0.66545 & 0.404085 & 0.139224 & 0.0433395 \\
\hline 0.6 & 3.02885 & 1.48851 & 0.784894 & 0.572355 & 0.412307 & 0.20026 & 0.088316 \\
\hline 0.7 & 1.30393 & 0.858746 & 0.600005 & 0.503078 & 0.417113 & 0.269891 & 0.159778 \\
\hline 0.8 & 0.626033 & 0.525758 & 0.466578 & 0.44146 & 0.413846 & 0.344506 & 0.26415 \\
\hline 0.9 & 0.31113 & 0.324688 & 0.359181 & 0.380275 & 0.39951 & 0.41917 & 0.406171 \\
\hline 1 & 0.145648 & 0.190927 & 0.26608 & 0.31596 & 0.371837 & 0.487428 & 0.58728 \\
\hline
\end{tabular}

Variations of the dimensionless radial displacement, radial and hoop stresses along the radial direction for different inhomogeneity indexes are presented in Table 3. As observed from Table 3, variation of the inhomogeneity indexes from $\beta=5$ through $\beta=-5$ makes the radial dimensionless displacement small. However when the inhomogeneity indexes are changed from positive to the negative both radial and hoop stresses become much higher.

\section{Numerical Examples}

In this section it is aimed to study the thickness effects on the variation of the radial displacement, the radial stress and the hoop stress. The outer radius of the test annulus is determined as $b=10 \mathrm{~cm}=$ constant. The inner radius of the annulus varies from $a=2 \mathrm{~cm}$ to $a=9.95 \mathrm{~cm}$. The same material properties presented in Table 1 are used in the parametric study:

Numerical results are illustrated in Figures 2-6 for $a=2 \mathrm{~cm}, a=4 \mathrm{~cm}, a=6 \mathrm{~cm}$, $a=8 \mathrm{~cm}$, and $a=9.95 \mathrm{~cm}$, and presented in Tables 4 and 5 for $a=3 \mathrm{~cm}, a=5 \mathrm{~cm}$, $a=7 \mathrm{~cm}$, and $a=9 \mathrm{~cm}$. In these Figures and Tables inhomogeneity indexes are chosen as to be in the range of $-6 \leq \beta \leq 6$.

Some results are outlined below:

- Increasing the aspect ratio from 0.2 toward 0.995 results in a magnification in the radial displacements.

- Negative inhomogeneity indexes offer smaller radial displacements. 
- For a very thin annulus, that is for a ring, the effect of the inhomogeneity index on the radial displacement and the radial stress almost disappears. If it is small, however, it has still effect to some extent on the tangential stresses.

- Maximum radial stresses decrease with increasing aspect ratio from the thick annulus to the rings.

- Positive inhomogeneity indexes offer more small radial stresses.

- Positive inhomogeneity indexes also offer smaller hoop stresses.

- Centrifugal force-induced stresses are completely in tension for all inhomogeneity indexes and aspect ratios.

- Negative inhomogeneity parameters present more noticeable hoop stresses at the inner surface of the annulus.

- At the outer surface, positive inhomogeneity indexes have higher hoop stresses for higher aspect ratios that is for thinner annulus.

\section{Discussion and Conclusions}

In this study, a circular annulus rotating at a constant angular velocity and made of such functionally graded polar orthotropic materials is handled analytically. Navier equation in terms of the radial displacement is derived from the elasticity theory under axisymmetric plane stress assumption. To get a closedform solution, a simple power material grading rule is chosen. By doing so, the governing equation turns into a second order differential equation with constant coefficients at which Euler-Cauchy solution technique may be applied. The centrifugal force is added to the equilibrium equation in the radial direction as a body force.

After getting both the homogeneous and particular analytical solutions to the problem, a parametric study is accomplished. The ratio of the inner and outer radius of the annulus is defined as the aspect ratio. The effect of the aspect ratio of a rotating circular annulus with uniform thickness on the dimensionless radial displacement, the dimensionless radial stress and tangential stress is investigated. The aspect ratio of the annulus is assumed to be changed from 0.2 towards 0.995 for rings, while the inhomogeneity parameter is changing between -6 and 6 .

It is observed that both the aspect ratio and inhomogeneity index have significant impact on the linear elastic response arising out of rotation of the annulus at a constant angular velocity. Increasing aspect ratio from 0.2 toward 0.995 causes a magnification in the radial displacements. The effect of the inhomogeneity index on the radial displacement and the radial stress almost disappears while it has still effect to some extent on the tangential stresses. 
Table 4. Variation of Elastic Fields with $\beta=-6,-4,-2,0,2,4,6$

\begin{tabular}{|c|c|c|c|c|c|c|c|}
\hline$r-\mathrm{m}$ & $\beta=-6$ & $\beta=-4$ & $\beta=-2$ & $\beta=0$ & $\beta=2$ & $\beta=4$ & $\beta=6$ \\
\hline \multicolumn{8}{|c|}{$a / b=0.3 ; \bar{u}_{r}$} \\
\hline .03 & 0.051638 & 0.070893 & 0.120113 & 0.233505 & 0.418588 & 0.61716 & 0.778835 \\
\hline .04 & 0.048640 & 0.067417 & 0.114984 & 0.223366 & 0.398153 & 0.58322 & 0.73177 \\
\hline .06 & 0.056645 & 0.080338 & 0.134179 & 0.244985 & 0.409349 & 0.572028 & 0.695967 \\
\hline .07 & 0.065729 & 0.092327 & 0.148718 & 0.258519 & 0.415352 & 0.566822 & 0.680534 \\
\hline .09 & 0.085070 & 0.1138 & 0.169648 & 0.272012 & 0.413086 & 0.546648 & 0.645885 \\
\hline .10 & 0.087482 & 0.11534 & 0.169143 & 0.267391 & 0.402542 & 0.530384 & 0.625336 \\
\hline \multicolumn{8}{|c|}{$a / b=0.3 ; \quad \bar{\sigma}_{r}$} \\
\hline .04 & 6.2492 & 1.66112 & 0.486923 & 0.139081 & 0.032988 & 0.006241 & 0.001016 \\
\hline .05 & 3.1827 & 1.22138 & 0.488501 & 0.183234 & 0.057105 & 0.014619 & 0.003344 \\
\hline .06 & 1.53486 & 0.778176 & 0.395727 & 0.185284 & 0.073101 & 0.024557 & 0.007648 \\
\hline .07 & 0.73917 & 0.465808 & 0.287582 & 0.16256 & 0.079030 & 0.033898 & 0.0139 \\
\hline .08 & 0.336856 & 0.252518 & 0.183256 & 0.122133 & 0.071661 & 0.038334 & 0.020092 \\
\hline .09 & 0.121347 & 0.104739 & 0.087255 & 0.067354 & 0.046911 & 0.030678 & 0.020046 \\
\hline \multicolumn{8}{|c|}{$a / b=0.3 ; \quad \bar{\sigma}_{\theta}$} \\
\hline .03 & 236.113 & 29.1739 & 4.44862 & 0.778351 & 0.125576 & 0.016663 & 0.001893 \\
\hline .04 & 31.8744 & 7.16504 & 1.96705 & 0.607093 & 0.170807 & 0.039511 & 0.007849 \\
\hline .05 & 7.59394 & 2.70986 & 1.14372 & 0.526756 & 0.220776 & 0.077096 & 0.023412 \\
\hline .06 & 2.56071 & 1.30551 & 0.759704 & 0.473158 & 0.271195 & 0.132153 & 0.056795 \\
\hline .07 & 1.05683 & 0.712368 & 0.534233 & 0.426208 & 0.318407 & 0.206284 & 0.119242 \\
\hline .08 & 0.48122 & 0.407713 & 0.379926 & 0.378213 & 0.358722 & 0.29943 & 0.224643 \\
\hline .09 & 0.22033 & 0.229379 & 0.263252 & 0.32581 & 0.388197 & 0.409244 & 0.388405 \\
\hline .10 & 0.08748 & 0.11534 & 0.169143 & 0.267391 & 0.402542 & 0.530384 & 0.625336 \\
\hline \multicolumn{8}{|c|}{$a / b=0.5 ; \quad \bar{u}_{r}$} \\
\hline .05 & 0.22403 & 0.267705 & 0.335178 & 0.429083 & 0.541008 & 0.65368 & 0.752386 \\
\hline .06 & 0.21294 & 0.254947 & 0.319673 & 0.40949 & 0.516192 & 0.623205 & 0.71656 \\
\hline .07 & 0.20905 & 0.250899 & 0.314643 & 0.402101 & 0.504862 & 0.606832 & 0.694883 \\
\hline .08 & 0.20949 & 0.251241 & 0.313812 & 0.398467 & 0.496773 & 0.593367 & 0.6761 \\
\hline .09 & 0.21074 & 0.251643 & 0.31222 & 0.393435 & 0.487114 & 0.578705 & 0.656869 \\
\hline .10 & 0.20777 & 0.247226 & 0.305487 & 0.383446 & 0.473253 & 0.560985 & 0.635813 \\
\hline \multicolumn{8}{|c|}{$a / b=0.5 ; \quad \bar{\sigma}_{r}$} \\
\hline .06 & 0.749997 & 0.361178 & 0.172664 & 0.079158 & 0.033810 & 0.013339 & 0.004919 \\
\hline .07 & 0.508027 & 0.307171 & 0.181099 & 0.101314 & 0.052744 & 0.025548 & 0.011718 \\
\hline .08 & 0.264157 & 0.191608 & 0.134379 & 0.089312 & 0.055623 & 0.032676 & 0.018487 \\
\hline .09 & 0.101571 & 0.085427 & 0.069409 & 0.053726 & 0.039434 & 0.027754 & 0.019138 \\
\hline \multicolumn{8}{|c|}{$a / b=0.5 ; \quad \bar{\sigma}_{\theta}$} \\
\hline .05 & 28.6757 & 8.56657 & 2.68142 & 0.858166 & 0.270504 & 0.08171 & 0.023512 \\
\hline .06 & 7.86928 & 3.40506 & 1.5404 & 0.710189 & 0.321549 & 0.139281 & 0.057441 \\
\hline .07 & 2.71624 & 1.60033 & 0.980712 & 0.60989 & 0.371864 & 0.217085 & 0.12089 \\
\hline .08 & 1.09138 & 0.833789 & 0.659946 & 0.529343 & 0.416886 & 0.31524 & 0.228015 \\
\hline .09 & 0.476145 & 0.456059 & 0.452578 & 0.455954 & 0.452204 & 0.43159 & 0.394573 \\
\hline .10 & 0.207771 & 0.247226 & 0.305487 & 0.383446 & 0.473253 & 0.560985 & 0.635813 \\
\hline \multicolumn{8}{|c|}{$a / b=0.7 ; \quad \bar{u}_{r}$} \\
\hline .07 & 0.524053 & 0.557942 & 0.596839 & 0.639616 & 0.684468 & 0.729245 & 0.77193 \\
\hline .08 & 0.502458 & 0.535108 & 0.572543 & 0.613669 & 0.656738 & 0.699681 & 0.740564 \\
\hline .09 & 0.486931 & 0.51855 & 0.554696 & 0.594294 & 0.635652 & 0.676785 & 0.715848 \\
\hline .10 & 0.472149 & 0.502599 & 0.53737 & 0.575425 & 0.615138 & 0.654608 & 0.692069 \\
\hline \multicolumn{8}{|c|}{$a / b=0.7 ; \quad \bar{\sigma}_{r}$} \\
\hline .08 & 0.104376 & 0.073666 & 0.051252 & 0.035020 & 0.023443 & 0.015365 & 0.009870 \\
\hline .09 & 0.058106 & 0.0480345 & 0.0390588 & 0.0311825 & 0.0244304 & 0.0188055 & 0.0142602 \\
\hline \multicolumn{8}{|c|}{$\begin{array}{ll}a / b=0.7 ; & \bar{\sigma}_{\theta} \\
\end{array}$} \\
\hline .07 & 6.36339 & 3.3197 & 1.74005 & 0.913738 & 0.479128 & 0.250131 & 0.129738 \\
\hline .08 & 2.43244 & 1.6588 & 1.13619 & 0.779343 & 0.533595 & 0.363615 & 0.246122 \\
\hline .09 & 1.03839 & 0.894981 & 0.774571 & 0.67124 & 0.580637 & 0.499958 & 0.427692 \\
\hline .10 & 0.472149 & 0.502599 & 0.53737 & 0.575425 & 0.615138 & 0.654608 & 0.692069 \\
\hline \multicolumn{8}{|c|}{$a / b=0.9 ; \quad \bar{u}_{r}$} \\
\hline
\end{tabular}




\begin{tabular}{|l|r|r|r|r|r|r|r|}
\hline .09 & 0.85616 & 0.861416 & 0.866746 & 0.872121 & 0.877518 & 0.882913 & 0.888282 \\
\hline .10 & 0.825576 & 0.830649 & 0.835787 & 0.840969 & 0.846171 & 0.85137 & 0.856545 \\
\hline \multicolumn{8}{|c|}{$a / b=0.9 ; \quad \bar{\sigma}_{\theta}$} \\
\hline .09 & 1.79001 & 1.45882 & 1.18895 & 0.969023 & 0.789766 & 0.643643 & 0.524522 \\
\hline .10 & 0.825576 & 0.830649 & 0.835787 & 0.840969 & 0.846171 & 0.85137 & 0.856545 \\
\hline
\end{tabular}

Table 5. Variation of Elastic Fields with $\beta=-5,-3,-1,0,1,3,5$

\begin{tabular}{|c|c|c|c|c|c|c|c|}
\hline$r-m$ & $\beta=-5$ & $\beta=-3$ & $\beta=-1$ & $\beta=0$ & $\beta=1$ & $\beta=3$ & $\beta=5$ \\
\hline \multicolumn{8}{|c|}{$a / b=0.3 ; \bar{u}_{r}$} \\
\hline .03 & 0.059117 & 0.0898232 & 0.166765 & 0.233505 & 0.319633 & 0.520584 & 0.703657 \\
\hline .04 & 0.0559492 & 0.0857695 & 0.15973 & 0.223366 & 0.304983 & 0.493538 & 0.662963 \\
\hline .06 & 0.0661576 & 0.101819 & 0.181217 & 0.244985 & 0.323319 & 0.494433 & 0.639235 \\
\hline .07 & 0.0766369 & 0.115269 & 0.19597 & 0.258519 & 0.333875 & 0.494939 & 0.628632 \\
\hline .09 & 0.0971885 & 0.137037 & 0.214307 & 0.272012 & 0.340275 & 0.483503 & 0.600673 \\
\hline .10 & 0.0992596 & 0.137761 & 0.212039 & 0.267391 & 0.332809 & 0.469952 & 0.582079 \\
\hline \multicolumn{8}{|c|}{$\begin{array}{ll}a / b=0.3 ; & \bar{\sigma}_{r}\end{array}$} \\
\hline .04 & 3.17189 & 0.893102 & 0.263997 & 0.139081 & 0.0697796 & 0.0147079 & 0.002551 \\
\hline .05 & 1.95422 & 0.772259 & 0.304249 & 0.183234 & 0.105131 & 0.0294793 & 0.007051 \\
\hline .06 & 1.08881 & 0.557069 & 0.275448 & 0.185284 & 0.119179 & 0.0430143 & 0.0137655 \\
\hline .07 & 0.586635 & 0.36821 & 0.219739 & 0.16256 & 0.115608 & 0.0523087 & 0.0217375 \\
\hline .08 & 0.292173 & 0.216587 & 0.151788 & 0.122133 & 0.0950424 & 0.0527636 & 0.0277305 \\
\hline .09 & 0.113032 & 0.0962325 & 0.0776141 & 0.0673544 & 0.0568893 & 0.0380657 & 0.0247382 \\
\hline \multicolumn{8}{|c|}{$a / b=0.3 ; \quad \bar{\sigma}_{\theta}$} \\
\hline .03 & 81.0933 & 11.0893 & 1.85294 & 0.778351 & 0.319633 & 0.0468526 & 0.0056996 \\
\hline .04 & 14.7696 & 3.66296 & 1.09071 & 0.607093 & 0.329406 & 0.0841139 & 0.0178648 \\
\hline .05 & 4.44563 & 1.72605 & 0.776294 & 0.526756 & 0.348404 & 0.133342 & 0.0430442 \\
\hline .06 & 1.79907 & 0.980615 & 0.599787 & 0.473158 & 0.365031 & 0.193051 & 0.0876627 \\
\hline .07 & 0.856725 & 0.608961 & 0.476847 & 0.426208 & 0.374338 & 0.260828 & 0.158543 \\
\hline .08 & 0.438212 & 0.388772 & 0.378166 & 0.378213 & 0.373431 & 0.333103 & 0.262026 \\
\hline .09 & 0.222439 & 0.242548 & 0.291741 & 0.32581 & 0.360187 & 0.40496 & 0.40276 \\
\hline .10 & 0.0992596 & 0.137761 & 0.212039 & 0.267391 & 0.332809 & 0.469952 & 0.582079 \\
\hline \multicolumn{8}{|c|}{$a / b=0.5 ; \bar{u}_{r}$} \\
\hline .05 & 0.243321 & 0.298104 & 0.379052 & 0.429083 & 0.483783 & 0.598366 & 0.705333 \\
\hline .06 & 0.231508 & 0.284131 & 0.361672 & 0.40949 & 0.461684 & 0.570722 & 0.67211 \\
\hline .07 & 0.227606 & 0.279731 & 0.355663 & 0.402101 & 0.452508 & 0.556957 & 0.653068 \\
\hline .08 & 0.228092 & 0.279661 & 0.353653 & 0.398467 & 0.446822 & 0.54623 & 0.636886 \\
\hline .09 & 0.229031 & 0.279237 & 0.350522 & 0.393435 & 0.439582 & 0.534059 & 0.61985 \\
\hline .10 & 0.225433 & 0.273783 & 0.342269 & 0.383446 & 0.427698 & 0.518228 & 0.600378 \\
\hline \multicolumn{8}{|c|}{$a / b=0.5 ; \quad \bar{\sigma}_{r}$} \\
\hline .06 & 0.519942 & 0.250475 & 0.117776 & 0.0791583 & 0.0522513 & 0.0214402 & 0.0081585 \\
\hline .07 & 0.395639 & 0.237006 & 0.136561 & 0.101314 & 0.0737995 & 0.0370107 & 0.0173952 \\
\hline .08 & 0.22564 & 0.161351 & 0.110407 & 0.0893119 & 0.0710605 & 0.0428976 & 0.0246569 \\
\hline .09 & 0.0934648 & 0.0774105 & 0.0614763 & 0.0537263 & 0.0463205 & 0.0332147 & 0.0230732 \\
\hline \multicolumn{8}{|c|}{$\begin{array}{cc}a / b=0.5 ; & \bar{\sigma}_{\theta}\end{array}$} \\
\hline .05 & 15.5725 & 4.76967 & 1.51621 & 0.858166 & 0.483783 & 0.149591 & 0.0440833 \\
\hline .06 & 5.14399 & 2.28003 & 1.04587 & 0.710189 & 0.479972 & 0.212964 & 0.0899609 \\
\hline .07 & 2.07309 & 1.24801 & 0.773638 & 0.60989 & 0.478338 & 0.285863 & 0.16289 \\
\hline .08 & 0.949075 & 0.73924 & 0.591226 & 0.529343 & 0.471693 & 0.364602 & 0.269498 \\
\hline .09 & 0.463674 & 0.452696 & 0.45426 & 0.455954 & 0.455794 & 0.444213 & 0.414759 \\
\hline .10 & 0.225433 & 0.273783 & 0.342269 & 0.383446 & 0.427698 & 0.518228 & 0.600378 \\
\hline \multicolumn{8}{|c|}{$a / b=0.7 ; \bar{u}_{r}$} \\
\hline .07 & 0.540332 & 0.576817 & 0.617842 & 0.639616 & 0.661915 & 0.707001 & 0.750958 \\
\hline .08 & 0.518146 & 0.553278 & 0.592741 & 0.613669 & 0.635087 & 0.678355 & 0.720484 \\
\hline .09 & 0.502135 & 0.536108 & 0.574157 & 0.594294 & 0.614875 & 0.65637 & 0.696674 \\
\hline .10 & 0.486796 & 0.519494 & 0.556077 & 0.575425 & 0.595191 & 0.635022 & 0.673684 \\
\hline \multicolumn{8}{|c|}{$a / b=0.7 ; \quad \bar{\sigma}_{r}$} \\
\hline .08 & 0.0878205 & 0.0615715 & 0.0424692 & 0.0350196 & 0.0287284 & 0.0190286 & 0.0123439 \\
\hline
\end{tabular}




\begin{tabular}{|l|l|l|l|l|l|l|l|}
\hline .09 & 0.0529315 & 0.0434105 & 0.0349816 & 0.0311825 & 0.0276647 & 0.0214786 & 0.0164032 \\
\hline \multicolumn{8}{|c|}{$a / b=0.7 ; \quad \bar{\sigma}_{\theta}$} \\
\hline .07 & 4.59275 & 2.4024 & 1.2609 & 0.913738 & 0.661915 & 0.34643 & 0.180305 \\
\hline .08 & 2.00731 & 1.37233 & 0.941023 & 0.779343 & 0.645142 & 0.440807 & 0.299431 \\
\hline .09 & 0.963382 & 0.832307 & 0.72108 & 0.67124 & 0.624558 & 0.539177 & 0.462829 \\
\hline .10 & 0.486796 & 0.519494 & 0.556077 & 0.575425 & 0.595191 & 0.635022 & 0.673684 \\
\hline \multicolumn{8}{|c|}{$a / b=0.9 ; \bar{u}_{r}$} \\
\hline .09 & 0.858776 & 0.864074 & 0.869429 & 0.872121 & 0.874818 & 0.880217 & 0.885602 \\
\hline .10 & 0.828103 & 0.833212 & 0.838374 & 0.840969 & 0.843569 & 0.848772 & 0.853962 \\
\hline \multicolumn{8}{|c|}{$a / b=0.9 ; \quad \bar{\sigma}_{\theta}$} \\
\hline .09 & 1.61594 & 1.31698 & 1.07337 & 0.969023 & 0.874818 & 0.712976 & 0.581044 \\
\hline .10 & 0.828103 & 0.833212 & 0.838374 & 0.840969 & 0.843569 & 0.848772 & 0.853962 \\
\hline
\end{tabular}

Figure 2. Variation of the Dimensionless Radial Displacement with Inhomogeneity Indexes and Aspect Ratio
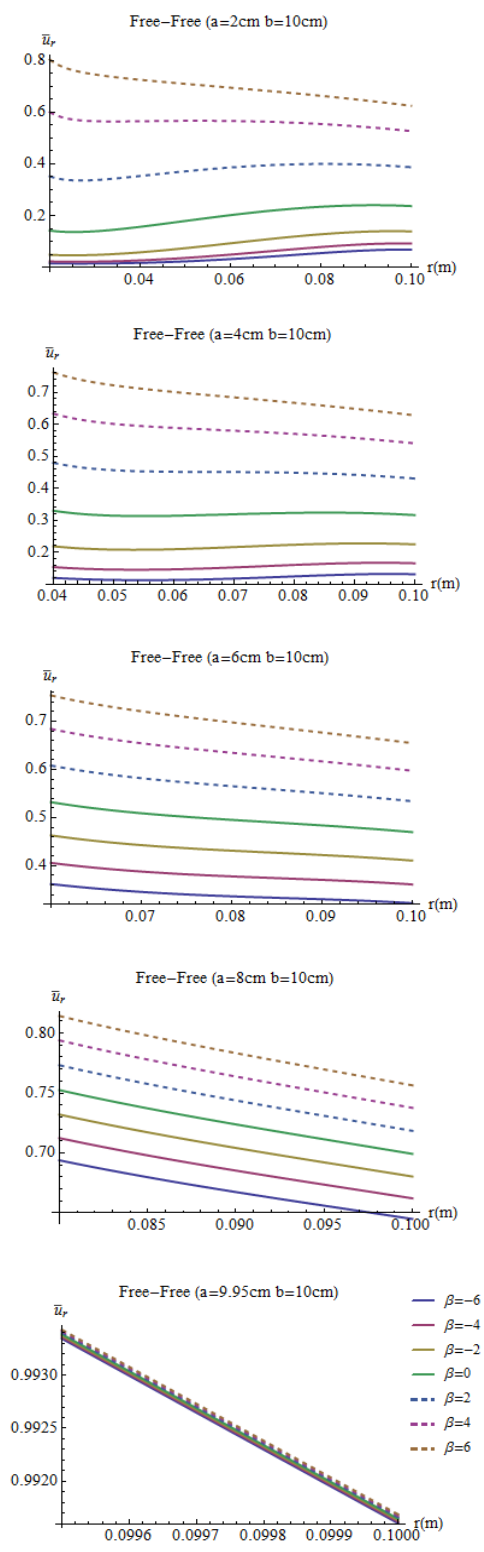
Figure 3. Variation of the Dimensionless Radial Stress with Inhomogeneity
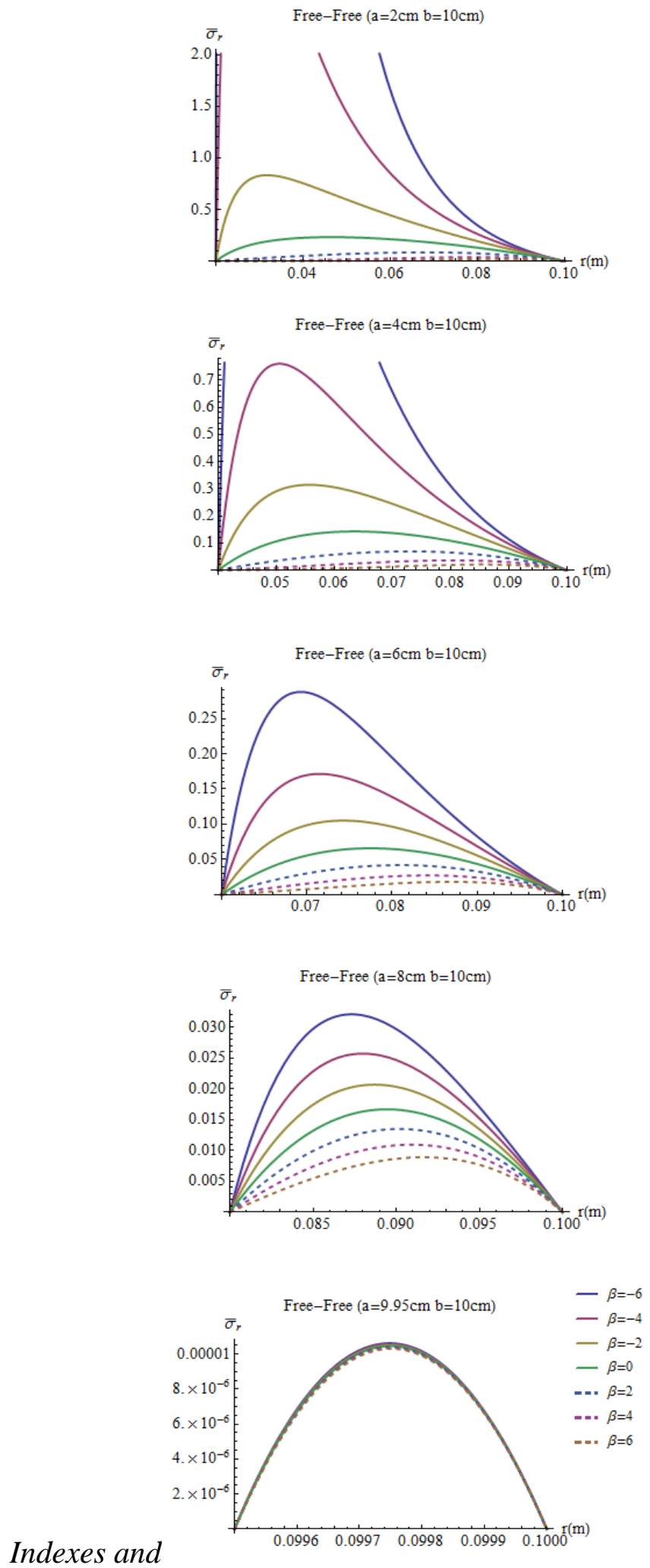

Aspect Ratio 
Figure 4. Variation of the Dimensionless Hoop Stress with Inhomogeneity Indexes and Aspect Ratio
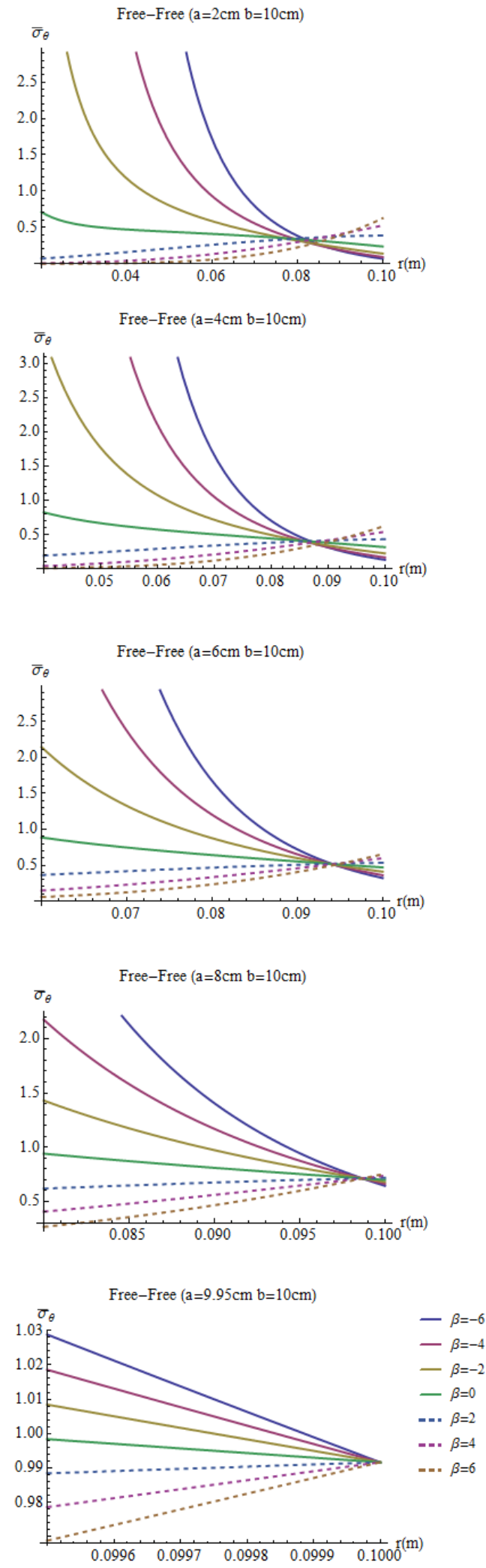
Figure 5. Variation of the Dimensionless Hoop Stress with Inhomogeneity Indexes and Aspect Ratio at the Inner Surface
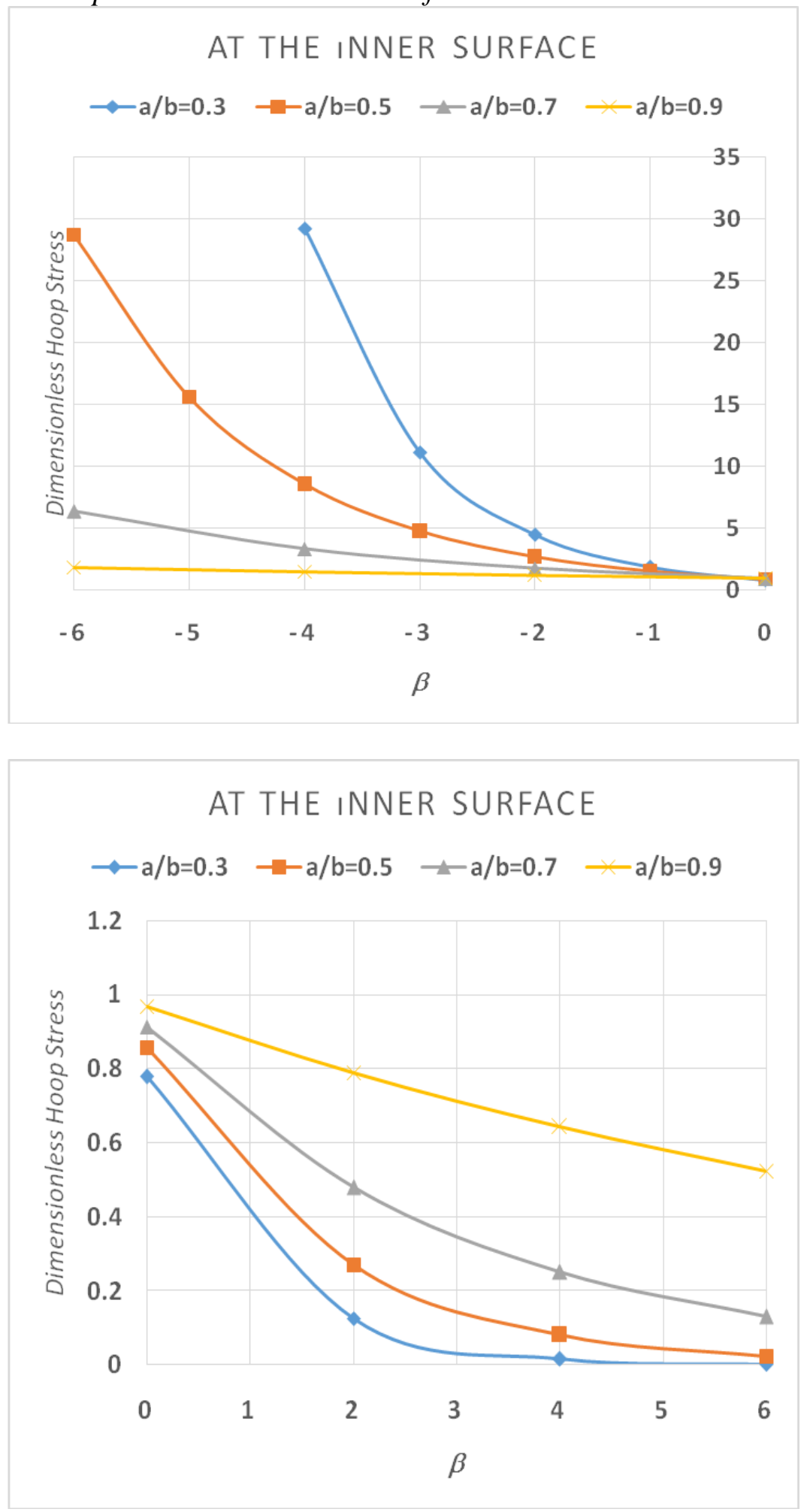
Figure 6. Variation of the Dimensionless Hoop Stress with Inhomogeneity Indexes and Aspect Ratio at the Outer Surface

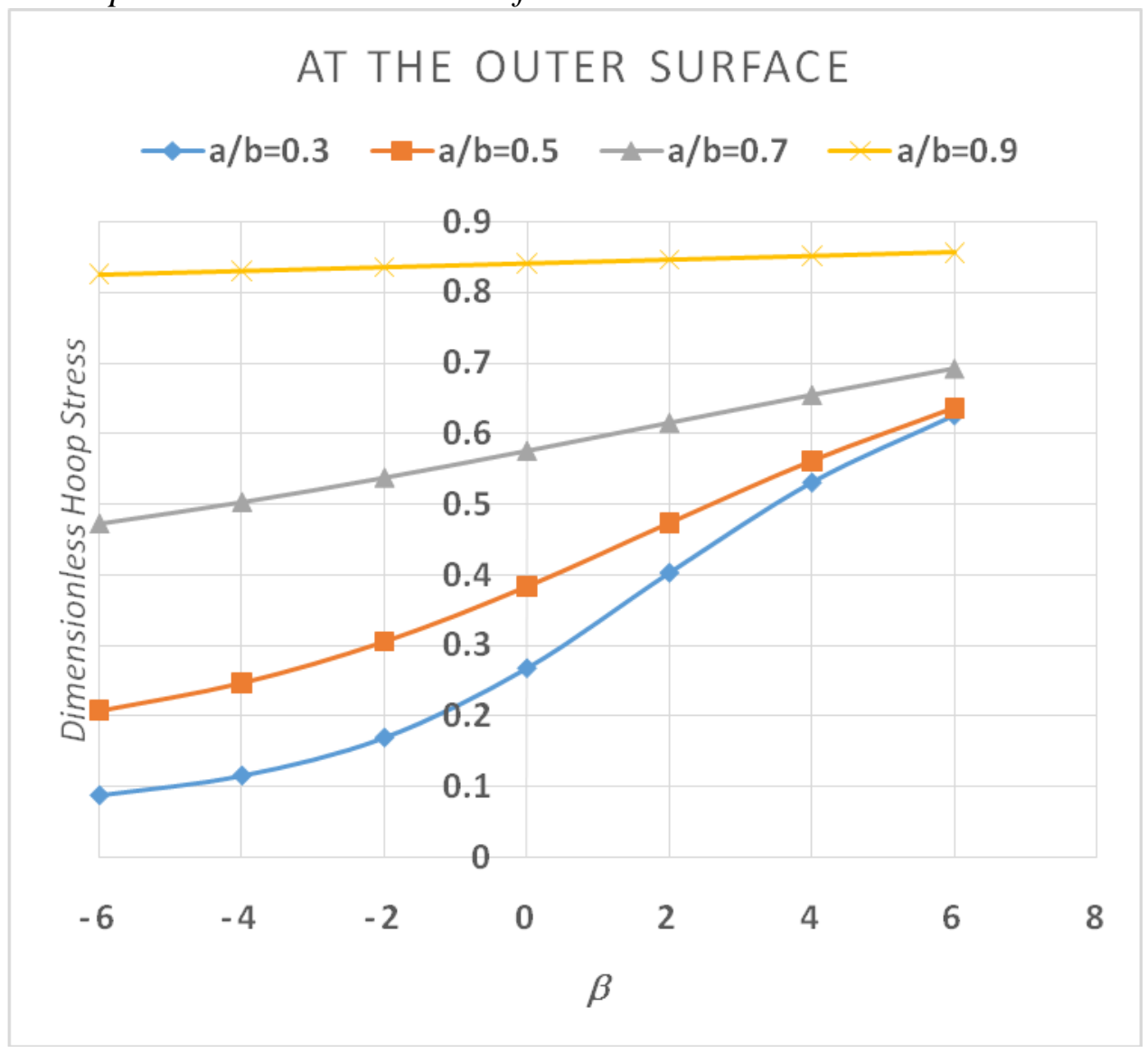

\section{Notations}

$\begin{array}{ll}a & \text { outer radius } \\ b & \text { inner radius } \\ C_{1}, C_{2} & \text { integration constants } \\ C_{i j} & \text { material on-axis rigidities } \\ E_{r}(r) & \text { Young's modulus in the } r \text { - direction } \\ E_{\theta}(r) & \text { Young's modulus in the } \theta \text {-direction } \\ E_{\theta}^{b} & \text { the reference value of Young's modulus of the mixture material } \\ r & \text { located at the outer surface in the circumferential direction } \\ u_{r} & \text { radial direction } \\ \beta & \text { radial displacement } \\ \varepsilon_{r} & \text { inhomogeneity index } \\ \varepsilon_{\theta} & \text { radial strain } \\ \lambda_{2} & \text { tangential strain } \\ v_{\theta r}, v_{r \theta} & \text { anisotropy/polar degree of the material }\end{array}$




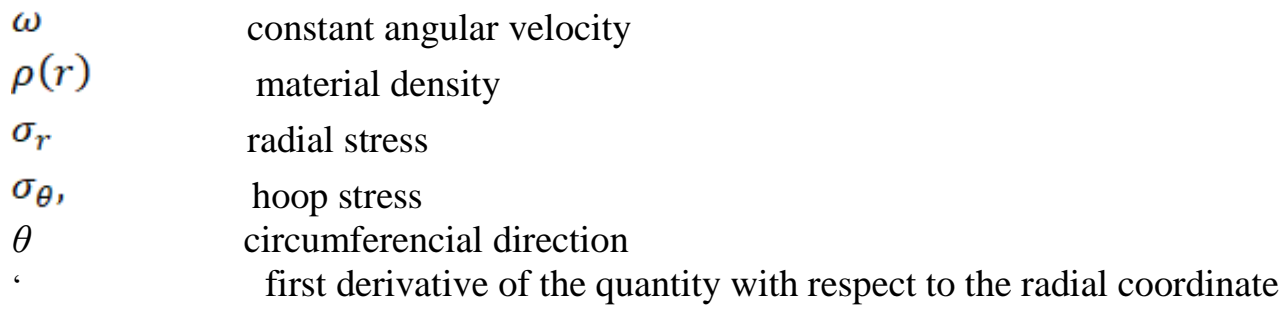

\section{References}

Ari-Gur J, Stavsky Y (1981) On rotating polar-orthotropic circular disks. International Journal of Solids and Structures 17(1): 57-67.

Boga C (2016) Analytical and numerical axisymmetric elastic stress analyses of stationary/rotating discs made of isotropic/orthotropic functionally graded materials by the transfer matrix method. Dissertation. Department of Mechanical Engineering, Çukurova University. No. 1698.

Çallığlu H (2007) Thermal stress analysis of curvilinearly orthotropic rotating discs. Journal of Thermoplastic Composite Materials 20(4): 357-369.

Çallıŏlu H, Topçu M, Altan G (2005) Stress analysis of curvilinearly orthotropic rotating discs under mechanical and thermal loading. Journal of Reinforced Plastics and Composites 24(8): 831-838.

Çallığlu H, Topçu M, Tarakçılar AR (2006) Elastic-plastic stress analysis of an orthotropic rotating disc. International Journal of Mechanical Sciences 48(9): 985990.

Campbell FC (2010) Structural Composite Materials. Ohio, USA: ASM International.

Chen J, Ding H, Chen W (2007) Three-dimensional analytical solution for a rotating disc of functionally graded materials with transverse isotropy. Archive of Applied Mechanics 77(4): 241-251.

Durodola J, Attia O (2000) Deformation and stresses in functionally graded rotating disks. Composites Science and Technology 60(7): 987-995.

Eraslan AN, Kaya Y, Varlı E (2016) Analytical solutions to orthotropic variable thickness disk problems. Pamukkale University Journal of Engineering Sciences 22(1): 24-30.

Essa S, Argeso H (2017) Elastic analysis of variable profile and polar orthotropic FGM rotating disks for a variation function with three parameters. Acta Mechanica 228(11): 3877-3899.

Gopalakrishnan S, Chakraborty A, Roy Mahapatra D (2008) Spectral Finite Element Method. Wave Propagation, Diagnostics and Control in Anisotropic and Inhomogeneous Structures. London: Springer-Verlag.

Gupta U, Ansari A, Sharma S (2006) Buckling and vibration of polar orthotropic circular plate resting on Winkler foundation. Journal of Sound and Vibration 297(3-5): 457476.

Gurushankar GV (1975) Thermal stresses in a rotating, nonhomogeneous, anisotropic disk of varying thickness and density. The Journal of Strain Analysis for Engineering Design 10(3): 137-142.

Jain R, Ramachandra K, Simha KRY (1999) Rotating anisotropic disk of uniform strength. International Journal of Mechanical Sciences 41(6): 639-648.

Jain R, Ramachandra K, Simha KRY (2000) Singularity in rotating orthotropic disks and shells. International Journal of Solids and Structures 37(14): 2035-2038. 
Kacar İ, Yıldırım V (2017) Exact elastic analysis of functionally power-graded polar orthotropic rotating uniform disks under various boundary conditions. In $\mathrm{S}$ Sahinkaya, E Kalıpcı (Eds.) Digital Proceeding of ICOCEE - Cappadocia 2017. Nevsehir, Turkey, May 8-10.

Koo KN (2006) Vibration analysis and critical speeds of polar orthotropic annular disks in rotation. Composite Structures 76(1): 67-72.

Koo KN (2008) Mechanical vibration and critical speeds of rotating composite laminate disks. Microsystem Technologies 14(6): 799-807.

Li SR, Batra RC, Ma LS (2007) Vibration of thermally post-buckled orthotropic circular plates. Journal of Thermal Stresses 30(1): 43-57.

Liang DS, Wang HJ, Chen LW (2002) Vibration and stability of rotating polar orthotropic annular disks subjected to a stationary concentrated transverse load. Journal of Sound and Vibration 250(5): 795-811.

Lubarda VA (2012) On pressurized curvilinearly orthotropic circular disk, cylinder and sphere made of radially nonuniform material. Journal of Elasticity 109(2): 103-133.

Mahamood RM, Akinlabi ET, Shukla M, Pityana S (2012) Functionally graded material: An overview. Proceedings of the World Congress on Engineering, WCE 2012, July 4-6. Volume III. London, U.K.

Mahamood RM, Akinlabi ET (2017) Functionally Graded Materials. Springer International Publishing.

Mian MA, Spencer A (1998) Exact solutions for functionally graded and laminated elastic materials. Journal of the Mechanics and Physics of Solids 46(12): 2283-2295.

Murthy D, Sherbourne A (1970) Elastic stresses in anisotropic disks of variable thickness. International Journal of Mechanical Sciences 12(7): 627-640.

Peng XL, Li XF (2012) Elastic analysis of rotating functionally graded polar orthotropic disks. International Journal of Mechanical Sciences 60(1): 84-91.

Reddy TY, Srinath H (1974) Elastic stresses in a rotating anisotropic annular disk of variable thickness and variable density. International Journal of Mechanical Sciences 16(2): 85-89.

Singh R, Jain S (2004) Free asymmetric transverse vibration of parabolically varying thickness polar orthotropic annular plate with flexible edge conditions. Journal of Science and Engineering 7(1): 41-52.

Tang S (1969) Elastic stresses in rotating anisotropic disks. International Journal of Mechanical Sciences 11(6): 509-517.

Tütüncü N (2000) Effect of anisotropy on stresses in rotating disks. International Journal of Mechanical Sciences 37(8): 873-881.

Wang X, Sudak LJ (2008) Three-dimensional analysis of multi-layered functionally graded anisotropic cylindrical panel under thermomechanical loading. Mechanics of Materials 40(4-5): 235-254.

Yildırım V (2018a) The Complementary Functions Method (CFM) Solution to the Elastic Analysis of Polar Orthotropic Rotating Discs. Journal of Applied and Computational Mechanics 4(3): 216-230.

Y1ldirım V (2018b) Unified exact solutions to the hyperbolically tapered pressurized/ rotating disks made of nonhomogeneous isotropic/orthotropic materials. International Journal of Advanced Materials Research 4(1): 1-23.

Yildırım V (2018c) The complementary functions method solution to the functionally graded polar orthotropic rotating hyperbolic disks with both radially and circumferentially aligned fibers. International Journal of Engineering \& Applied Sciences (IJEAS) 10(4): 276-290. 
Y1lırım V (2018d) Numerical/analytical solutions to the elastic response of arbitrarily functionally graded polar orthotropic rotating discs. Journal of the Brazilian Society of Mechanical Sciences and Engineering 40/320(6): 1-21.

Zenkour AM (2009) Stress distribution in rotating composite structures of functionally graded solid disks. Journal of Materials Processing Technology 209(7): 3511-3517.

Zheng Y, Bahaloo H, Mousanezhad D, Vaziri A, Nayeb-Hashemi H (2017) Displacement and stress fields in a functionally graded fiber-reinforced rotating disk with nonuniformthickness and variable angular velocity. Journal of Engineering Materials and Technology 139(3): 031010-1-9. 



\title{
Porous Silica for Removing Organic Impurities from Wastewater
}

\author{
By Hussien Motaweh ${ }^{*} \&$ Marwa Nabil
}

\begin{abstract}
In this study, the production of different architectures of two type's porous silica (amorphous and crystalline) is shown, using simple and inexpensive dual technique (alkali chemical etching process and ultra-sonication). The chemical, physical and morphological properties are the master factors, which produce a variety of application fields. It has been decided the importance degree of the porous spherical shape; as one of the most important architectures, that assist the dyes adsorption process in various industrial fields as (foods, pharmaceutics industries, and the textile industry). As it increases the breadth of the surface area of the material and it can also be used as thermal insulation due to increased electrical resistance and thermal material as well as chemical stability. Thus, we demonstrated the importance of devising different properties of the material for reuse in different applications in many applied fields. This study discusses how to remove many organic pollutants (dyes and oils) from wastewater. Therefore, the study reviewed many sizes and shapes of porous silica in different buildings, which opens the way for us to use in new applications. The both promise percentages of oil and Congo red removal are 100\% and $99.8 \%$, respectively. The amounts of used synthesized powder are very fine in each; $(0.7 \mathrm{gm} / \mathrm{L})$ of amorphous porous $\mathrm{SiO}_{2}$ for oil removing and $33.3 \mathrm{gm}$ of crystalline porous $\mathrm{SiO}_{2} /$ (at congo red concentration 50 ppm).
\end{abstract}

Keywords: Electrical Resistance, Morphology, Porous Silica, Thermal Resistance.

\section{Introduction}

Silica particles have been widely used due to their chemical stability, biocompatibility, non-toxicity and relatively easy synthesis, enabling adjustable size, morphology and porosity (Nikolić et al. 2016). In recent years, the studies of nanoparticles and nanostructures have attracted increasing interests worldwide. Porous nanospheres can potentially provide the advantages of both nanoparticles and high surface areas from micro-and mesopores in the nanoparticles (Ahmad et al. 2010).

Porous materials are solids that contain empty pores dispersed within their framework (Xiong et al. 2016). The pores may be open pores connecting to the outside of the material or closed pores isolated from the outside. Porous materials have lower density and higher surface area compared with dense materials (Morsi and Mohamed 2018). Porous Silica (Porous $\mathrm{SiO}_{2}$ ) from renewable sources can be used in very different materials, such as paints (Castillo et al. 2014), membranes for fuel cells (Zakarya et al. 2009), Li-ion batteries (Lisowska-Oleksiak et al. 2014), adsorbents (Lee et al. 2016), catalysts (Bernardos and Kouřimská 2013), and so on. The synthesis of (Porous $\mathrm{SiO}_{2}$ ) has greatly expanded the possibilities

\footnotetext{
*Professor and Vice Rector, Damanhour University, Egypt.

${ }^{*}$ Researcher, Advanced Technology and New Materials Research Institute, City for Scientific Research and Technology Applications, Egypt.
} 
for the design of open pore structures. Porous $\mathrm{SiO}_{2}$ has great potential in environmental and industrial processes, because of its large surface area, pore size and pore shape (Feng et al. 1997).

Nowadays the most promising technique for treating wastewater is adsorption process (i.e adsorbents agro-industrial) (Rovani et al. 2018). Porous $\mathrm{SiO}_{2}$ produced from commercial silicon has also been applied as green adsorbents (Nabil and Motaweh 2019). The main factors, which effect on the adsorption success in wastewater are the values of the porosity degree, the internal surface area, and the favorable chemical surface of the adsorbents. Several studies have already used porous $\mathrm{SiO}_{2}$ for the adsorption of organic contaminants with success (Mahmoodi et al. 2014).

Functional groups were introduced to the porous surface of porous $\mathrm{SiO}_{2}$ as the terminal groups of organic monolayers. So, the siloxane groups undergo hydrolysis, become covalently attached to the substrate and cross-linked to one another (Feng et al. 1997).

In this paper, two types of porous $\mathrm{SiO}_{2}$ particles (amorphous and crystalline), with different structures, functionalities and sizes are synthesized using the dual technique (i.e. alkali chemical etching and ultra-sonication) for available commercially silicon, porous $\mathrm{SiO}_{2}$ can be synthesized in bulk form, which can be produced in large quantities. The effect of porous $\mathrm{SiO}_{2}$ particle type on adsorption efficiency of organic impurities is also investigated. It is showing the dependence of adsorbent material on the variety of porous $\mathrm{SiO}_{2}$ morphological shapes. In addition, it shows the removal percentage of organic impurities (dye, and oil) that present in wastewater.

\section{Methodology}

\section{Porous $\mathrm{SiO}_{2}-$ Powder Preparation}

The dual technique (Ultra-sonication technique and the alkali chemical etching process) is used in porous $\mathrm{SiO}_{2}$ preparation (Nabil et al. 2018). The suitable amount of silicon powder (silicuim, Pulver-99\%), was scattered in a solution that contains different concentrations of $\mathrm{KOH}$, 1-propanol (30 vol \%), and water for different sonication times. The product powder is dried after filtration process.

The structure of the porous $\mathrm{SiO}_{2}$ powder were characterized by X-ray diffraction (XRD; using $\mathrm{Cu} \mathrm{K \alpha}$ radiation of $1.5405^{\circ} \mathrm{A}$ at a scanning rate of $4^{\circ}$ $\min ^{-1}$, Shimadzu 7000 diffractometer). The formation of chemical bonds for the formation of $\mathrm{P}_{-} \mathrm{SiO}_{2}$ powder was determined by Fourier Transform Infrared (FTIR) spectroscopy FTIR-8400 S spectrophotometer, Shimadzu, Japan from the various vibrational modes (each infrared spectrum was collected from 400 to 4000 $\mathrm{cm}^{-1}$ ). Porous $\mathrm{SiO}_{2}$ powder morphology is investigated using SEM (Scanning electron microscopy, JEOL (JSM 5300), magnification from 500 to 27000, at an accelerating voltage of $10 \mathrm{kV}$. 


\section{Porous $\mathrm{SiO}_{2}$ Applications}

Batch Equilibrium Method (Sharma et al. 2009); it was selected because of its simplicity and reliability. All experiments were executed at room temperature (27 ${ }^{\circ} \mathrm{C}$ ) in batch mode. They were done by taking $40 \mathrm{ml}$ metal ion sample (AR grade) in a $100 \mathrm{ml}$ Erlenmeyer flask and after $\mathrm{pH}$ adjustments; a known quantity of solution dried adsorbent (Porous $\mathrm{SiO}_{2}$ ) was added.

The flasks were shaken at $200 \mathrm{rpm}$ for time rounds till equilibrium conditions. After the shaking process, it became suspension. The residual biomass adsorbed with soya beam oil molecules and Congo red dye molecules, the filtrate was collected and subjected for guest molecules. The filtrated solution is estimated using (FTIR) spectroscopy. The values of percent oil and dye uptake by the sorbent (Sorption efficiency (Aminu et al. 2010) and the amount of it, has been calculated using the mathematical relations in our previous research (Nabil and Motaweh 2018).

\section{Results}

Figure 1 presents SEM-micrographs of synthesis porous $\mathrm{SiO}_{2}$ powder morphology. The pores interconnection is the most important structure characteristics of porous $\mathrm{SiO}_{2}$ prepared in this work, as shown in Figure 1a, b, c, and d, by which the type of application is determined. The spongy shape (Yan et al. 2009), appears in Figure 1, a, b, which is formed at preparation conditions $(6 \mathrm{wt} \% \mathrm{KOH}$ and 30 vol \% n-propanol). Its pore size is in range $(0.06-0.35 \mu \mathrm{m})$. So, it's ready to adsorb the oil molecules, due to the large size of the oil molecule (Jokić et al. 2013), as shown in the following. Oils are nonpolar (Nwabueze and Okocha 2008), and as a result they're not attracted to the polarity of water molecules. In fact, oils are hydrophobic, or "water fearing". Instead of being attracted to water molecules, oil molecules are repelled by them. Because oil is less dense and has higher viscosity than water (Vuong et al. 2009), it will always float on top of water, creating a surface layer of oil. So, the synthesis porous $\mathrm{SiO}_{2}$ powder is suitable to remove the oil from waste water as presented in the following (Santos et al. 2014).

Either in case of the $\mathrm{KOH}$ concentration ( $3 \mathrm{wt} \%$ ), Figure 1c and d show the formation of micro-wires $\mathrm{SiO}_{2}$ (wire length in the range 380-2297 $\mu \mathrm{m}$ and the wire width in the range $0.8-6.5 \mu \mathrm{m}$ ). Then, the outer surface of the micro-wires $\mathrm{SiO}_{2}$ is the active area of adsorption process. It permits the adsorption process in a wider manner, whatever the size of the particles of the adsorbed substance (small or large).

Also, XRD is very useful technique for studying the crystal structure changes, which are produced by etching processes as a result of using the dual technique, as shown in Figure 1e (Russo et al. 2011). It displays the diffraction features of the $\mathrm{SiO}_{2}$ NPs broadened peak of powders that appears at around $2 \theta=20^{\circ}$ with high intensity (Nabil and Motaweh 2015) and (Abou- Rida and Harb 2014). That is produced by consecutive chemical erosion processes with different $\mathrm{KOH}$ concen- 
trations ( 3 and 6 wt \% $\mathrm{KOH}$ ). Noticeable, the powder product wasn't separated from the etchant solution. It corresponds to amorphous $\mathrm{SiO}_{2}$.

Figure 1. Scanning Electron Micrographs of Porous $\mathrm{SiO}_{2}$ obtained with $(a, b) 6$ $w t \% \mathrm{KOH}(c, d) 3$ wt \% KOH (c) Without Separation Process, and (e) X-ray Diffraction Patterns of Amorphous Porous $\mathrm{SiO}_{2}$ Obtained at (6, and 3 wt \% KOH)
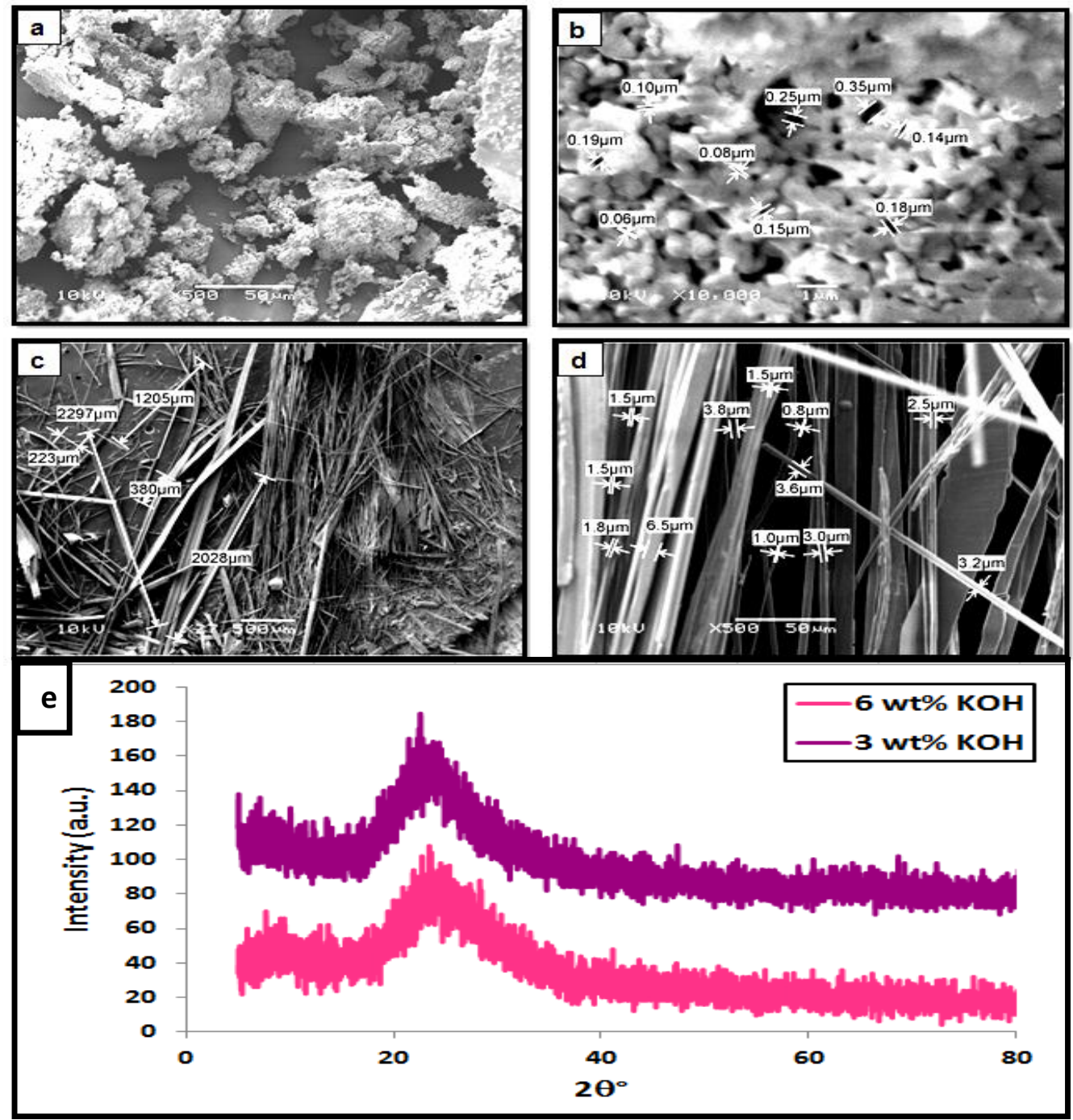

Figure 2 shows $\mathrm{SEM}$ images of porous $\mathrm{SiO}_{2}$ powder product. It clearly shows three different porous architectures (sheets, rod array, and clusters) (Singh et al. 2011), which is as a result of using $\mathrm{KOH}$ concentration $=6 \mathrm{wt} \%$ at several sonication times, after separation process of the product powder and drying it at $40^{\circ} \mathrm{C}$. Figure $2 \mathrm{a}$, and $\mathrm{b}$ show the porous $\mathrm{SiO}_{2}$ sheets, at the sonication time (t) $2 \mathrm{hr}$, its lengths are in the range 3.3-9.9 $\mu \mathrm{m}$. The diameter of the porous $\mathrm{SiO}_{2}$ rods array is in the range $(0.634-0.894 \mu \mathrm{m})$ and its length is $\approx 3.12 \mu \mathrm{m}$ with a smooth porous surface, which is formed at $\mathrm{t}=3 \mathrm{hr}$, as shown in Figure 2c, and d. In addition, its pore size is $(28-140 \mathrm{~nm})$. The third architecture is porous $\mathrm{SiO}_{2}$ clusters that are formed at $\mathrm{t}=4 \mathrm{hr}$, as shown in Figure 2e and $\mathrm{f}$. The powder product porous $\mathrm{SiO}_{2}$, 
with different architectures, is most suitable for using in water treatment process (for settling heavy metals, dyes and other mineral) (Chaemiso and Nefo 2019), as shown in our previous study (Nabil and Motaweh 2018). So, the porous $\mathrm{SiO}_{2}$ surface area is more useful than the commercial silicon powder for many environmental applications (Juárez et al. 2016); as a removing of different dye types and heavy metals in wastewater for recycling use (Kaykhaii et al. 2018).

Figure 2. Scanning Electron Micrographs of Porous $\mathrm{SiO}_{2}$ obtained with 6 wt \% $\mathrm{KOH}(a, b)$ Micro-Sheets at $t=2 \mathrm{hr}(c, d)$ Rod-Clusters at $t=3 \mathrm{hr}(e, f)$ Clusters at $t=4 \mathrm{hr}$, and $(\mathrm{g}) X$-ray Diffraction Patterns of Crystalline Porous $\mathrm{SiO}_{2}$ Obtained

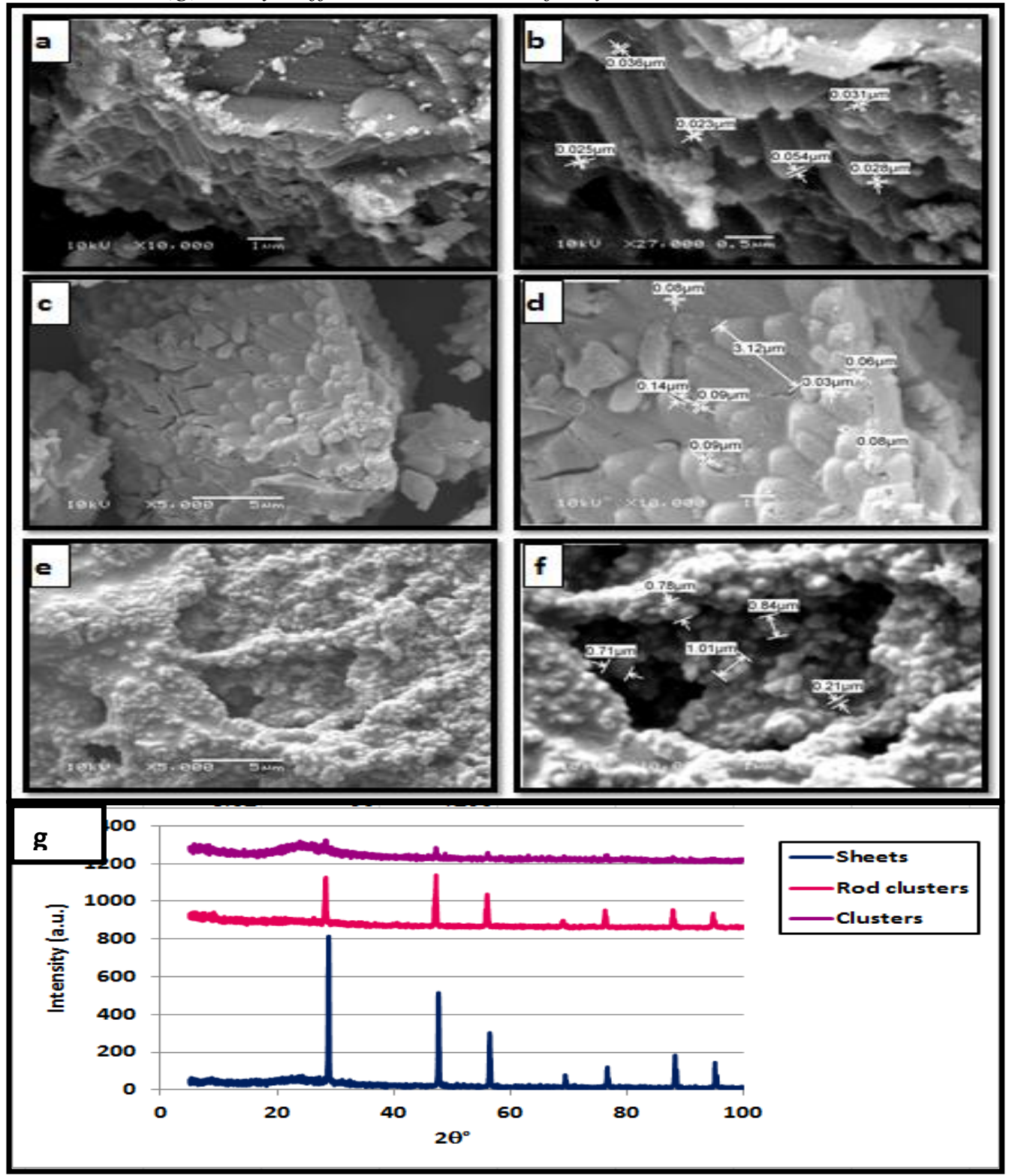


And for studying the plane form of the last architecture, XRD shows the crystalline porous $\mathrm{SiO}_{2}$ formation (Narayan et al. 2018), as shown in Figure 2g. It shows the position in the diffraction pattern at around $28.22^{\circ}, 47.21^{\circ}, 56.02^{\circ}$, $68.88^{\circ}, 76.27^{\circ}, 87.91^{\circ}$, and $94.78^{\circ}$ (JCPDS card nos. 01-079-0613 and 00-0271402) (Kashyout and Nabil 2018). They correspond to crystalline planes (111), (220), (211), (400), (331), (422), and (511), respectively (Joni et al. 2018). In addition, each plane of the crystalline porous $\mathrm{SiO}_{2}$ has variation of the presence percentage at differentiation of the preparation time, as shown in the following (Nabil et al. 2018). So, the physical and chemical properties of each porous $\mathrm{SiO}_{2}$ powder product are varying as a result of changing the material construction (Davraz and Gunduz 2005).

At 6, and 3 wt $\% \mathrm{KOH}$, as shown in Figure 3, the FTIR spectra listed the broad transmittance band centered at $3443 \mathrm{~cm}^{-1}$ that correspond to the $\mathrm{O}-\mathrm{H}$ stretching vibrational band (Smit et al. 2017) of hydrogen-bonded water molecules (H-O-H) (Nabil and Motaweh 2015). The band at $1633 \mathrm{~cm}^{-1}$ is due to the bending vibration of water molecules (Nabil et al. 2018). The shoulder at $2338 \mathrm{~cm}^{-1}$ was assigned to the stretching vibrations of $\mathrm{Si}-\mathrm{OH}$ groups in the structure of amorphous $\mathrm{SiO}_{2}$ (Musić et al. 2011), which also confirm the XRD data as shown in Figure 1e. The presence of the $\mathrm{Si}-\mathrm{OH}$ group is proof of bonded water. The very strong and broad FTIR band at $1082 \mathrm{~cm}^{-1}$ is usually assigned to $\mathrm{Si}-\mathrm{O}-\mathrm{Si}$ asymmetric stretching vibrations (Kashyout et al. 2013), and (Kashyout et al. 2018). The band at $789 \mathrm{~cm}^{-1}$ can be assigned to $\mathrm{Si}-\mathrm{O}-\mathrm{Si}$ symmetric stretching vibrations (Trivedi et al. 2015), whereas the FTIR band at $470 \mathrm{~cm}^{-1}$ is due to O$\mathrm{Si}-\mathrm{O}$ bending vibrations (Hernández-Ortiz et al. 2015). Of course, the crystalline porous $\mathrm{SiO}_{2}$ has more pronounced FTIR bands with narrower line widths (Nabil et al. 2018), which confirm the XRD data as shown in Figure $2 \mathrm{~g}$. The strong transmittance bands at 3441 and $1089 \mathrm{~cm}^{-1}$ correspond to the terminal $-\mathrm{OH}$ groups (Nabil et al. 2017).

Figure 3. Fourier Transform Infrared Spectra of the Precipitated Porous $\mathrm{SiO}_{2}$ Powders obtained with Different KOH Concentrations prepared by Wet Chemical Etching and Slow Drying at Room Temperature; a)Amorphous Silica - b) Crystalline Silica

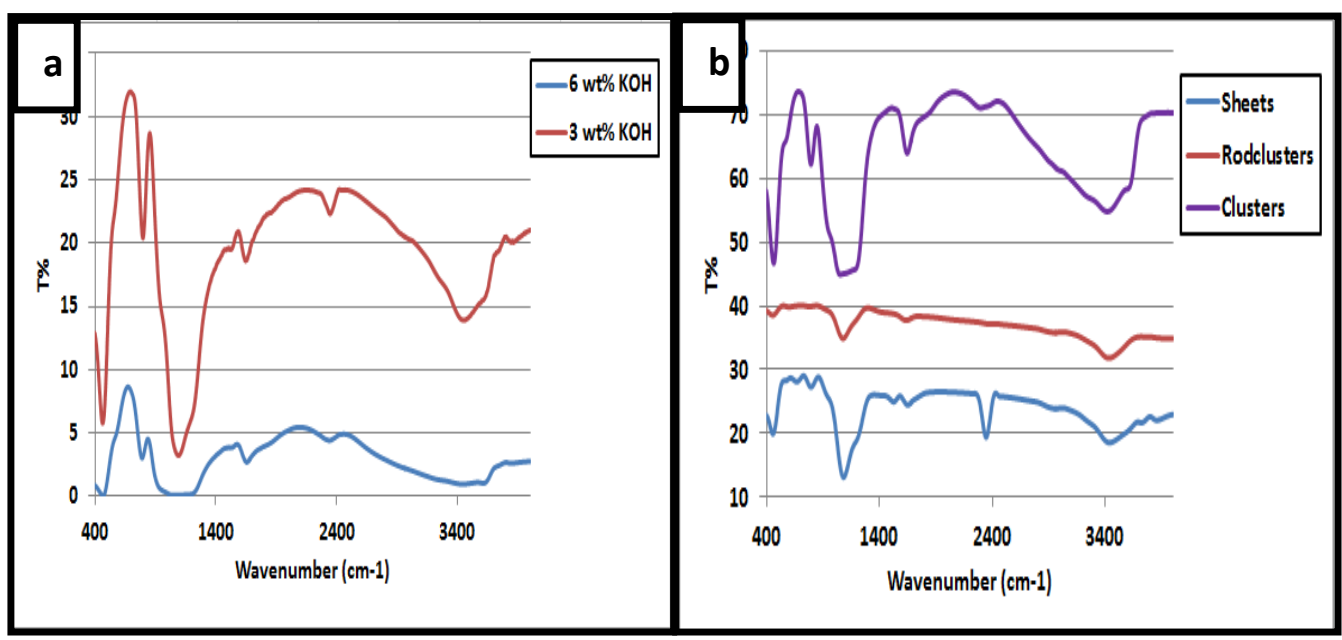


Porous $\mathrm{SiO}_{2}$ powder is one of the best materials used to remove organic compounds from wastewater (Jiang et al. 2018), as shown in Figure 4. For removing the excess oils or dyes from the industrial wastewater (Ahmad et al. 2002), the porous $\mathrm{SiO}_{2}$ is suitable for that. Figure 4 a shows the removing process of the soybean oil using amorphous porous $\mathrm{SiO}_{2}$ powder (Cho and Moon 2017). The removal percent is $100 \%$ at using $0.7 \mathrm{gm} / \mathrm{L}$ (at $5 \mathrm{vol} \%$ soybean oil), which is a promising result. On the other hand, using the crystalline porous $\mathrm{SiO}_{2}$ is useless, as shown in Figure $4 \mathrm{~b}$. That as a result of the exposed surface area value of the porous $\mathrm{SiO}_{2}$ as an adsorbed material, which is previously described in Figure 1 and Figure 2. Noticeable, the size of the soybean oil molecule is large with respect to the molecule size of congo red dye (Kashyout et al. 2015). But the suitable value used is the $33.3 \mathrm{gm}$ of crystalline porous $\mathrm{SiO}_{2} / \mathrm{l}$ (at congo red concentration $50 \mathrm{ppm}$ ). The removal percent of dye is $99.8 \%$, as shown in Figure $4 \mathrm{c}$.

So, the synthesis amorphous porous $\mathrm{SiO}_{2}$ is most suitable for removing the high viscosity organic liquids as soybean oil. On the other hand, the synthesis crystalline porous $\mathrm{SiO}_{2}$ is most suitable for removing the low viscosity organic liquids as Congo Red dye solution. The adsorption process depends on the particle size value of each liquid.

Figure 4. FTIR Spectra of the Soybean Oil Removal Using; a) Amorphous Porous $\mathrm{SiO}_{2}$, b) Crystalline Porous $\mathrm{SiO}_{2}$, and c) UV Spectra of the Congo Red Removal Use Crystalline Porous $\mathrm{SiO}_{2}$

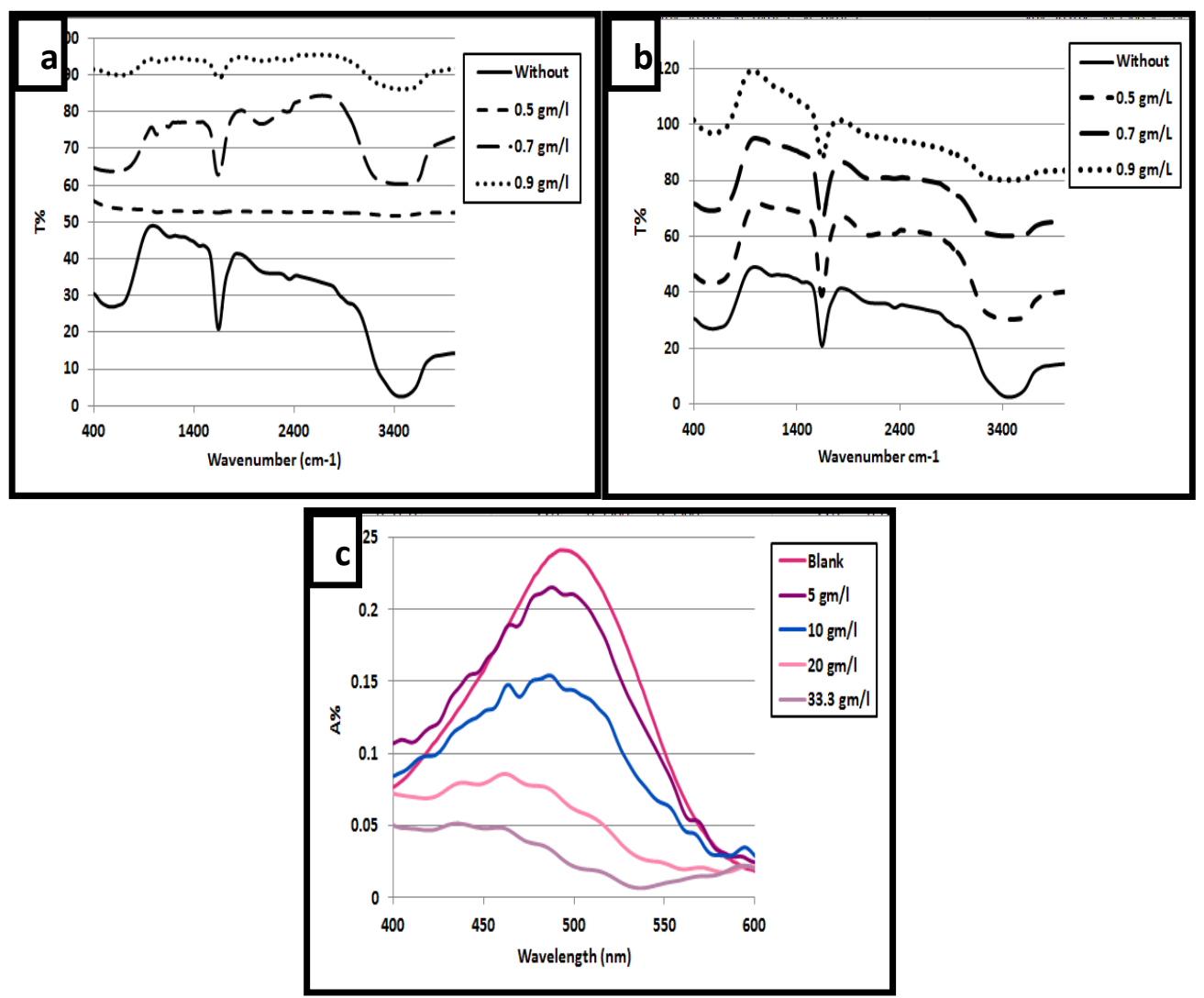




\section{Conclusions}

Porous $\mathrm{SiO}_{2}$ powder is prepared by dual technique (alkali chemical etching process and the ultra-sonication technique). The results of this study are presenting the importance of the porous $\mathrm{SiO}_{2}$ morphology and crystanillity. So, the ability of the adsorption process for different organic compounds (as soybean oil and Congo red dye) is depending on the active surface area of the porous $\mathrm{SiO}_{2}$ powder with different architectures. The amorphous type of porous $\mathrm{SiO}_{2}$ is the most suitable one for all organic impurities removal from industrial wastewater that as a result of its large pore sizes (micrometer range). So, it's easy to adsorb micro and nanometer molecule's sizes. On the other hand, the crystalline type of synthesis porous $\mathrm{SiO}_{2}$ powder isn't suitable for adsorption process to soybean oil molecules as a result of its molecules size which is in micrometer range. Then, it's agreed only for Congo red dye molecule removal because of its molecular size (nanometer range).

\section{References}

Abou-Rida M, Harb F (2014) Synthesis and characterization of amorphous silica nanoparitcles from aqueous silicates using cationic surfactants. Journal of Metals, Materials and Minerals 24(1): 37-42. DOI=10.14456/jmmm.2014.7.

Ahmad A-L, Harris WA, Syafiie, Seng, OB (2002) Removal of dye from wastewater of textile industry using membrane technology. Jurnal Teknologi 36: 31-44. DOI=10.11113/jt.v36.581.

Ahmad A, Clowes R, Willneff E, Myers P, Zhang H (2010) Porous silica spheres in macroporous structures and on nanofibres. Philosophical Transactions of the Royal Society A 368(1927): 4351-4370. DOI=10.1098/rsta.2010.0136.

Aminu AS, Gimba CE, Kagbu J, Turoti M, Itodo AU, Sariyya AI (2010) Sorption efficiency study of Pesticide adsorption on Granulated activated carbon from Groundnutshell using GC/MS. Electronic Journal of Environmental, Agricultural and Food Chemistry 9(7): 1222-1231.

Bernardos A, Kouřrimská L (2013) Applications of mesoporous silica materials in food. Journal of Food Science 31(2): 99-107. DOI= 10.17221/240/2012-CJFS.

Castillo SIR, Ouhajji S, Fokker S, Erné BH, Schneijdenberg CTWM, Thies-Weesie DME, Philipse AP (2014) Silica cubes with tunable coating thickness and porosity: From hematite filled silica boxes to hollow silica bubbles. Microporous and Mesoporous Materials 195: 75-86.

Chaemiso TD, Nefo T (2019) Removal methods of heavy metals from laboratory wastewater. Journal of Natural Sciences Research 9(2): 36-42. DOI=10.7176/JNSR.

Cho Y-S, Moon J-W (2017) Collection of industrial oil using nanoparticles and porous powders of silica. Arch. Metall. Mater. 62: 1371-1375. DOI=10.1515/amm-20170211.

Davraz M, Gunduz L (2005) Engineering properties of amorphous silica as a new natural pozzolan for use in concrete. Cement and Concrete Research 35(7): 1251-1261. DOI=10.1016/j.cemconres.2004.11.016.

Feng X, Fryxell GE, Wang LQ, Kim AY, Liu J, Kemner KM (1997) Functionalized monolayers on ordered meso porous supports. Science 276(5314): 923-926. DOI= 10.1126/science.276.5314.923. 
Hernández-Ortiz M, Hernández-Padrón G, Bernal R, Cruz-Vázquez C, Castaño VM (2015) Nanocrystalline mimetic opals: synthesis and comparative characterization vs. natural stones. International Journal of Basic and Applied Sciences 4(2): 238-243. DOI=10.14419/ijbas.v4i2.4174.

Jiang N, Shang R, Heijman SGJ, Rietveld LC (2018) High-silica zeolites for adsorption of organic micro-pollutants in water treatment: A review. Water Research 144: 145161. DOI=https://doi.org/10.1016/j.watres.2018.07.017.

Jokić S, Sudar R, Svilović S, Vidović S, Bilić M, Velić D, Jurković V (2013) Fatty acid composition of oil obtained from soybeans by extraction with supercritical carbon dioxide. Czech Journal of Food Sciences 31(2): 116-125. DOI=10.17221/8/2012CJFS.

Joni IM, Nulhakim L, Vanitha M, Panatarani C (2018) Characteristics of crystalline silica $\left(\mathrm{SiO}_{2}\right)$ particles prepared by simple solution method using sodium silicate $\left(\mathrm{Na}_{2} \mathrm{SiO}_{3}\right)$ precursor. Journal of Physics: Conference Series 1080, (2018): 012006-012012. DOI=10.1088/1742-6596/1080/1/012006.

Juárez GS, Barojas EG, González EQ, Mora ES, López JAL (2016) Oxidized porous silicon as a non-interfering support for luminescent dyes. Mesoporous Biomaterials 3(1): 61-66. DOI=https://doi.org/10.1515/mesbi-2016-0008.

Kashyout A-HB, Soliman HMA, Nabil M, Bishara AA (2013) Fabrication of nano-porous silicon using alkali etching process. Materials Letters 100: 184-187. DOI=http://dx.doi.org/10.1016/j.matlet.2012.12.107.

Kashyout A-HB, Soliman HMA, Nabil M, Bishara AA (2015) Impact of Congo red dye in nano-porous silicon as pH-sensor. Sensors and Actuators $B$ 216: 279-285. DOI=http://dx.doi.org/10.1016/j.snb.2015.03.099.

Kashyout A-HB, Nabil M (2018) Production of high throughput nano-porous silicon (NPS) powder with different architectures. Materials Chemistry and Physics 216: 454-459. DOI=https://doi.org/10.1016/j.matchemphys.2018.05.048.

Kaykhaii M, Sasani M, Marghzari S (2018) Removal of dyes from the environment by adsorption process. Chemical and Materials Engineering 6(2): 31-35. DOI=10.13189/cme.2018.060201.

Lee J-Y, Chen C-H, Cheng S, Li H-Y (2016) Adsorption of $\mathrm{Pb}$ (II) and $\mathrm{Cu}(\mathrm{II})$ metal ions on functionalized large-pore mesoporous silica. International Journal of Environmental Science and Technology 13(1): 65-76. DOI=10.1007/s13762-0150841-y.

Lisowska-Oleksiak A, Nowak AP, Wicikowsk B (2014) Aquatic biomass containing porous silica as an anode for lithium ion batteries. RSC Advances 4(76): 4043940443. DOI=10.1039/C4RA06420H.

Mahmoodi NM, Maghsoudi A, Najafi F, Jalili M, Kharrati H (2014) Primary-secondary amino silica nanoparticle: synthesis and dye removal from binary system. Desalination and Water Treatment 52: 7784-7796. DOI=10.1080/19443994. 2013.833872.

Morsi RE, Mohamed RS (2018) Nanostructured mesoporous silica: influence of the preparation conditions on the physical-surface properties for efficient organic dye uptake. Royal Society Open Science 5(3): 172021-172036. DOI=0000-0002-36952738.

Musić S, Vinceković NF, Sekovanić L (2011) Precipitation of amorphous $\mathrm{SiO}_{2}$ particles and their properties. Brazilian Journal of Chemical Engineering 28(1): 89-94. DOI=10.1590/S0104-66322011000100011. 
Nabil M, Motaweh HA (2015) Silica nanoparticles preparation using alkali etching process. Applied Mechanics and Materials 749: 155-158. DOI=10.4028/www.scien tific.net/AMM.749.155.

Nabil M, Elnouby M, Gayeh N, Sakr AH, Motaweh HA (2017) Enhancement of porous silicon photoluminescence using (Ni) Treatment. IOP Conference Series: Materials Science and Engineering 248: 012001-012008. DOI=10.1088/1757-899X/248/ $1 / 012001$.

Nabil M, Motaweh HA (2018) Porous silicon powder as an adsorbent of heavy metal (Nickel). AIP Conference Proceedings 1957: 020005-020010. DOI=10.1063/1. 5034324.

Nabil M, Mahmoud KR, El-Shaer A, Nayber HA (2018) Preparation of crystalline silica (quartz, cristobalite, and tridymite) and amorphous silica powder (one step). Journal of Physics and Chemistry of Solids 121: 22-26. DOI=https://doi.org/10.1016/j.jpcs. 2018.05.001.

Nabil M, Motaweh HA (2019) Shape control of silica powder formation. Journal of Materials Science and Chemical Engineering 7(3): 49-55. DOI=https://doi.org/10.42 36/msce.2019.73004.

Narayan R, Nayak UY, Raichur AM, Garg S (2018) Mesoporous silica nanoparticles: a comprehensive review on synthesis and recent advances. Pharmaceutics 10(3): 2-49. DOI=10.3390/pharmaceutics10030118.

Nikolić MP, Ribić-Zelenović L, Trišović T, Stanojević-Nikolić S (2016) Synthesis and characterization of porous silica particles for bioseparation application. Acta. Agriculturae Serbica XXI(41): 47-55. DOI=10.5937/AASer1641047N.

Nwabueze TU, Okocha KS (2008) Extraction performances of polar and non-polar solvents on the physical and chemical indices of African breadfruit (Treculia africana) seed oil. African Journal of Food Science 2: 119-125. DOI=e http://www. academicjournals.org/ajfs.

Rovani S, Santos JJ, Corio P, Fungaro DA (2018) Highly pure silica nanoparticles with high adsorption capacity obtained from sugarcane waste ash. ACS Omega 3(3): 26182627. DOI=10.1021/acsomega. 8 b00092.

Russo L, Colangelo F, Cioffi R, Rea I, Stefano LD (2011) A mechanochemical approach to porous silicon nanoparticles fabrication. Materials 4(6): 1023-1033. DOI=10.3390 /ma4061023.

Santos RG, Loh W, Bannwart AC, Trevisan OV (2014) An overview of heavy oil properties and its recovery and transportation methods. Brazilian Journal of Chemical Engineering 31(3): 571-590. DOI=10.1590/0104-6632.20140313s0000 1853.

Sharma YC, Upadhyay USN, Gode F (2009) Adsorptive removal of a basic dye from water and wastewater by activated carbon. Journal of Applied Sciences in Environmental Sanitation 4(1): 21-28. DOI=10.1016/j.desal.2007.05.018.

Singh LP, Agarwal SK, Bhattacharyya SK, Sharma U, Ahalawat S (2011) Preparation of silica nanoparticles and its beneficial role in cementitious materials. Nanomaterials and Nanotechnology 1(1): 44-51. DOI=10.5772/50950.

Smit WJ, Tang F, Nagata Y, Sanchez MA, Hasegawa T, Backus EHG, Bonn M, Bakker $\mathrm{HJ}$ (2017) Observation and identification of a new $\mathrm{OH}$ stretch vibrational band at the surface of ice. Journal of Physical Chemistry Letters 8(15): 3656-3660. DOI=10.10 21/acs.jpclett.7b01295.

Trivedi MK, Branton A, Trivedi D, Shettigar H, Bairwa K, Snehasis Jana S (2015) Fourier transform infrared and ultraviolet-visible spectroscopic characterization of biofield treated salicylic acid and sparfloxacin. Natural Products Chemistry \& Research 3(186): 5 - 11. DOI=http://dx.doi.org/10.4172/2329-6836.1000186. 
Vuong DH, Zhang HQ, Sarica C, Li M (2009) Experimental study on high viscosity oil/water flow in horizontal and vertical pipes. Society of Petroleum Engineers 124542. DOI=10.2118/124542-MS.

Xiong Q, Baychev TG, Jivkov AP (2016) Review of pore network modelling of porous media: Experimental characterisations, network constructions and applications to reactive transport. Journal of Contaminant Hydrology 192: 101-117. DOI=https:// doi.org/10.1016/j.jconhyd.2016.07.002.

Yan D, Cheng S, Zhuo RF, Chen JT, Feng JJ, Feng HT, Li HJ, Wu ZG, Wang J, Yan PX (2009) Nanoparticles and 3D sponge-like porous networks of manganese oxides and their microwave absorption properties. Nanotechnology 20(10): 105706-105715. DOI=10.1088/0957-4484/20/10/105706.

Zakarya A, Matos BR, De-Florio DZ, Licoccia S, Traversa E, Esposito V, Santiago EI, Fonseca FC (2009) Nafion-mesoporous silica as electrolyte for ethanol fuel cells. ECS Transactions 25(1): 853-860. DOI=10.1149/1.3210639. 



\title{
Testing Artificial Intelligence by Customers' Needs
}

\author{
By Thomas Fehlmann* \& Eberhard Kranich ${ }^{*}$
}

\begin{abstract}
Artificial Intelligence (AI) is everywhere, nowadays. No longer limited to computer laboratory, it now sets up media campaigns, influences people, decides elections, protects property, and drives cars. The principles of AI are quite old; most of them originate from the early times of computer science and had been discussed in the seventies and the eighties. But they were theoretical concepts as computer power was a scarce resource, and not enough data was available to feed the perception of that time. However, now AI governs even safety-criminal systems. How can it be tested? The answer is surprisingly simple: consider the system's goals.
\end{abstract}

Keywords: Artificial Intelligence, Neural Networks, Safety Metrics, Software Metrics, Support Vector Machines, Test Coverage, Test Metrics.

\section{Introduction}

The principles of AI are classification of entities and the solution of the equation $\boldsymbol{f}(\boldsymbol{x})=\boldsymbol{y}$, where $\boldsymbol{x}$ and $\boldsymbol{y}$ are vectors in spaces of different dimensions and semantics. For instance, $y$ could be the observable behavior of people or extrasolar planets, and $\boldsymbol{x}$ the unknown cause of it. Traditional solution methods are regression, where both $\boldsymbol{x}$ and $\boldsymbol{y}$ are measurable, or eigenvector methods, where the $\boldsymbol{x}$, is not directly measurable but the correlation between the two is measurable. If there is not much known about the transfer function $f$, neural networks can be set up that learn the transfer function, based on experience.

If a car uses an image recognition system, it must learn to distinguish between people walking, running, children playing, waiting, and bicycles riding, or being walked. The system should also be able to recognize people and things if not seen in full, even partly hidden behind a bush, by fog, or at night. Such a system is programmed to learn; neither image characteristics nor pattern recognition algorithms are programmed into it.

Unfortunately, such neural networks do not only learn, they also unlearn. Van Gerven et al. (2018) have shown that they can get distressed ("mad") as any neural information processing, similar to humans. Before I dare to sit into an autonomous car, I probably want to know whether and when this car with its current state of the learning system had passed its last test.

\footnotetext{
*Senior Researcher, Euro Project Office AG, Switzerland.

${ }^{\star}$ Senior Researcher, Euro Project Office, Germany.
} 


\section{Our Approach}

This requires the ability to test software-intense systems autonomously. It must be possible to test a car's image analysis capabilities in regular intervals to see whether it still works as expected; thus, detecting "madness" early enough to avoid damage. Whether the old capabilities still work, it needs being tested.

Moreover, tests must evolve as well. They cannot be static; test suites need to expand for new learnings, new environments, and new standards and regulations.

This is Autonomous Real-time Testing (ART). ART needs AI techniques to generate enough test cases, and thanks to this expandability ART is capable of testing other AI.

\section{Why Learning is Not Good Enough without Testing}

The death of Elaine Herzberg (August 2, 1968 - March 18, 2018) was the first recorded case of a pedestrian fatality involving an autonomous car, following a collision that occurred at around 10pm Mountain Standard Time (UTC-7) in the evening of Sunday, March 18, 2018 (The National Transportation Safety Board 2018). The following narrative is extracted from the said source.

Herzberg was pushing a bicycle across a four-lane road in Tempe, Arizona, United States, when she was struck by Volvo XC90 taxi outfitted with a sensor system, operated under test conditions by Uber. Since 2015, Uber conducted tests with various levels of automation in Arizona. The car was operating in self-drive mode with a human safety backup driver sitting in the driving seat. Following the collision, Herzberg was taken to the hospital where she died of her injuries.

According Uber, the accident was largely caused by the software that decides how the car should react to objects it detects. The car's sensors detected the pedestrian, who was crossing the street with a bicycle. Uber's software first registered Elaine Herzberg on lidar six seconds before the crash - at the speed it was traveling, that puts first contact at about $115 \mathrm{~m}$ away. As the vehicle and pedestrian paths converged, the self-driving system software classified the pedestrian first as an unknown object, then as a vehicle, and then as a bicycle with varying expectations of future travel path. The software decided it did not need to react right away. Like other autonomous vehicle systems, Uber's software can ignore "false positives," or objects in its path that are not an obstacle for the vehicle, such as a plastic bag floating over a road.

Then, 1.3 seconds before impact, which is to say about $24 \mathrm{~m}$ away, the selfdriving system determined that an emergency braking maneuver was needed to mitigate a collision. According to Uber, emergency braking maneuvers are not enabled while the vehicle is under computer control, to reduce the potential for erratic vehicle behavior. The vehicle operator is relied on to intervene and act. The system is not designed to alert the operator. The Volvo model's built-in safety systems - collision avoidance and emergency braking, among other things were also disabled while in autonomous testing mode. 
The self-driving system data showed that the vehicle operator intervened less than a second before impact by engaging the steering wheel. The vehicle speed at impact was $62 \mathrm{~km} / \mathrm{h}$. The operator began braking less than a second after the impact. The data also showed that all aspects of the self-driving system were operating normally at the time of the crash, and that there were no faults or diagnostic messages.

The dead of Elaine Herzberg raises one major question: Why were the visual recognition systems tested in real life situations only, instead under labor conditions before hitting the road?

\section{A Primer on Metrics for Testing Software}

A Test is a finite collection of Test Stories. Test stories are finite collections of Test Cases, characterized by some common business value delivered. Business value is defined by User Stories. Test stories are related to user stories but typically not the same. Test stories address more than just one user story, combining different aspects from loosely related sources.

Test cases $\left\{x_{1}, x_{2}, \ldots, x_{n}\right\} \rightarrow y$ start with a set of preconditions $x_{1}, x_{2}, \ldots, x_{n}$ and yield some known response $y$. Test cases always contain weakest assertions; thus, inequalities or range specification rather than sample numbers; see the book of the author (Fehlmann 2016, p. 319ff).

\section{A Model for Software Functionality: ISO/IEC 19761 COSMIC}

When consulting the ISO/IEC/IEEE 29119 testing standard (ISO/IEC/IEEE 29119-4, 2015), it astonishes that part 4 identifies 23 different so-called Test Coverage Items. But tests primarily address software functionality. It is unnecessary to define extra "Items" that undergo testing.

Functional models are available and in use since the past 40 years for sizing software. Tests cover its model elements. We chose the ISO/IEC 19761 COSMIC standard (ISO/IEC 19761 2011). This model of software functionality consists of Data Movements, moving Data Groups from one Object of Interest into another. Thus, there exists only one test coverage item: obviously, the data movement.

\section{Data Movement Maps}

A piece of software connecting objects of interest that represent functionality, persistent stores, devices and other applications, can be modeled as Data Movement Maps. The connectors are called Data Movements.

Data movement maps have some resemblance to UML Sequence Diagrams (Bell 2004) but with less detail, and sequencing is not prescribed. The advantage of this representation is that size is immediately visible; useful as size count according ISO/IEC 19761. Data movements always move a Data Group, which can be thought as a data record. A data movement counts for size only if its data group is unique. 
Uniqueness is indicated by color-filled trapezes. Another move of same data group between the same objects within a COSMIC functional process lets the trapeze blank.

There are four kinds of data movements: An Entry to some functional process; an eXit to some device or other application; Reading from and Writing into a permanent store. Counting data movements yields the Functional Size (Figure 1).

Figure 1. Sample Data Movement Map

\section{Entry $(E)+2$ eXit $(X)+1$ Read $(R)+1$ Write $(W)=6$ CFP}

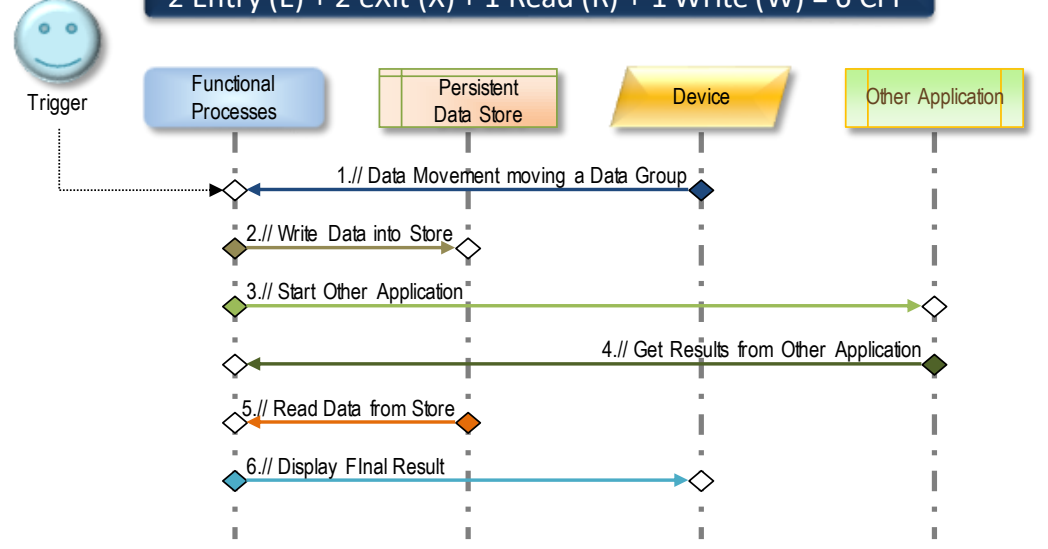

When executing a test case, it is straightforward to identify the data movements that are executed. The initial data movements are those whose data group meets the assertions made for test data; the last data movement meets the response assertion. The test case simply is represented by a sub-map of the data movement map for the app being tested.

Moreover, objects of interest can be expected to provide test stubs; this means that such objects can provide test data without executing all the data creation functionality that under normal operational conditions is needed. If there is some hardware in the loop, test stubs are needed anyway to simulate the sensors' or actuators' data supplied into the test.

\section{Test Size}

Test Size thus is the number of data movements needed to execute some test case for producing the test response. According COSMIC rules, moving the same data group is counted only once for size. However, since a test story consists of many test cases, a specific data movement is executing many times within a test story, typically with different test data. All test cases within a test story must be different from each other.

Test Intensity in turn is an average number characterizing how many times on average a data movement becomes part of test case. Since high test intensity, does not rule out that not all data movements are executed at least once in a test, Test Coverage remains an important indicator, specifying the percentage of data movements not covered with one test case in some test story. 
The total size of a test story is the sum of all test case sizes executed within a test story, thus increasing test size when executing more test cases.

In statistics, test distribution indicates the degree to which test intensity differs within one test story, or within the full test suite. For practical purposes, such a metric seems not very telling, since it does not replace test coverage. It is rather expected that high business value increases test intensity while data movements moving irrelevant data are well tested with a few test cases only. Thus, test intensity depends from business value and is not normally distributed. Therefore, test distribution is not a meaningful indicator.

\section{Test Walk}

The data movement maps can be used to visualize tests cases. You can walk the tests, similar, but less in detail, as walking through code. Such visualization might help in crowd testing for identifying bugs found. The tester sees selected sequences in the data movement map; he can "walk" the data movements when planning or executing tests. This makes functionality visible to the development team, localizes defects that impact functionality, and supports communication between testers, users, and developers. Figure 2 shows how Data Walker walks four data movements of a test case and detects a bug at the fourth data movement.

A Bug is defined the traditional way: a test case that returns an unexpected response. Because our data walker can detect only one bug at a time, we are able to count defects unambiguously and thus define what defect density is. The maximum number of defects per test case is its test size. One test story only counts for a maximum of one defect per data movement

Figure 2. Test Walk on Data Movement Maps (One Bug Found in Fourth Step)
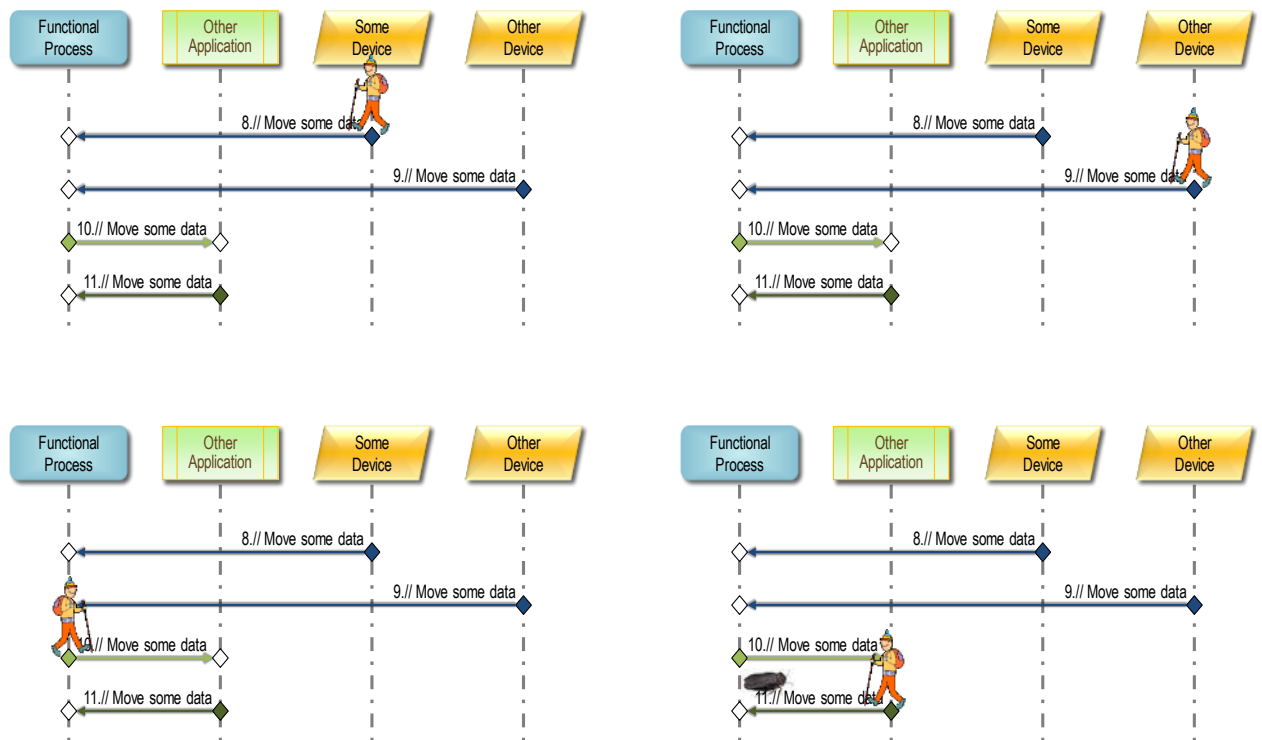


\section{Defect Density}

What is a defect? A defect means that the response does not meet the assertion of the response in the respective arrow term. It is therefore obvious that a defect relates to a test story. It refers to some data movement that exhibits the flawed response when executed by some specific test case.

Thus, counting defects become a limited task. You can count a maximum of one defect per data movement per test story. Defect Density is therefore a percentage of the total of defect opportunities. This definition opens the possibility to apply the usual Six Sigma techniques to defect density and defect distribution. Traditional defect counts obtained from counting the number of entries in a bug repository are not suitable for applying Six Sigma.

\section{Test Coverage}

Key among test metrics is Test Coverage. Test coverage has to do with users', or customers', values. It is useless to test pieces of software that deliver nothing visible to the user, or nothing that has any value. Test coverage refers to functionality, and not to code. Code implements functionality, and tests cover functionality, not code. Functionality can originate from anywhere, the cloud, other services. Code might provide other things that user functionality, e.g., additional security or traceability.

For defining test coverage, functionality needs evaluation in view of customer values. It is obvious that just counting whether any given piece of functionality is covered by tests does not yield useful metrics, because users see value in respective functionality differently.

\section{Creating a Customer Needs Profile}

The usual way of valuating functionality is by prioritizing user stories. Agile teams set priorities when selecting user stories for a sprint. Priorities are set by the product owner; however, the methods used for setting priorities are not standardized. Since product owner is the most difficult role in agile development, especially with Scrum (Schwaber and Beedle 2002), it is helpful to use a method dedicated to developing a product towards customer needs.

The method of choice is the Analytical Hierarchy Process (AHP), proposed by Saaty (2003) and used in Fehlmann (2016, p. 21), based on calculating Eigenvector solutions. The applicable ISO 16355 standard (ISO 16355-1:2015 2015) lists many more excellent alternatives for Voice of the Customer (Mazur 2014), e.g., Net Promoter ${ }^{\circledR}$ surveys (Fehlmann and Kranich 2014), and Gemba visits (Mazur and Bylund 2009). All these methods are part of Quality Function Deployment (QFD) (Fehlmann 2016, p. 16). 
Effectiveness of the Implemented System

With customer needs established, user stories can easily be prioritized with a Six Sigma Transfer Function that maps user stories onto customers' needs. Transfer functions map causes to effects and have a Convergence Gap that indicates how well the effective profile of the transfer function matches the goal profile. The functional effectiveness transfer function uses the frequency of data movements needed for implementing the user stories. The resulting profile defines the user stories' priorities. These transfer functions are explained in Fehlmann (2016, p. 21ff, p. 196).

In turn, mapping test stories onto user stories, again using the frequency of data movements used in test cases, defines Test Coverage. The matrix looks familiar; tester uses it to assess coverage of code by tests. However, without proper test metrics you cannot assess a test coverage matrix for its quality. If the test cases in a series of test stories cover the user stories, and the transfer functions yields a satisfactory convergence gap, the tests cover customer needs exactly, up to the said convergence gap (Figure 3).

Figure 3. Transfer Functions Overview

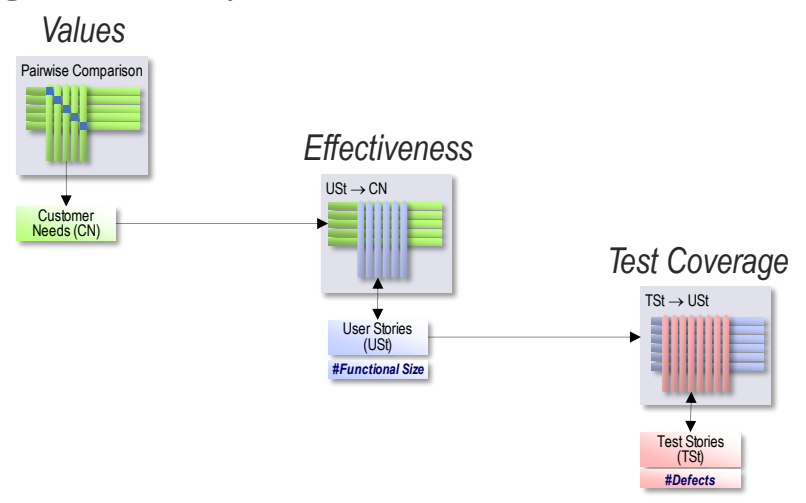

Thus, the test coverage matrix represents a transfer function providing assurance that the test stories verify the correct implementation of the user stories. The convergence gap measures how well the correct implementation of user stories can be proved by these tests.

These tests do not prove anything else than the requirements expressed in the user stories. Adding user stories requires adding test stories. And as ever with transfer functions, there is no way of proving that the selected test stories are the only selection that works, not even the minimal one; you just can prove that the selected test stories work sufficiently well. Thus, the convergence gap, in turn, is a metric that can be used for test automation. It eliminates test stories that are not needed in view of the values of the customer.

\section{Test Acceptance Criteria}

Test coverage within a given convergence gap replaces traditional test completion criteria, as extensively spread out in the respective ISO standard 
(ISO/IEC/ IEEE 29119-4 2015, p. 125). Test cases are considered for inclusion in the test coverage transfer function only if passed when executing the test. The full test suite is passed if test coverage, computed with valid test cases only, results in a convergence gap below a certain limit. Currently, we believe a suitable limit is 0.1 , corresponding to a $10 \%$ match between goal of testing and tests executed (Fehlmann 2016, p. 13ff).

\section{How to Test Artificial Intelligence}

Computer Vision and Artificial Intelligence (AI) overlap. AI is different from ordinary software by its capability to learn. This means, AI can adapt to new environments, data, images and videos. While AI can be used for other tasks, computer vision is concerned with the theory behind artificial systems that extract information from images. Areas of AI deal with autonomous planning or deliberation for robot systems to navigate through an environment. A detailed understanding of these environments is required to navigate through them. Information about the environment could be provided by a computer vision system, acting as a vision sensor and providing high-level information about the environment and the robot.

AI and computer vision share other topics such as pattern recognition and learning techniques. Consequently, computer vision is sometimes seen as a part of the AI field. Testing AI in computer vision obviously is not so straightforward; mainly, because it is not possible to predict what the correct outcome is. The test case might produce different responses, and all are correct at a given state of experience collection.

Recall that AI basically is sorting data into categories based on previous learning, or sample sets. In the Elaine Herzberg case, the Uber car did exactly that when its Lidar, and ten visual cameras, recognized the object moving towards the car's driveway. The difficulty was to find the right category. Humans encounter the same difficulty, when a biker enters the road from the pedestrian sidewalk. Expecting a pedestrian, they rapidly must adapt categories to a bicycle that follows different traffic rules than a pedestrian. Things become even more complicated if suddenly the pedestrian conjures up a skateboard, or a scooter. Traffic rules for the latter two conveyances are unknown, or do not exist. Humans are disturbed, and so are visual recognition systems, despite lidar and cameras.

Since the important contribution of the visual recognition system is categorization, it should be tested whether categories detected by the visual recognition system remain the same over its lifetime. But that is not enough. Behavior on certain sample image sequences should also remain stable - except if new learnings tell it otherwise. Obviously, tests must adapt to learnings. On the other hand, learning systems can become neurotically disturbed - mentally sick, like humans (Gerven and Bohte 2017). Thus, this is a case for Autonomous Realtime Testing (ART) (Fehlmann and Kranich 2017). Testing AI must be possible anytime, autonomous, without human intervention. 


\section{Baselining}

You start testing AI as any other software:

Identify the software under test

Identify the goals of testing

Draw a data movement map

Calculate functional effectiveness

Adjust scope of testing until goal and functional effectiveness converge

Prepare the Test Stories:

- Identify new test stories

- Fill test stories by test cases

- Calculate test coverage

Repeat above three steps until test coverage converges

Perform the tests and validate test stories and test cases. Identify defects and remove them, or mitigate them, until your system is defect-free.

\section{Extending Test Cases}

Consider the AI domain when extending test cases. For instance, for traffic vehicles, use video sequences from traffic scenes already described in the test story. Use video sequences that have been used for deep learning and other who were not. You must manually classify the videos for the category of traffic it represents; it is therefore the same kind of work for testing as for learning.

With ART, you keep the test stories from the initial test suite stable while adding more test cases to improve test intensity and to detect more defects. For visual systems, the primary source for new test cases is new images and videos. Keeping test coverage good enough is somewhat easier than in other ART instances, since you only exchange test data. You do not change the aim of testing.

One primary source for new test cases is the contents of the data groups moved by the data movements in the ISO/IEC 19761 COSMIC model. Whatever can enter a certain functional process must become part of a test case, even for nothing else than proving it has no effect at all. Thus, according the combinatory logic approach, we combine all possible input as test data in the test cases and select those test cases that keep the convergence gap of the test coverage matrix small.

This is an automatic task; it has some resemblance to AI techniques as it means searching and categorizing data. The data stems from the data groups in the ISO/IEC 19761 COSMIC data movements; the combinatory algebra defines its structure. For more details see Fehlmann and Kranich (2018). 


\section{Interpreting Test Results}

The aim of AI testing is to verify stable behavior in performing categorization as previously learned. This is different from human learning where humans should be able to interfere correct evaluations from their skills. As already mentioned, AI has not so much to do with the Latin origin of the word "Intelligence", namely intellegere, read, or infer, between the lines, or other objects. Testing machine intelligence means verifying that the software keeps identifying the same categories and does not change them. Testing AI remains simple while no new categories are added.

If something else is being tested than categorization, interpreting test results can become quite difficult. Remember that test results should be known in advance. AI behavior is not known before executing the test.

Thus, it can happen that when evaluating test results, responsibility must turn back to humans in case the response of the test case is something else than one of AI's established categories. Adding another category to AI is connected to relearning from scratch. You must supply all given evidence again and accept that the category borders move. In such cases, testing AI also re-starts from the beginning with establishing a new baseline. As ultimate consequence of such a worst-case scenario, the AI-driven VRS might go out of service until completely retested.

\section{Repeat the Tests - Forever}

Not only learning data changes, categories themselves are not except from change. Certain categories such as legal behavior in traffic are also subject to change and must be adapted to new environments and facts. Testing AI will detect such changes.

Therefore, for the lifetime of the AI system, testing must repeat. AI systems consist not of stable, always repeatable software but depend from their environment. If the AI system fails to reproduce correct answers, it might indicate a shift in the learning data and probably learning must restart from the beginning. Such restarts are required, for instance, if in traffic new conveyors appear, such as scooters, electro-scooters, electro-bikes, or if rules change.

\section{An Advanced Driving Assistance System (ADAS) as an Example}

The sample ADAS service we use to demonstrate the principles is a Car Driving Function based on a Visual Recognition System (VRS; Camera driven by a Sensor Bus) interpreting images. A Lidar - Light Detection and Ranging, a device that measures distances with a pulsed laser light - delivers distances and allows the Car Driving Function to build a 3D-model of the immediate surroundings, identifying fixed and movable objects from the image captured and analyzed. Sequences of images serve for determining the objects movements and direction. 


\section{ADAS Functionality}

The Car Driving Function asks the Recommender for advice and acts in accordance with the selected route that the navigation system stored in the Remember Routes persistent database. This is a simplified ADAS for instructional purpose only; it possibly can power a model car. The model is equipped with camera, Lidar, and sensors for slippery roads. It uses a Navigator service to find a route. Both the recommender and the VRS are implemented as neural network engines. However, the system lacks the redundancy required for the real world.

The initial part of Figure 4 connects these services with sensors and car steering devices, triggered by Look and Act. The full ADAS application for our model car consists of four more parts:

Find Route, e.g. by help of a navigation system, or according car user's preference.

Locate, compare current location with actual route.

Check Route, used to compare different possible routes in terms of traffic, weather, any other obstacles or fitting car user's preferences.

Amend Route; after receiving an Alert from the Navigator application because conditions changed under way, changing route might help.

Finding a route is usually based on some Navigator service that can propose a route between current location and some known destinations. The complete ADAS is shown in Figure 4 as a data movement map; sizing information included in the upper left corner.

\section{Testing the ADAS}

This piece of software first prepares the setting - collecting car specifics, test cases, extending them - then executes testing first the neural network engine, then the recommender, finally the Lidar and the camera.

The testing software resides local, on the car, but the test data originate from a repository called Testing Cloud common to all cars undergoing the same tests. Test cases originate there, and the Testing AI engine also works on this cloud service. The ADAS of the car could upload images taken for adding those to the testing cloud; however, this is neither reflected in the part of the ADAS shown before, nor in Figure 5. Only test results are recorded in the testing cloud, upon approval by the car user, the owner of the test results. Figure 5 consists of test preparation, execution of tests for the Neural Network, the Recommender, and the Visual Recognition Systems including the Lidar, plus a test result recording and test result presentation for the tester testing the ADAS. It represents an application by itself, with user stories and the need for testing. 
Figure 4. The Complete ADAS Model

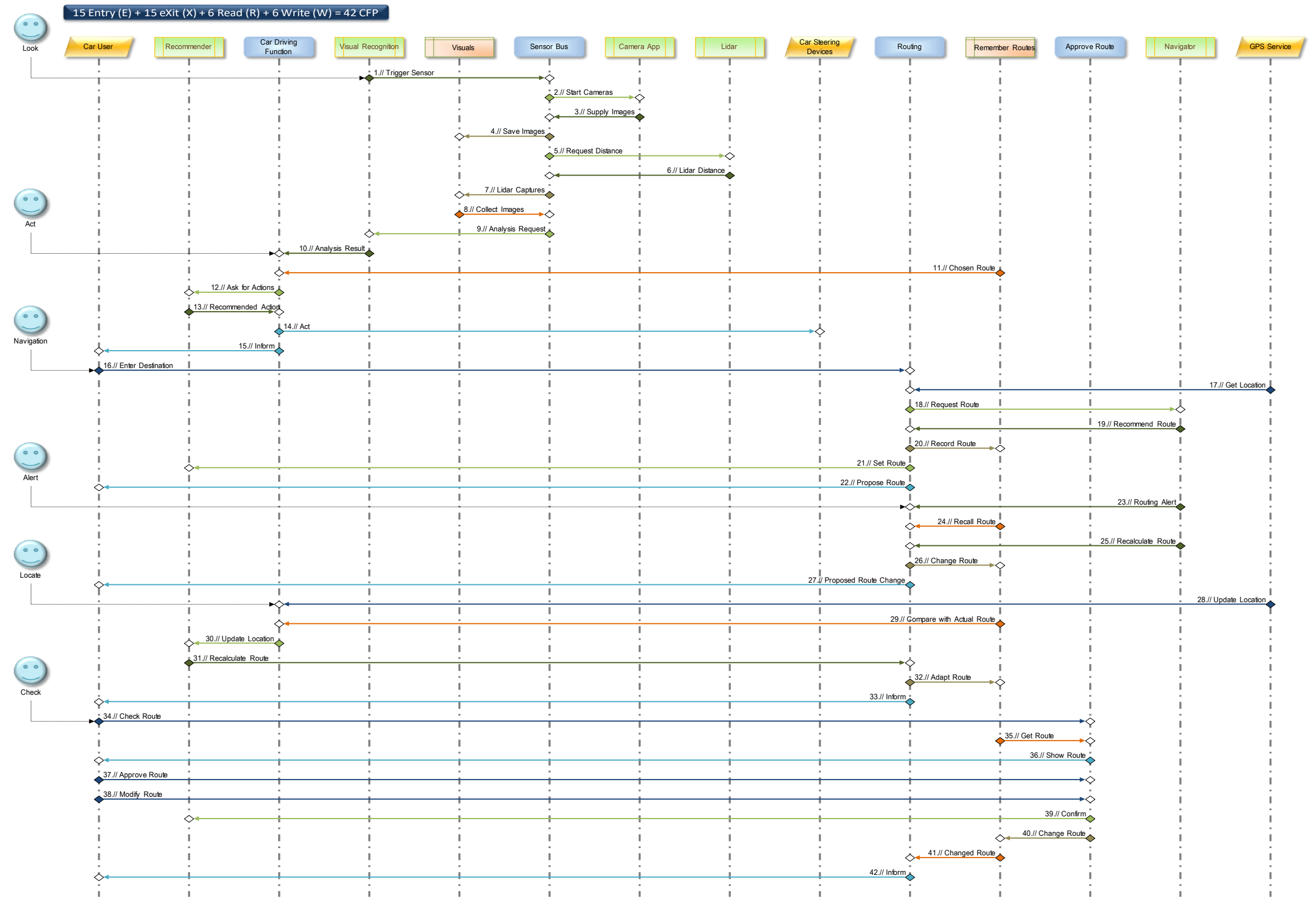


Figure 5. Automated Real-Time Testing (ART) for Advanced Driving Assistant System (ADAS)

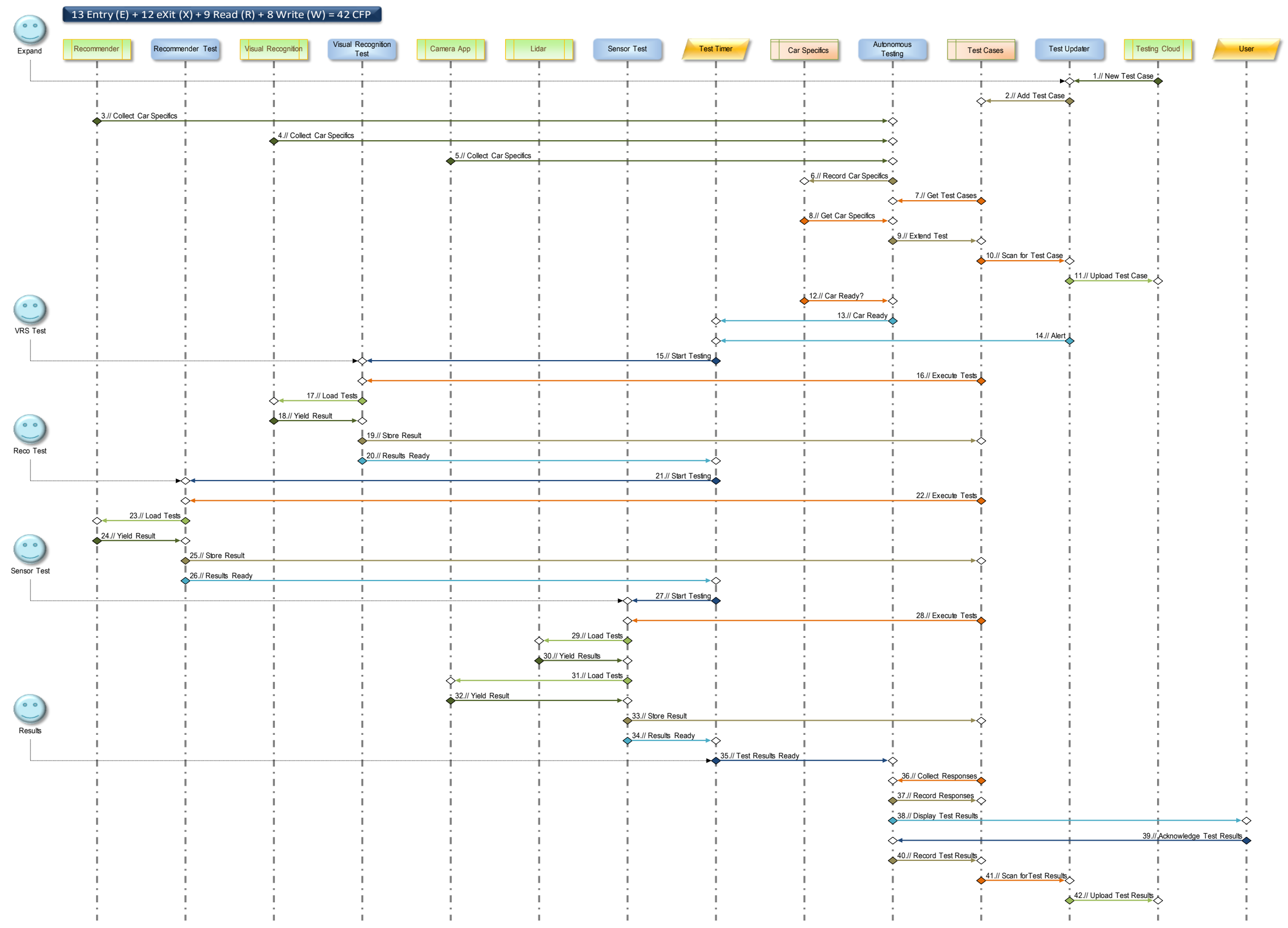




\section{The Car Users' Needs}

Using the AHP, we identify the following major values for users of the ADAS as listed in Figure 6.

Figure 6. Car Users' Needs

\begin{tabular}{|l|l|}
\hline & \multicolumn{1}{|c|}{ Customer's Needs Topics } \\
\hline Y.a Drive Fast & y1 Agile Driving \\
& y2 Smooth Driving \\
& y3 Arrive in Time \\
Y.b Drive Safe & y4 Avoid Incidences \\
y5 No Surprises
\end{tabular}

\begin{tabular}{|lll|}
\hline Attributes & & \\
\hline Arrive safe & Do not block other traffic & Have fun \\
Drive predictibly & Do not break unnecessarily & \\
Arrive predictibly & Avoid obstacles & \\
Drive foresightful & Know what's ahead & Know my way \\
Communicate & Never surprise anybody & Give signs \\
\hline
\end{tabular}

AHP Priorities

\begin{tabular}{|c|c|}
\hline Weight & Profile \\
\hline $16 \%$ & 0.36 \\
\hline $15 \%$ & 0.32 \\
\hline $23 \%$ & 0.50 \\
\hline $27 \%$ & 0.58 \\
\hline $19 \%$ & 0.42 \\
\hline
\end{tabular}

The AHP process is used to analyze these needs and produce a profile for its relative importance. The profile for the car users' needs is based on the following pairwise comparison, shown in Figure 7. This is again a basic AHP.

Figure 7. AHP for $A D A S$

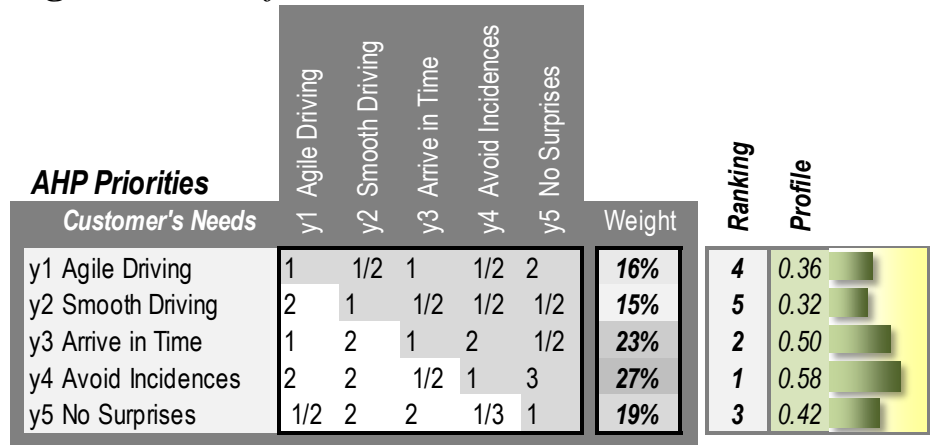

The needs of human drivers in today's traffic might be individually quite different; however, in view of an ADAS, characteristics linked to safety and avoidance of disturbance are dominant. You use an ADAS because you need something that helps through dense urban traffic, avoids jams and incidences, and makes driving experience smoother.

An ADAS is less suited for people who drive cars just for fun. They eventually turn it off. Their needs are not investigated by that AHP; an AHP for such people likely would produce a different car users' needs profile.

\section{User Stories - The Functional User Requirements (FUR)}

The data movements are those of the joint ADAS data movement map Figure 4. The user stories for ADAS are summarized in Table 1. 
Table 1. ADAS User Stories

\begin{tabular}{|l|c|c|c|c|}
\hline Label & $\begin{array}{c}\text { As a } \\
\ldots\end{array}$ & I want to ... & Such that ... & So that ... \\
\hline $\begin{array}{l}\text { Populated } \\
\text { Area }\end{array}$ & $\begin{array}{c}\text { Car } \\
\text { User }\end{array}$ & $\begin{array}{c}\text { let my car reduce } \\
\text { speed }\end{array}$ & $\begin{array}{c}\text { my car can } \\
\text { safely stop }\end{array}$ & $\begin{array}{c}\text { my car is not } \\
\text { causing delays by } \\
\text { an incidence }\end{array}$ \\
\hline Obstacle & $\begin{array}{c}\text { Car } \\
\text { User }\end{array}$ & $\begin{array}{c}\text { let my car avoid } \\
\text { obstacles }\end{array}$ & $\begin{array}{c}\text { my car can } \\
\text { drive around }\end{array}$ & $\begin{array}{c}\text { my car is not } \\
\text { stopping } \\
\text { unnecessarily }\end{array}$ \\
\hline $\begin{array}{l}\text { Know my } \\
\text { Way }\end{array}$ & $\begin{array}{c}\text { Car } \\
\text { User }\end{array}$ & $\begin{array}{c}\text { let my car take } \\
\text { appropriate routes }\end{array}$ & $\begin{array}{c}\text { my car avoids } \\
\text { blocked routes } \\
\text { and traffic jams }\end{array}$ & $\begin{array}{c}\text { I know when I'll } \\
\text { arrive }\end{array}$ \\
\hline $\begin{array}{l}\text { Amend } \\
\text { my Way }\end{array}$ & $\begin{array}{c}\text { Car } \\
\text { User }\end{array}$ & $\begin{array}{c}\text { optimize my route } \\
\text { when needed }\end{array}$ & $\begin{array}{c}\text { no incidence } \\
\text { blocks my way }\end{array}$ & $\begin{array}{c}\text { I still can predict } \\
\text { when I'll arrive }\end{array}$ \\
\hline $\begin{array}{l}\text { Able to } \\
\text { Stop }\end{array}$ & $\begin{array}{c}\text { Car } \\
\text { dispprove the car's }\end{array}$ & $\begin{array}{c}\text { I can take my } \\
\text { preferred route } \\
\text { have my car break } \\
\text { soon enough }\end{array}$ & $\begin{array}{c}\text { it can avoid } \\
\text { dangerous } \\
\text { situations }\end{array}$ & I feel in control \\
\hline $\begin{array}{l}\text { It recognizes } \\
\text { obstacles ahead } \\
\text { my Way }\end{array}$ & $\begin{array}{c}\text { Car } \\
\text { User }\end{array}$ & $\begin{array}{c}\text { approve or } \\
\text { disapprove the car's } \\
\text { choice for routing }\end{array}$ & $\begin{array}{c}\text { I can take my } \\
\text { preferred route }\end{array}$ & I feel in control \\
\hline
\end{tabular}

The user stories remain on a high epic level without specifying the details how the ADAS should behave in specific cases. With these user stories, the functional effectiveness matrix yields a satisfying rationale for the user stories (Figure 8). It means that the data movement map implements the user stories completely and without any wrong focus.

The functional effectiveness transfer function maps the user stories onto the car users' needs by counting how many data movements contribute to the user stories. This yields the cause-effect relation between functionality and requirements; also, it assigns data movements to at least one user story.

Figure 8. Functional Effectiveness for ADAS

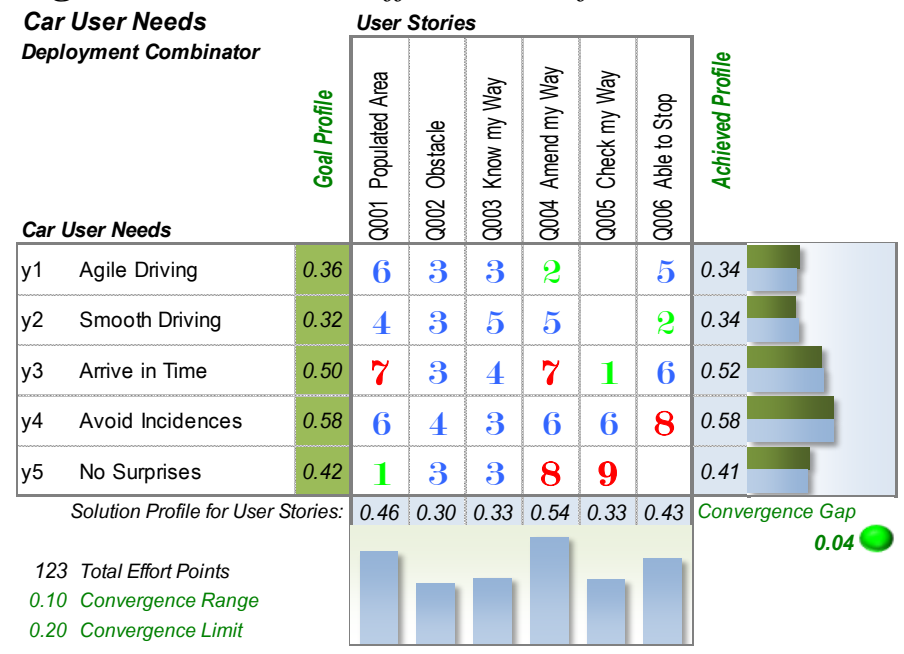




\section{The Test Stories}

The test stories in Table 2 specify more details how to implement the ADAS.

Table 2. Test Stories for ADAS for User Stories Shown in Table 1

\begin{tabular}{|l|c|l|c|l|}
\hline & & Test Story & \multicolumn{1}{|c|}{ Informal Description } \\
\hline A & $\begin{array}{c}\text { People } \\
\text { Around }\end{array}$ & A.1 & $\begin{array}{c}\text { People } \\
\text { around }\end{array}$ & $\begin{array}{l}\text { The ADAS identifies people staying near the } \\
\text { car, or sit on a specific vehicle }\end{array}$ \\
\hline B & Obstacle & B.1 & $\begin{array}{c}\text { Obstacle } \\
\text { ahead }\end{array}$ & $\begin{array}{l}\text { Static or moving obstacles I the way are } \\
\text { identified and correctly classified }\end{array}$ \\
\hline C & $\begin{array}{c}\text { Know } \\
\text { my way }\end{array}$ & C.1 & Get route & $\begin{array}{l}\text { The ADAS always knows where to go next, be } \\
\text { it at a crossing or at the end of the route }\end{array}$ \\
\hline & & C.2 & $\begin{array}{c}\text { Change } \\
\text { route }\end{array}$ & $\begin{array}{l}\text { The route to take is periodically changed, based } \\
\text { on alerts received from Navigator }\end{array}$ \\
\hline D & $\begin{array}{c}\text { Choose } \\
\text { way }\end{array}$ & D.1 & $\begin{array}{c}\text { Update } \\
\text { position }\end{array}$ & $\begin{array}{l}\text { The correct position is always known to the } \\
\text { ADAS }\end{array}$ \\
\hline & E.1 & $\begin{array}{l}\text { Arrival } \\
\text { time }\end{array}$ & $\begin{array}{l}\text { When choosing the route, the car user must } \\
\text { approve the decision } \\
\text { user }\end{array}$ \\
\hline & E.2 & $\begin{array}{c}\text { Learnings } \\
\text { The ADAS has a repository of routes taken and } \\
\text { can rely on past experiences, e.g. jams }\end{array}$ \\
\hline & F.1 & $\begin{array}{c}\text { Keep under } \\
\text { control }\end{array}$ & $\begin{array}{l}\text { The ADAS is always in control of the car, even } \\
\text { if he car user intervenes }\end{array}$ \\
\hline & F.2 & $\begin{array}{c}\text { Brake } \\
\text { action }\end{array}$ & $\begin{array}{l}\text { Brake action is known to ADAS, depending on } \\
\text { weather and road condition }\end{array}$ \\
\hline & F.3 & $\begin{array}{c}\text { Avoid } \\
\text { stops }\end{array}$ & $\begin{array}{l}\text { The ADAS tries to drive smoothly, adapting } \\
\text { speed, avoiding unnecessary stops }\end{array}$ \\
\hline
\end{tabular}

Remember that we had no clue how our visual recognition system determines the list of valid objects that it recognizes. Possibly it is implemented as a neural network, or a Support Vector Machine (SVM) is used (Pupale 2018). Nevertheless, we use our data movement map model to assess functional effectiveness with the later goal of testing it. In other words: we test what we think how the VRS works. We test our model.

For this paper, we give only informal descriptions, leaving it to the reader to invent suitable test cases. For the calculation below, we used around five test cases per test story. This yields the following test coverage (Figure 9).

The numbers in the cell represent the number of data movements that support the respective user story. With a convergence gap of 0.11 we are within convergence range, set a bit wider than in usual transfer functions. 
Figure 9. Initial Test Coverage

Test Coverage

Deployment Combinator

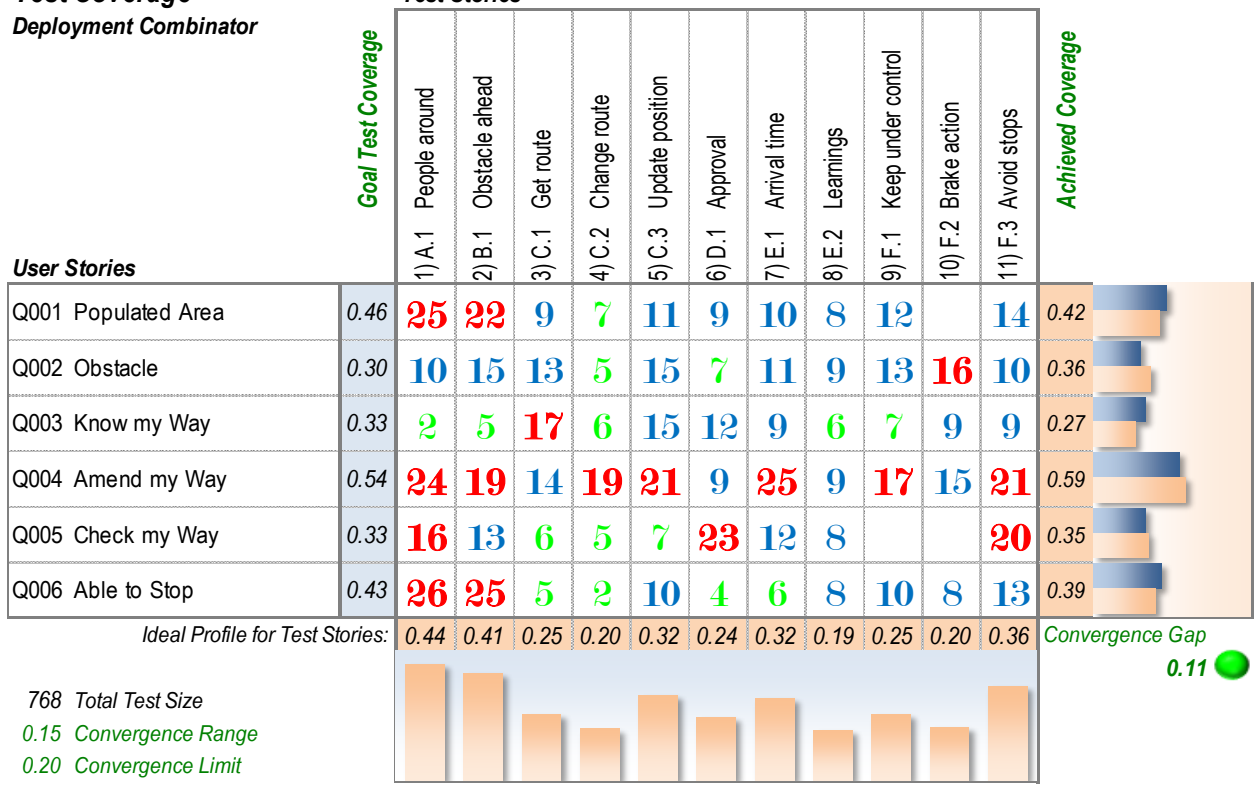

\section{Extending Test Cases}

Extending test cases within the same test stories yields more reliable results, and a higher test intensity (see Figure 13). In this example, extension works in two stages:

Adding test cases that refer to bad weather forecast. If the Navigator reports rain on the route, driving speed and arrival forecast must be adapted.

More test cases are added after the Navigator reports stormy weather causing eventually a change to the chosen route.

The following matrices (Figures 10 and 11) show the results after each of the two steps outlined above.

\section{Figure 10. After Adding Bad Weather Cases}

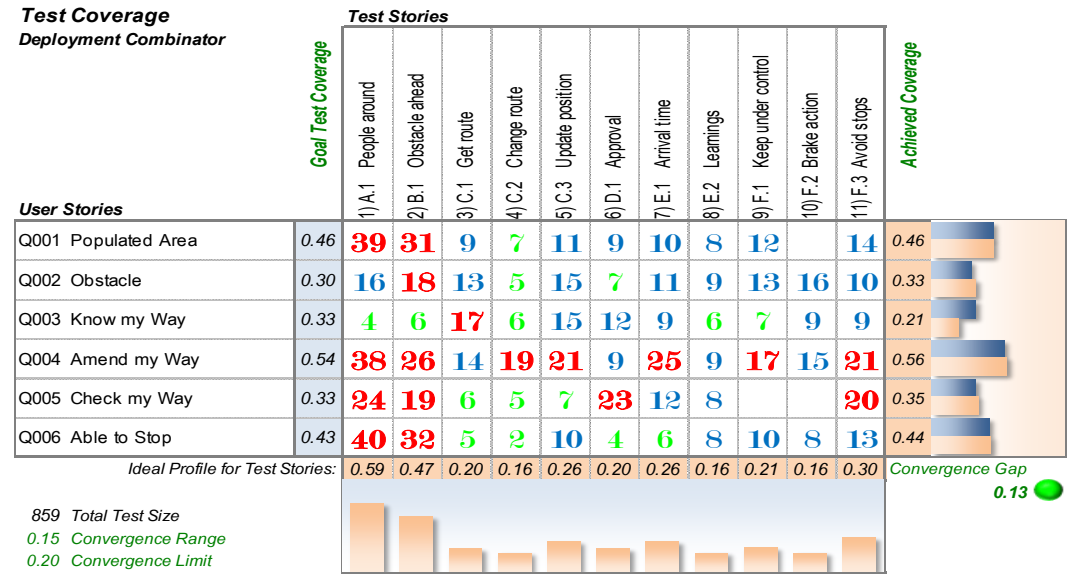


Figure 11. After Adding Adaption to Changed Route

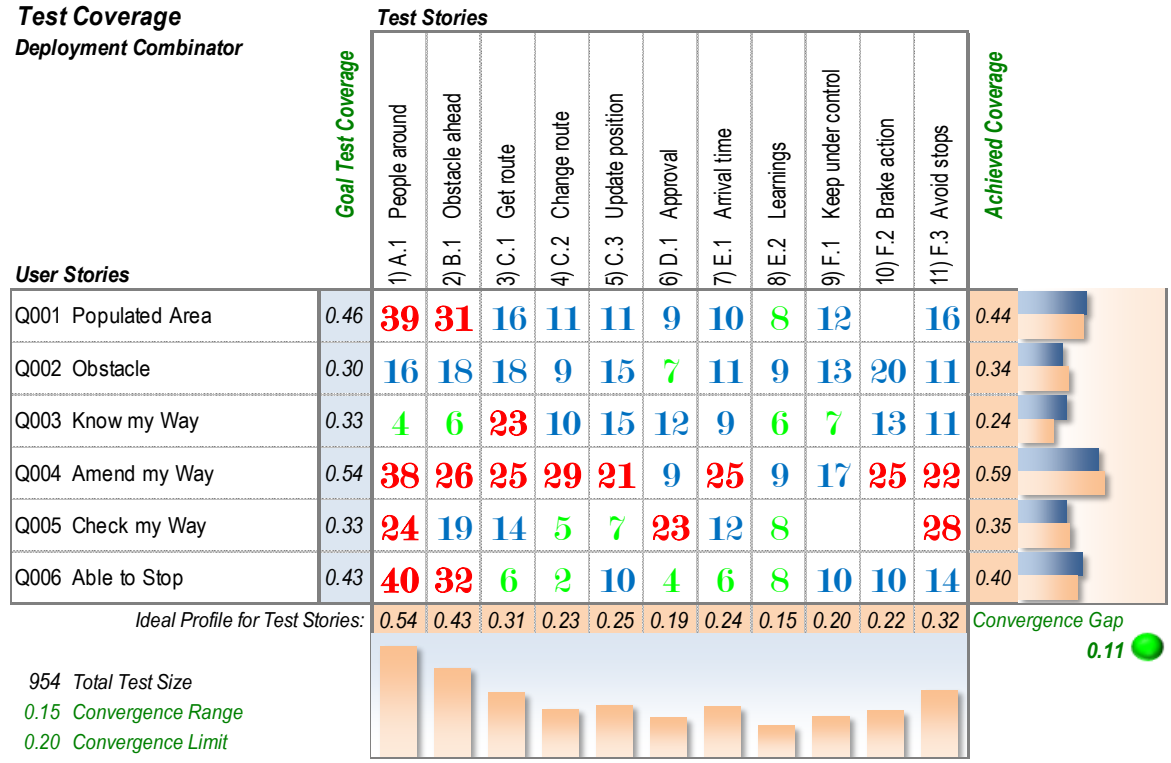

ART detects these new test cases because the data group received from the Navigator contains a weather forecast, as part of the route description. New test cases are created starting from the existing ones, by variation of test data, considering other all data received from data movements. Obviously, weather forecast changes the driving time prediction. Among the many test cases that can be created, ART keeps the convergence gap within limits, using this as selection process. Total test size is growing, and convergence gap is stable, or shrinking. This is the benefit of using customers' needs as goal for testing.

\section{How Came the Weather Forecast into ART?}

The additional test cases improve reliability and accuracy. ART finds such extensions by scanning data groups of the data movements involved. Since the chosen route is not fix but changes on receiving an Alert from the Navigator, ART learns that conditions such as rainy and stormy weather can exist and generates suitable test cases; shown in data movement map Figure 12.

Figure 12. Amend Route upon Navigator's Alert

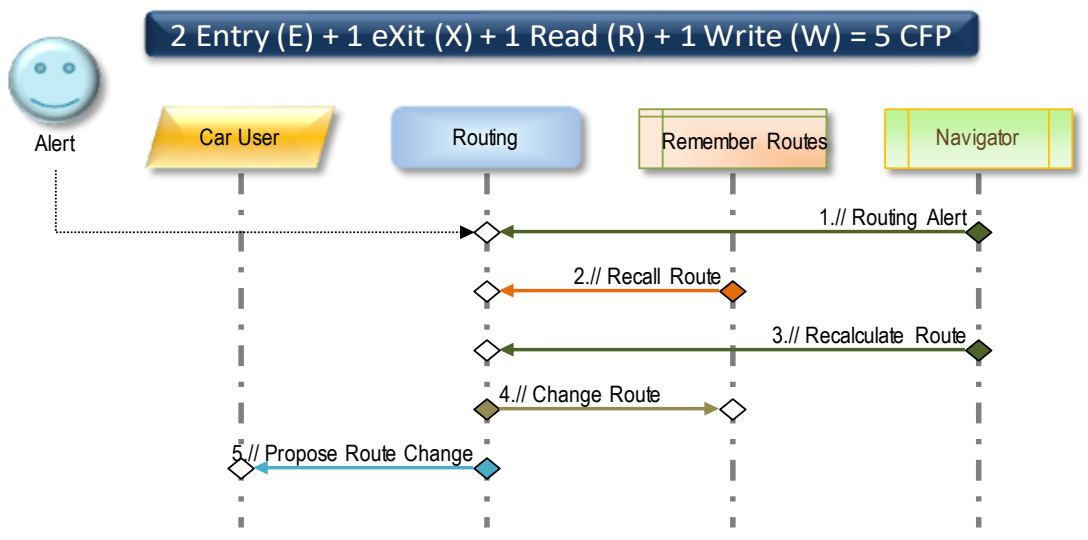


The data group moved by the data movement Routing Alert from the Navigator application to the Routing functional process contains all sort of alerts, including traffic jams and bad weather conditions. The ART mechanism extending test cases considers weather as a reason to change driving. Thus, when replacing other reasons for choosing a route, the Chosen Route data movement in Look \& Act (initial two triggers in Figure 4) tells the Car Driving Function about the changed weather conditions. This attribute is now selectable by ART for generating new test cases, also for the Visual Recognition system (VRS). Thus, it will be added as another test case for VRS, sooner or later. And because the new test case fits well with the car users' needs, rather sooner than later.

ART thus must find images showing people, or other vehicles, in the rain, or in a storm, to produce the same results in the test stories A.1: People around; B.1: Obstacle ahead; C.1: Get route; and C.2: Change route.

Weather is one thing that can be considered. But there is much more before autonomous cars can hit the road, for instance a tendency, or the need, to use bikes for transporting bags in certain social environments. Moreover, where Ms. Herzberg crossed, there is a functional road strip across the median of the four-lane road with the potential of being abused by pedestrians. If the Navigator could also consider additional information about the neighborhoods traversed, Elaine Herzberg possibly would still be alive, and trust in autonomous cars unhampered.

\section{Summary View}

The summary view on the original and the two extended test suites reveals, as expected, that test size and intensity increased, while we might expect more defects detected after the tests were executed.

Figure 13. Initial Test Suite, and Two Extensions

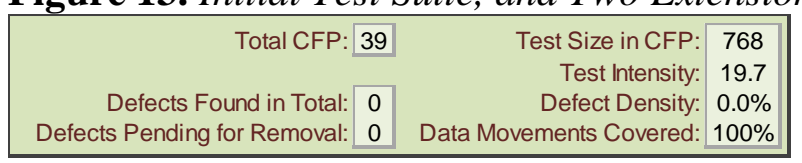

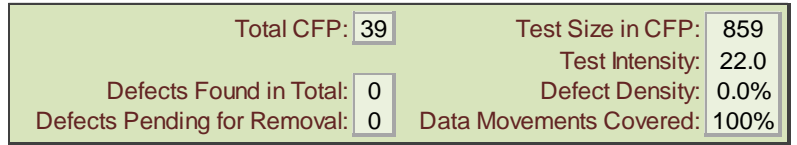

\begin{tabular}{|c|c|c|}
\hline Total CFP: 39 & $\begin{array}{r}\text { Test Size in CFP: } \\
\text { Test Intensity: }\end{array}$ & $\begin{array}{r}954 \\
24.5\end{array}$ \\
\hline Defects Found in Total: 0 & Defect Density: & $0.0 \%$ \\
\hline Defects Pending for Removal: 0 & Data Movements Covered: & $100 \%$ \\
\hline
\end{tabular}

Functional size remained stable: CFP 39, while increasing test size also increased test intensity.

Thus, improving testing is always possible by simply extending the test cases by similar ones, provided test coverage keeps the convergence gap narrow enough. ART provides value without increasing functional size. In this 
example, it was enough to trace back data movements that could contribute extra data to tests. Thus, the data movement map is paramount for automatic test case generation.

For testers, it is enough to provide an initial test suite (Table 2). The rest is left to AI. So, you test AI with AI. You can increase test intensity as much as you like, and our budget allows More tests certainly increase opportunities for detecting defects that can be removed and add marketable value for the customer. Thanks to the test coverage transfer function and its convergence gap, those additional tests remain relevant. Moreover, since tests are generated randomly, there is no bias blocking certain test cases, although extending test cases along some application cases such as weather or route change might allow for targeted test extensions.

\section{The Next Steps, and a Preliminary Conclusion}

The basic idea how to deal with "untestable" neuronal networks and deep learning is to create a data movement map as a model, specifying what users expect the AI part to do.

Clearly, a VRS needs more tests than fitting in this paper. ART generates more test cases out of the fourteen test stories to increate test intensity. However, at the current stage of research, we have no clue what test intensity is enough for a VRS in an autonomous car.

The proposed method can be upscaled to larger test coverage transfer functions. Real software systems have a few hundred user stories, and even more test stories. Solving such test coverage matrices requires big data algorithms but these tools are readily available nowadays.

A promising approach is to use the AHP for initial test coverage. With many user stories and test stories, a complex system often splits into smaller parts than can be tested separately, at least initially, and the full test coverage matrix fills in automatically by ART (Fehlmann 2019).

Applying ART means adding more test cases, more image sequences, always with respect to the convergence gap, aiming at improving the convergence gap. This limits combinatorial explosion, as it allows selecting relevant test cases only.

\section{References}

Bell D (2004) UML basics: the sequence diagram - introductory level. Armonk, NY: IBM DeveloperWorks.

Fehlmann TM (2016) Managing complexity - uncover the mysteries with six sigma transfer functions. Berlin, Germany: Logos Press.

Fehlmann TM (2019) Autonomous real-time testing - testing artificial intelligence and other complex systems. Berlin, Germany: Logos Press.

Fehlmann TM, Kranich E (2014) Uncovering customer needs from net promoter scores. Istanbul, Turkey: $20^{\text {th }}$ International Symposium on Quality Function Deployment. 
Fehlmann TM, Kranich E (2017) Autonomous real-time software \& systems testing. Göteborg: s.n.

Fehlmann TM, Kranich E (2018) Theoretical aspects of consumer metrics for safety \& privacy. In X Larrucea, I Santamaria, R O'Connor, R Messnarz (eds), Systems, Software and Services Process Improvement. EuroSPI 2018. Communications in Computer and Information Science, 649-653. Springer, Cham.

Gerven Mv, Bohte S (2017) Artificial neural networks as models of neural information processing. Lausanne: Frontiers Media.

ISO 16355-1:2015 (2015) Applications of statistical and related methods to new technology and product development process - part 1: general principles and perspectives of quality function deployment (QFD). Geneva, Switzerland: ISO TC 69/SC 8/WG 2 N 14.

ISO/IEC 19761 (2011) Software engineering - COSMIC: a functional size measurement method. Geneva, Switzerland: ISO/IEC JTC 1/SC 7.

ISO/IEC/IEEE 29119-4 (2015) Software and systems engineering — software testing - part 4: test techniques. Geneva, Switzerland: ISO/IEC JTC 1.

Mazur G (2014) QFD and the new voice of customer (VOC). Istanbul, Turkey: International Council for QFD (ICQFD), 13-26.

Mazur G, Bylund N (2009) Globalizing gemba visits for multinationals. Savannah, GA, USA: Transactions from the $21^{\text {st }}$ Symposium on Quality Function Deployment.

Pupale R (2018) Support vector machines (svm) - an overview. Retrieved from: https:// bit.ly/36KQkRD. [Accessed 28 March 2019].

Saaty TL (2003) Decision-making with the AHP: why is the principal eigenvector necessary? European Journal of Operational Research 145(1): 85-91.

Schwaber K, Beedle M (2002) Agile software development with scrum. Upper Saddle River, NJ: Prentice Hall PTR.

The National Transportation Safety Board (2018) Preliminary Report Highway Hwy18mh010. Retrieved from: https://bit.ly/2NtKIZO. [Accessed 13 March 2019].

van Gerven M, Bothe S (2018) Artificial neural networks as models of neural information processing. Lausanne: s.n. 



\title{
Some Improvements in Nonparametric Multivariate Kernel Density Estimation
}

\author{
By Michael Ogbeide ${ }^{*} \&$ Joseph Osemwenkhae
}

\begin{abstract}
A popular technique of density estimation is the kernel density estimation (KDE). It is a nonparametric estimation approach which requires a kernel function and a bandwidth (smoothing parameter H). It aid density estimation and pattern recognition. This paper presents new approaches in nonparametric density construction problem, particularly at the boundary points using the dataset and a pilot plot. However, since the main way to improve density estimation is to obtain a reduced mean squared error (MSE). When the MSE for these approaches were evaluated and compared. Some improvements were seen in two proposed approaches. These were achieved under a sufficiently smoothing technique in the existing approaches. These approaches are adaptive and they reduce under fitting and over fitting as the case may be of the data set and aid statistical inference.
\end{abstract}

Keywords: Adaptive, bandwidths, error, kernel density estimation.

\section{Introduction}

Data density estimation provides a nonparametric estimate of the probability function from which a set of data is drawn. Often, optimal pattern recognition algorithms require the knowledge of the underlying dataset to construct densities. Primarily, it is better to estimate the density from the data. This is not always the case, hence nonparametric approach, which has the flexibility of the model specification. One of the common nonparametric approaches is the Kernel density estimation (KDE). It has been widely regarded that the performance of the kernel methods depends largely on the smoothing parameter (window width) but depends very little on the form of the kernel. According to Scott (1992) and Osemwenkhae (2003) most times, analyses of multivariate data are more prevalent in practice than the univariate cases. The crucial problem in the multivariate kernel density estimation (MKDE) is to select the window widths (bandwidth parameters) $H$. The window widths control the smoothness of the fitted density curve. The multivariate kernel density estimator that we are going to study is a direct extension of the univarite estimator. Let $X_{1}, \ldots, X_{n}$ denote a d-variate random sample having a density $f$. We shall use the notation $X_{i}=\left(X_{i 1}, \ldots, X_{i n}\right)^{T}$ to denote the $X_{i}$ and a generic vector $x \in \mathfrak{R}^{d}$ has the representation $x=\left(x_{1}, \ldots, x_{d}\right)^{T}$. The d-variate random sample $X_{1}, \ldots, X_{n}$ drawn from $f$ the kernel estimator evaluated at $x$. This according to Wand and Jones (1995) is given by;

\footnotetext{
*Department of Mathematics and Statistics, Ambrose Alli University, Nigeria.

* Department of Mathematics, University of Benin, Nigeria.
} 


$$
\hat{f}(X, H)=\frac{1}{n} \sum_{i=1}^{n} K_{H}\left(x-X_{i}\right)
$$

where $n$ is the sample size, and $H$ is a symmetric positive definite $d \times d$ matrix called the window widths, the smoothing parameters or the bandwidth matrix. $K_{H}(x)=|H|^{-\frac{1}{2}} K\left(H^{-\frac{1}{2}} x\right),|\cdot|$ stands for the determinant of $\mathrm{H}$ and $\mathrm{K}$ is d-variate kernel satisfying $\int k(x) d x=1$, where it is understood that the integral is over $\mathfrak{R}^{d}$ unless stated otherwise. The kernel function is often taken to be a $d$-variate probability density function.

The two common techniques for obtaining multivariate kernel from the univariate kernel k:

$$
K^{P}(x)=\prod_{i=1}^{d} k(x) \text { - a product kernel. }
$$

$K^{S}(x)=c_{K, d} \cdot k\left(x^{T} x\right), c_{K, d}=\left(\int k\left(x^{T} x\right)^{\frac{1}{2}} d x\right.$ - a spherically symmetric kernel.

Remark: The spherically symmetric kernel corresponding to the Epanechnikov kernel when $d=2$ is given as:

$$
K^{S}(x)=\frac{2}{\Pi}\left(1-x_{1}^{2}-x_{2}^{2}\right), \quad x_{1}^{2}+x_{2}^{2} \leq 1
$$

And the product kernel $K^{P}(x)=\frac{9}{16}\left(1-x_{1}^{2}\right)\left(1-x_{2}^{2}\right), \quad x_{1} \cdot x_{2} \in[-1,1]$.

However, the gaussian kernel $k(u)=\frac{1}{\sqrt{2 \pi}} \exp \left(-\frac{u^{2}}{2}\right)$ is a popular choice among many kernels (Bowman and Azzalini 1997, Kathovnik and Shmulevich 2002).

The matrix $H$ is a smoothing parameter and specifies the 'width' of the kernel around each sample point $X_{i}$. A well behaved $K$ (that is a kernel bounded compactly) must satisfy the following regularity conditions:
1. $\int_{R^{d}} K(w) d w=1$
2. $\int_{R^{d}} w K(w) d w=0$
3. $\int_{R^{d}} w w^{T} K(w) d w=I_{d}$

Where $I_{d}$ is a $d$ dimensional identity matrix.

The first condition accounts for the fact that the sum of the kernel function over the whole region is unity. The second condition imposes the equation constraint that the means of the marginal kernel $K_{i}\left(w_{i}\right), i=1, \ldots, d$ are all zero. The third condition term states that the marginal kernels are all pairwise uncorrelated and each has unit variance.

However, the most important part of the estimator in (1.1) is the bandwidth matrix which contained the window sizes used for smoothing density. The fixed window size method are not sensitive to local peculiarities in the data, such as 
clustering/sparseness of sample value, though oversmoothing/ undersmoothing (as the case may be) tends to reduce or overcome this.

The adaptive (smoothing) methods are nonparametric density estimators that are sensitive to clustering/sparseness of sample values and other peculiarities, particularly at the tails or other peculiarities of the data set. Here the smoothing parameter $H$ varies, hence the "adaptive" techniques.

This work on density estimation, is based on KDE with the analysis of the existing intersection of confidence intervals (ICI), the kernel cluster sampling approach in estimating density approaches. We modified two approaches to the multivariate kernel density estimation, and therefore, proposed the modified intersection of confidence interval $\left(M I C I_{H}\right)$ and the modified multivariate cluster sampling kernel density estimate (MMCKDE).

\section{Literature Review}

This work focuses on the kernel density estimation. There are other several density estimation approaches like the Histogram, the Scatter plots, the Orthogonal series density, the nearest neighbour method, and the Projection pursuit density estimation (Fukunaga 1990, Ogbeide et al. 2016). Clearly, in practice, one does not have access to the true density function $f(x)$ which is to be estimated (Wand and Jones 1995, Wu et al. 2006). Thus, a number of approaches can be taken for finding the bandwidth that will lead to better density estimation via varying the bandwidths (Wand and Jones 1995, Katkovnik 1999, Jarnicka 2009, Ogbeide et al. 2016). Details studies on the Histograms which are the oldest density methods, the Scatter plots, the Orthogonal series density, the nearest neighbour method and the Projection pursuit density estimation approaches can be seen in (Tukey 1947, Cencov 1962, Friedman and Stuetzle 1982, Rudemo 1982, Scott and Thompson 1983, Silverman 1986, Wand and Jones 1995, Isenman 1991, Bowman and Azzalini 1997). These methods are not bonafide probability density estimates (Silverman 1986, Wand and Jones 1995). These approaches take time and they have poor visual display with poor meaning from inference. It can be difficulties to make complete inference from them. However, Scott and Thompson (1983) and Wand and Jones (1995) noted that these approaches are merely convenient presentational device in an attempt to discern features for the distribution or model underling the data.

According to Wand and Jones (1995) and Bowman and Azzalini (1997), the discontinuity in the histogram method density estimates makes it less attractive for proper adaptive uses This discontinuity leads to poor visual display which affects inference from it (Silverman 1986, Isenman 1991). We observed in Wand and Jones (1995) that Scatter plots approach is not good for most bivariate data set and beyond. Estimates from the Scatter plot obviously do not detect or highlight certain features of the data set. The Orthogonal series density method requires a lot of evaluation before its smoothing parameters could be achieved, its application is mainly asymptotic, so there is need for better straight forward computation of the smoothing parameter and faster rate 
of convergence (Osemwenkhae 2003). Silverman (1986) and Katkovnik and Shmulevich (2002) noted that the nearest neighbour methods suffer underfittings or over fittings during estimation. This makes it less attractive. The convergence rate of this method is poor when compared to the kernel density estimation (Osemwenkhae 2003). The projection pursuit density estimation (PPDE) is multivariate density estimation technique that attempt to reduce the curse of dimensionality while estimating density. It does not spring from the univariate density estimation generalization. It was developed by Friedman and Stuetzle (1982). It transforms the data set around the origin zero with a covariance matrix as the identity and determines the estimates of $\hat{f_{H}}$ in iterative manner. Though this approach takes time, the number of iterations determine the number of different smoothing parameters and the stopping rule is determine by balancing the bias against the variance estimate (Friedman and Stuetzle 1982, Friedman et al. 1984, Alan 1991).

Multivariate kernel density estimation (MKDE) approach is a bonafide probability density estimate. It requires a kernel function and a smoothing parameter $H$ which is the window size. Wand and Jones (1995) noted that the MKDE is a well behaved density method with a kernel which satisfies the following regularity conditions. This method gives a good representation of the real data. We observed from the Scott (1992) and Bowman and Azzalini (1997) that density estimation curves either underfits or overfits as the case may be. However, this method uses a fixed value from the bandwidth matrix to estimate and smooth densities. This usually leads to over-fitting or under-fitting as the case may be (Scott 1992, Duong and Hazelton 2003). The Adaptive Multivariate kernel density estimation (AMKDE) approach requires a kernel function and smoothing parameters which are the window sizes corresponding to the data set. This varying choice of the smoothing parameter makes it adaptive. This method gives a good representation of the real data. Its density estimation curves either try to correct under fits or over fits as the case may be. This estimation method according to Scott (1992) and Wand and Jones (1995), under the regularity conditions noted that the AMKDE is a well behaved density method with varying optimal choice of $H_{i} \in H$. The $K$ (that is a kernel bounded compactly) which must satisfy the regularity conditions. Our approach in this work is based on this technique. This approach is also called the dynamic smoothing technique or the variable kernel method. This method is called dynamic smoothing technique or the variable kernel method due to the adjustable nature of the smoothing parameter $H$ (Silverman 1986, Sain 2002, Tower (2002). The variable kernel method estimates integrate to unity (Abramson 1982, Silverman 1986, Duong and Hazelton 2003). This method is a bonafide probability density estimates. It has smooth curves corresponding to the dataset adequately. According to Wand and Jones (1995) as $n \rightarrow \infty$, the mean integrated squared error $M I S E \rightarrow 0$. That is the kernel density estimate converges to the mean square error and also in probability to the true density $f$. The convergence of the method is a confirmation of the statement in the motivation of this study that the kernel methods lead to reasonably density estimation. An ideal optimal 
bandwidths selectors according to Bowman and Azzalini (1997) and Duong and Hazelton (2005a) should be based on every data set elements. The ideal selector which contains the unknown density function $f$, that cannot be used directly, hence the approach of varying $H_{i} \in H$ optimally.

The variable kernel density estimator was first proposed by Victor (1976) and Breimen et al. (1977). Victor (1976) suggested varying window sizes to enhance data density evaluation in medical decision making. This according to him is due to the fact that fitting medical data obtained at different times and rates with a single window size may not best represent the true density. Breimen et al. (1977) obtained the probability of the variable kernel density estimation. Abramson (1982) derived the square-root law for achieving higherorder bias for a kernel function. Jones (1990) clarified the main differences between the local and the variable kernel approaches. Some other works on variable kernel methodology include (Muller 1985, Hall and Park 1987, Hall 1990, Fukunaga 1990, Jones 1990, Hall 1992, Handle and Scott 1992, Scott 1992, Jones et al. 1994, Elio and Edgar 2003, Wu et al. 2008). They worked on the properties and efficiency of variable kernel method. Katkovnik and Shmulevich (2002) developed an adaptive method based on intersection of confidence intervals. The Cluster sampling approach to MKDE by $\mathrm{Wu}$ and Tsai (2004) and Wu et al. (2008) is an approach which utilized the idea of Breiman et al. (1977) and Abramson (1982) in determination of the density estimates. This approach uses the information matrix rows and columns to form clusters for sampling, where the cluster sizes and bandwidths factors are used to achieve the smoothing parameters. The method for multivariate density is adaptive, but $\mathrm{Wu}$ et al. (2008) proposed average Cluster sampling to correct deficiency with some points of discontinuities in $\mathrm{Wu}$ and Tsai (2004).

When we consider the studies on variable window sizes works on the multivariate cluster sampling kernel density estimate (MCKDE) and the intersection of confidence interval (ICI) methods applied to MKDE, though the methods are adaptive, one is tasked with how sensitive these methods are, and the errors committed using these methods? What are the effects when we extend them to multivariate kernel density? These questions led to the reasons for their modifications in this research. We identified points for improvements, so that the methods could be more adaptive. Recently, a wide variety of sophistication of the basic kernel estimator has been proposed, all pointing to the importance of adaptive kernel estimator (Kathovnik and Shmulevich 2002, Salgado-Ugarte and Perez-Hernandez 2003, Wu and Tsai 2004, Wu et al. 2008). The "adaptive" nature of the density estimate arises from the varying bandwidth used in the data estimation process. If $h$, the bandwidth in (1.1) above, is "fixed" during data estimation, we have the fixed kernel density estimation approach, but when it is allowed to vary all though the process of the estimation, we have the adaptive kernel method. A number of work considering the problem of kernel size selection exist (Abramson 1982, Silverman 1986, Breiman et al. 1977, Hall 1990, Jones 1990, Cao et al. 1994, Wand and Jones 1995, Simonoff 1996, Wu et al. 2007, Ogbeide et al. 2016). The main intentions are that they all aimed at improving kernel density estimation. 
The most commonly used optimality criterion for selecting a bandwidth matrix is the mean integrated squared error (MISE) expressed according to Wu et al. (2006) as;

$$
\operatorname{MISE}(H)=E\left\{\int_{h}^{\hat{f}}(X)-f(X)\right]^{2} d X
$$

where $\int$ is a shorthand notation for $\int_{R^{n}}$ and $X$ is in $n$ Euclidean plane $R^{n}$.

According to Horova et al. (2008), this equation (2.1) does not have a general closed- form expression, so we result to its asymptotic approximation (AMISE). Hence (2.1) could be factored as;

$$
\operatorname{AMISE}(H) \approx n^{-1}|H|^{-\frac{1}{2}} R(K)+\frac{1}{4} m_{2}(K)^{2}\left(\operatorname{vec}^{T} H\right) \psi_{4}\left(\operatorname{vec}^{T} H\right)
$$

where

- $R(K)=\int K(X)^{2} d X$, with $R(K)=(4 \pi)^{-\frac{d}{2}}$ when $\mathrm{K}$ is a normal kernel.

- $D^{2} f$ is $d \times d$ Hessian matrix of second order partial derivatives of $f$.

- $\psi_{4}=\int\left(v e c D^{2} f(X)\right)\left(\operatorname{vec}^{T} D^{2}\right) d X$

- $D$ is a diagonal matrix with elements $X_{11}, X_{22}, \ldots, X_{d d}$

- vec is the vector operator which stacks the columns of a matrix into a single vector.

We observed that the quality of the AMISE to the MISE is given according to Horova et al. (2008) by

$$
\operatorname{MISE}(H)=\operatorname{AMISE}(H)+o\left(n^{-1}|H|^{-\frac{1}{2}}+t r H^{2}\right)
$$

where o indicates the usual o notation. This implies that AMISE is a 'good' approximation of the MISE as $n \rightarrow \infty$. It has been shown that optimal bandwidth selector $\mathrm{H}$ has $H=O\left(n^{-\frac{2}{(d+4)}}\right)$. According to Doung and Hazelton (2005b) substituting this into equation (2.3) yields the optimal $\operatorname{MISE}(H)$ order as $O\left(n^{-\frac{4}{(d+4)}}\right)$. The big $\mathrm{O}$ notation is applied element-wise. So when $n \rightarrow \infty$, MISE $\rightarrow 0$. This implies the kernel density estimate converges in mean squared error and so also in probability to the true density $f$. According to Wand and Jones (1995) and Horova et al. (2008), they asserted that it was better to estimate optimal MISE element-wise. They further asserted that the ideal optimal bandwidth selector that is point wise adaptive is given by

$$
H_{A M I S E}=\operatorname{agr} \min _{h \in \mathrm{H}} \operatorname{AMISE}(H)
$$

Since this ideal bandwidth selector contains the unknown density function $f$, that cannot be used directly. So some data density based approaches fixed the choice of bandwidth constant. However, we shall adopt point-wise adaptive bandwidth procedures in estimating densities. This implies that our 
bandwidth selection should be for every data 'element-wise 'adaptive to achieve the desire optimality.

The bandwidths used for the cluster approach by Wu et al. (2007) are optimal for information row/column (one dimensional) bandwidth per time in the multivariate data set. That is, it uses one bandwidth in the row or column during row/column cluster bandwidth selection. It is only row or column wise adaptive. Our approach is to make bandwidth selection to be data based on the smallest size of the row or column samples selections from the information matrix (data set). We modified the MCKDE and modified the ICI approach in estimating densities and they are presented below. The quality of the density estimates are assessed by comparing it to the density, obtained under the meansquared error criterion. The error generated using these approach would be considered.

This work, present two novel data-driven methods that require the knowledge of pilot plot from optimal fixed window size and the variance of the estimate. This invariably reduces the amount of error at arriving at the "true density". These were achieved under a sufficiently smoothing technique in the existing approaches. They are adaptive approaches based on the data at hand. The aim is to reduce under fitting and over fitting as the case may be and improve statistical inference.

\section{Methodology}

\section{The Modified Multivariate Cluster Sampling Kernel Density Estimation (MMCKDE)}

This procedure is basically a minimization of $\operatorname{AMISE}(H)$ with respect to $\mathrm{H}$, where it is equivalent to the selection of optimal $h_{i j}$ in $\left\{H_{1}, H_{2}, \ldots, H_{n}\right\}$. This method is a modification of the cluster sampling approach to density estimate. The modified multivariate cluster sampling kernel density estimate (MMCKDE) is a modification of cluster sampling kernel density estimates by adjusting the amount of bandwidths using some idea from the kernel nearest neighbour estimation of the density to the multivariate data. Its smoothing parameter would be an $n \times d$ dimensional matrix obtained from forming relevant number of clusters in an information matrix. The Euclidean distance would be used to form bandwidths.

Let $h=h^{*} b$. According to Silverman (1986), we call $b$ the bandwidth factor and $h^{*}$ the global smoothing parameter. The common procedure is to first choose $b$ adaptively and then $h^{*}$, by regarding $b$ as fixed. But Wu et al. (2007) used $h=h^{*} b_{i}$, where $b=\left(b_{1}, \ldots, b_{n}\right)$ are the bandwidths factors reflecting the average local clusters from $X_{i}$ and adopt the stabilized fixed bandwidths selector of Wu et al. (2006) to select the global smoothing parameter. This approach gives a diagonal bandwidth matrix of varying smoothing parameters $h_{i}$. In our proposed 
approach, we aim at element-wise adaptive density estimation for any given data set $X_{i j}$. Let assume

$H=h_{i}^{*} b_{i^{*} j}$

where $i=1, \ldots, n, i^{*}=1, \ldots, n_{i}$ and $j=1, \ldots, d$.

with $\mathrm{H}$ a finite set of optimal bandwidths $H=H_{1}, \ldots, H_{n}$ and each $H_{i}=h_{i j}$. We choose our $h_{i}^{*}$ via each information data rows' $h_{M S E}$. That is using the MSE approach to get each $h_{i}^{*}$. This is more data sensitive than any fixed $h^{*}$. We have more bandwidth factors according to the number of clusters form (starting from step 3 in the proposed algorithm) from the element wise groups from the information data rows.

Then $b_{i^{*} j}$ will be small if as $n_{i^{*}}$ is large (that is a large number of mergers involving $X_{i}$ ). Basically, from the data set, the above scheme clusters are formed from the nearest nested sequence of clusters information data rows' elements with the property;

$$
\left\{X_{i}\right\}=C_{i 0} \subset C_{i 1} \subset \ldots \subset C_{i n_{*}^{*}}=\left\{X_{1}, \ldots, X_{n}\right\}
$$

This procedure gives a full bandwidth matrix of vary smoothing parameters for possible values of data sizes for $i$ rows and $j$ columns. $i \leq j$ and $i>j$.

To correct the problem of discontinuities at some points in the cluster sampling approach to MCKDE, points of discontinuity in the estimation are identified using the cluster sampling approach as a pilot guide. In this case, the use of standard techniques from cluster analysis is applied. Here, a modified sampling idea similar to $\mathrm{Wu}$ et al. (2006) is developed. In this case, when we consider the bandwidth factor $b_{i}$ to $X_{i}$ according to the number of clusters form, and use the idea of density at the boundaries to choose the bandwidths $H$. $\mathrm{Wu}$ et al (2006) used the average cluster method which reflects the average local clustering form. In this work a proposed scheme to address points of discontinuities is suggested.

Supposed that $f$ is a density function such that $f(x)=0$ for $x<0$ and $f(x)>0$ for $x \geq 0$. We further suppose that $f^{\prime \prime}$ is continuous away from $x=0$.

Then, we have $\hat{f}(x ; h)=\int_{-1}^{\alpha} k(z) f(x-h z) d z$, where $0 \leq \alpha \leq 1$-see Wand and Jones (1995, 46-47). Then at the boundary they obtained

$$
E \hat{f}(0 ; h)=\frac{1}{2} f(0)+O(h)
$$

We use this idea base on the intuitive knowledge of kernel estimator having to find a compromise between estimating two distinct values of $f$ on either side of discontinuity. We propose the use of semi inter-quartile range at the boundary values. Since the location of the boundary of $\hat{f}(x ; H)$ is usually known, we adopted this to achieve better performance in its vicinity. Suppose, 
we have for $\mathrm{S}$ number of row clusters and $\mathrm{T}$ number of column clusters, we have;

$d_{S T}=\sum_{i=1}^{n_{S}} \sum_{j=1}^{n_{T}} d_{i j}$

where $d_{i j}=\sqrt{\sum_{i=1}^{n} \sum_{j=1}^{d}\left(X_{i j}-X_{i+1 j+1}\right)^{2}}$ see Gray (1997) for lengths and distances' details. Then

$H=H_{i}=\frac{H_{i}}{v}$ and $H_{i+1} \leq H_{i}$.

where $H_{i}=\left\{h_{i j}\right\}$. Subjectively we adopt $v=2$, where $v$ is a positive real number.

The bandwidth sizes obtained are substituted into equation (1.1) above to obtain accompanying density estimates. The proposed algorithm is presented below. The modified procedures are stated below:

\section{Algorithm 1.}

Step 1: start with $\mathrm{n}$ clusters, each containing a single observation and an $n \times n$ symmetric matrix of distances $D=\left\{d_{i j}\right\}$.

Step 2: Search the distance matrix for the nearest pair of clusters. Let the distance between the "nearest" clusters S and T be $d_{S T}=\sum_{i=1}^{n_{S}} \sum_{j=1}^{n_{T}} d_{i j}$ in the case of observation $i$ in the cluster $\mathrm{S}$ and observation $j$ in the cluster $\mathrm{T}$, and $n_{S}$ and $n_{T}$ are the number of observations in cluster $\mathrm{S}$ and cluster $\mathrm{T}$, respectively.

Step 3: Merge (combine) cluster S and T. Label the newly formed cluster (ST). Update the entries in the distance matrix by (a) deleting the row's element and column's element corresponding to clusters $\mathrm{S}$ and T elements and (b) adding a row's element and a column's element giving the distances between cluster (ST) and the remaining clusters elements.

Step 4: Repeat steps 2 and 3 a total of $n-1$ times so that all observations will be in a single cluster at termination of the algorithm. Record the clusters that are merged and the distance levels at which the mergers take place.

Step 5: Let $b_{i^{*} j}$ distance level of $X_{i}$ in the dendrogram. Specifically, if $n_{i *}$ denotes the total number of times that a cluster containing $X_{i}$ is merged into a larger cluster (that is, total number of mergers that involve $X_{i}$ ), and $\ell_{1 i^{*}}, \ldots, \ell_{n_{i} i^{*}}$ the distance level at which these $n_{i}$ mergers take place, then $b_{i^{*} j} \equiv \ell_{1 i^{*}}, \ldots, \ell_{n_{i} i^{*}}$.

Step 6: generate $H_{i}=h_{i}^{*} b_{i^{*} j}$ where $h_{i}^{*}$ are determined via the MSE for each information data rows, and let each $H_{i}=h_{i j}$. 
Step 7: In the case of discontinuities, begin by applying (a) $d_{S T(O p t)}=H=\frac{H_{i}}{2}$ and (b) $H_{i+1} \leq H_{i}$ in the identified points in $H_{i}$ from the pilot plot. The window sizes obtained are substituted into equation (1.1) above to obtain accompanying density estimates.

The Modified Intersection of Confidence Intervals $\left(\mathrm{MICI}_{H}\right)$ Approach

The $\mathrm{MICI}_{H}$ procedure is basically a minimization of $\operatorname{AMISE}\left(H_{i}\right)$ with respect to $\mathrm{H}$, where it is equivalent to the selection of optimal $h_{i j}$ in $\left\{H_{1}, H_{2}, \ldots . . H_{n}\right\}$. Our data driven bandwidth matrix selector $\hat{H}$ is point wise data base selection approach. Its density uses a pilot plot in order to address identified problem(s).

$\hat{H}=\operatorname{agr} \min _{H_{D_{j}} \in \mathrm{H}} \operatorname{AMI\tilde {SE}}(H)$.

Assuming that

$$
H=\left\{H_{1} \leq H_{2} \leq \ldots . H_{n}\right\}
$$

is a finite collection of window sizes, starting with a smallest $h_{i j} \in H$ and we determine a sequence of confidence intervals given by;

$$
\begin{gathered}
\mathrm{D}_{\mathrm{ij}}=\left[\mathrm{L}_{\mathrm{ij}}, \mathrm{U}_{\mathrm{ij}}\right], \quad i=1, \ldots, n, j=1, \ldots, d \\
\overline{L_{i j}}=\hat{\hat{f}}\left(X_{i}\right)-\beta . \operatorname{std}\left\{\hat{f}\left(X_{H_{j}}\right)\right\} \\
U_{i j}=\hat{f}\left(X_{H_{j}}\left(X_{i}\right)+\beta . \operatorname{std}\left\{\hat{f}\left(X_{H_{j}}\right)\right\}\right.
\end{gathered}
$$

each $h_{i j}$ corresponding to a value in $H_{i} \in H$. We assume the data at hand is normally distributed. Subjecting the data to normality, we propose $\beta=1.06$ via normal reference rule of Silverman (1986). Then

$$
H_{o p t_{i}}(X)=\left[\frac{a b s}{v}\left[\bar{L}_{i j}, U_{i j}\right]\right]
$$

where $\operatorname{abs}\left[\bar{L}_{i j}, U_{i j}\right]=\left|\bar{L}_{i j}-U_{-}\right|=\sqrt{\sum_{i=1}^{n} \sum_{j=1}^{d}\left|\bar{L}_{i j}-U_{i j}\right|^{2}}$ see Gray (1997) for lengths and distances' details.

Subjectively, we adopt $v=2$, considering pilot plots. Where $v$ is a positive real number.

The $M I C I_{H}$ procedure is based on consideration of the intersection of the adjusted intervals $\mathrm{D}_{\mathrm{ij}}, 1 \leq i \leq n$ and $1 \leq j \leq d$. We adopt the bandwidth sizes $H_{\text {opt }_{j}}(X)$ to generate full bandwidths of smoothing parameters;

$H_{o p t_{i}}(X)=\left[\frac{a b s}{2}\left[\bar{L}_{i j}, U_{i j}\right]\right]$ with $H_{o p t_{i}}(X) \leq H_{o p t_{i-1}}(X)$ 
Consequently, substituting bandwidths $H_{\text {opt }_{i}}(X)$ from equation (3.2.5) into the kernel density estimator in (1.1) to obtain the density estimates. Thus, the proposed algorithm is as follows:

\section{Algorithm 2.}

\begin{tabular}{|c|c|}
\hline Step 1 & $L \Leftarrow-\infty, U_{-} \Leftarrow \infty$ \\
\hline Step 2 & while $(\bar{L} \leq U)$ and $(i \leq J) d o$ \\
\hline Step 3 & $\bar{L}_{i j} \Leftarrow \hat{f}\left(X_{H_{i}}\left(X_{i}\right)-\beta . s t d\left\{\hat{H}_{H_{i}}\left(X_{i}\right)\right\}\right.$ \\
\hline Step 4 & $\underset{-}{U_{i j}} \Leftarrow \hat{H_{i}} \underset{\hat{f}}{f}\left(X_{i}\right)+\beta . s t d\left\{\hat{H}_{i}\left(X_{i}\right)\right\}$ \\
\hline Step 5 & $\bar{L}_{i j} \Leftarrow \max \left[\bar{L}, \bar{L}_{i j}\right], U_{j} \Leftarrow \min \left[U, U_{i j}\right.$ \\
\hline Step 6 & $i \Leftarrow i+1$ \\
\hline Step 7 & $H_{o p t_{i}}(x)=\left[\frac{a b s}{2}\left[\bar{L}_{i j}, U_{i j}\right]\right]$ \\
\hline Step 8 & do $i \Leftarrow i+1$ \\
\hline Step 9 & $H_{o p t_{i}}(X) \leq H_{o p t_{i-1}}(X)$ \\
\hline Step 10 & compute $h_{i j}$ in $H_{i} \in H$ \\
\hline Step 11 & end while $(i=n)$ \\
\hline
\end{tabular}

\section{Results}

\section{Application/ Results}

Here we use the data of Little and Rubin (2002, Pg 310, exercise 14.7) with missing observations of a survey of 20 graduates of a university class five year after graduation with missing data of race (White or Others) and income (in Dollar), with estimates based on mode related expectation adaptive maximization (MEAM) imputation. 1 represents male, 2 represents female. 1 represents white race, 2 represents other race. The results are presented in Table 1. The obtained bandwidths from the MMCKDE and $\mathrm{MICI}_{H}$ approaches are substituted into equation (1.1) to get the resulting density presented in Table 2. The Mode-related Expectation Adaptive Maximization (MEAM) based on the Expectation Maximization (EM) approach for the data in missing data experiment showed reduced mean squared error and faster rate of convergence compared to some other approaches, hence it use for imputation (see Ogbeide 2018). 
Table 1. The Estimates of Data Set with Missing Observations in Little and Rubin (2002,Pg 310) using the MEAM Approach

\begin{tabular}{|c|c|c|c|c|c|c|c|c|c|c|c|c|c|c|c|c|c|c|c|c|}
\hline Case & 1 & 2 & 3 & 4 & 5 & 6 & 7 & 8 & 9 & 10 & 11 & 12 & 13 & 14 & 15 & 16 & 17 & 18 & 19 & 20 \\
\hline Sex & 1 & 1 & 1 & 2 & 2 & 2 & 2 & 2 & 2 & 2 & 2 & 1 & 1 & 2 & 2 & 1 & 1 & 1 & 2 & 2 \\
\hline Race & 1 & 1 & 1 & 1 & 1 & 1 & 1 & 1 & 1 & 1 & 1 & 2 & 2 & 2 & 2 & - & - & - & - & - \\
\hline MEAM $_{\text {Race }}$ & 1 & 1 & 1 & 1 & 1 & 1 & 1 & 1 & 1 & 1 & 1 & 2 & 2 & 2 & 2 & 2 & 2 & 2 & 1 & 1 \\
\hline Income & 25 & 46 & 31 & 05 & 16 & 26 & 08 & 10 & 02 & - & - & 20 & 29 & - & 32 & - & - & 38 & 15 & - \\
\hline $\begin{array}{c}\text { MEAM } \\
\text { Income }\end{array}$ & 25 & 46 & 31 & 05 & 16 & 26 & 08 & 10 & 02 & 11.1666 & 11.2380 & 20 & 29 & 37.292 & 32 & 34 & 34.6875 & 38 & 15 & 11.6005 \\
\hline
\end{tabular}


Table 2. Estimated Densities for the Multivariate Cluster Sampling Kernel Density Estimation (MCKDE), the Modified Multivariate Cluster Sampling

\begin{tabular}{|c|c|c|c|c|c|c|c|c|}
\hline Data point & & & Densit & from & andwidths & aches & & \\
\hline$X$ & $\begin{array}{c}\text { Fixed } \\
\text { H density Race }\end{array}$ & MCKDE $_{\text {Race }}$ & $\begin{array}{c}\text { MMCKDE } \\
\text { Race }\end{array}$ & $\begin{array}{c}\mathrm{MICI}_{H} \\
\text { Race }\end{array}$ & $\begin{array}{c}\text { Fixed H } \\
\text { Income }\end{array}$ & MCKDE & MMCKDE & $\mathrm{MICI}_{H}$ \\
\hline & & & & & & & & Income \\
\hline 1 & 0.0414 & 0.0414 & 0.0414 & 0.0414 & 0.0543 & 0.0543 & 0.0543 & 0.0543 \\
\hline 2 & 0.0414 & 0.0414 & 0.0414 & 0.0414 & 0.099 & 0.0981 & 0.099 & 0.0993 \\
\hline 3 & 0.0414 & 0.0414 & 0.0414 & 0.0414 & 0.0674 & 0.0660 & 0.0674 & 0.0674 \\
\hline 4 & 0.0414 & 0.0414 & 0.0414 & 0.0414 & 0.0109 & 0.0109 & 0.0163 & 0.0171 \\
\hline 5 & 0.0414 & 0.0414 & 0.0414 & 0.0414 & 0.0348 & 0.0348 & 0.0370 & 0.0382 \\
\hline 6 & 0.0414 & 0.0414 & 0.0414 & 0.0414 & 0.0565 & 0.0565 & 0.0770 & 0.0830 \\
\hline 7 & 0.0414 & 0.0414 & 0.0414 & 0.0414 & 0.0177 & 0.0174 & 0.0174 & 0.0172 \\
\hline 8 & 0.0414 & 0.0414 & 0.0414 & 0.0414 & 0.0301 & 0.0331 & 0.0329 & 0.0331 \\
\hline 9 & 0.0414 & 0.0414 & 0.0414 & 0.0414 & 0.0042 & 0.0043 & 0.0043 & 0.0044 \\
\hline 10 & 0.0414 & 0.0414 & 0.0414 & 0.0414 & 0.0231 & 0.0279 & 0.0279 & 0.0281 \\
\hline 11 & 0.0482 & 0.0488 & 0.0499 & 0.0501 & 0.0267 & 0.0312 & 0.0324 & 0.0332 \\
\hline 12 & 0.0820 & 0.0820 & 0.0820 & 0.082 & 0.0431 & 0.0435 & 0.0554 & 0.0556 \\
\hline 13 & 0.0820 & 0.0820 & 0.0820 & 0.0820 & 0.0621 & 0.0630 & 0.0630 & 0.0640 \\
\hline 14 & 0.0820 & 0.0820 & 0.0820 & 0.0820 & 0.0846 & 0.0853 & 0.0867 & 0.0872 \\
\hline 15 & 0.0820 & 0.0820 & 0.0820 & 0.0820 & 0.0693 & 0.0695 & 0.0695 & 0.0699 \\
\hline 16 & 0.0414 & 0.0414 & 0.0414 & 0.0414 & 0.0414 & 0.0401 & 0.0267 & 0.0269 \\
\hline 17 & 0.0414 & 0.0414 & 0.0418 & 0.0421 & 0.0826 & 0.0826 & 0.0826 & 0.0791 \\
\hline 18 & 0.0414 & 0.0414 & 0.0414 & 0.0414 & 0.0825 & 0.0825 & 0.0825 & 0.0831 \\
\hline 19 & 0.0414 & 0.0414 & 0.0414 & 0.0414 & 0.0341 & 0.0345 & 0.0347 & 0.0334 \\
\hline 20 & 0.0414 & 0.0414 & 0.0414 & 0.0414 & 0.0279 & 0.0279 & 0.0257 & 0.0250 \\
\hline Density sum & 0.9972 & 0.9978 & 0.9993 & 0.9998 & 0.9523 & 0.9601 & 0.9927 & 0.9995 \\
\hline
\end{tabular}


Below are the table of the calculated bandwidth selections errors and convergence rate from the data set with missing observations in Little and Rubin (2002, Pg 310).

The relative errors, $h^{*}$ (which is the error in relation to the fixed optimal bandwidth value), AMISE ${ }^{*}$ and the convergence rates of methods are given in Table 3.

Table 3. Table of Bandwidth Selection Errors and Convergence Rate from the Estimated Bandwidths for the Race and Income Using the Multivariate Cluster Sampling Kernel Density Estimation (MCKDE), the Modified Multivariate Cluster Sampling Kernel Density Estimation (MMCKDE) and the MICI $_{H}$ Approaches from the Data Set with Missing Observation in Little and Rubin (2002)

\begin{tabular}{|c|c|c|c|c|c|c|}
\hline Approach & $\begin{array}{l}\text { Relative } \\
\text { error v }\end{array}$ & Variance & $\delta$ & $h^{*}$ & $A M I S E^{*}$ & $\begin{array}{l}\text { Convergence } \\
\text { rate }\end{array}$ \\
\hline $\begin{array}{l}\text { MCKDE } \\
\text { (Race) }\end{array}$ & 0.3000 & 0.2812 & 0.5302 & 0.1637 & $6.5021 \times 10^{-2}$ & 0.4071 \\
\hline $\begin{array}{l}\text { MMCKDE } \\
\text { (Race) }\end{array}$ & 0.1000 & 0.1875 & 0.4330 & 0.1091 & $2.3555 \times 10^{-2}$ & 0.7411 \\
\hline $\begin{array}{l}\mathrm{MICI}_{H} \\
\text { (Race) }\end{array}$ & 0.0080 & 0.0072 & 0.0848 & 0.0041 & $5.4365 \times 10^{-3}$ & 0.9763 \\
\hline $\begin{array}{l}\text { MCKDE } \\
\text { (Income) }\end{array}$ & -0.0097 & 8.003 & 2.8289 & 4.6596 & $8.9928 \times 10^{-2}$ & 1.0029 \\
\hline $\begin{array}{l}\text { MMCKDE } \\
\text { (Income) }\end{array}$ & -0.2085 & 7.7639 & 2.7863 & 4.5204 & $5.7629 \times 10^{-2}$ & 1.8675 \\
\hline $\begin{array}{l}\mathrm{MICI}_{H} \\
\text { (Income) }\end{array}$ & -0.2313 & 6.9157 & 2.6297 & 4.0265 & $5.5502 \times 10^{-2}$ & 1.9995 \\
\hline
\end{tabular}

Table 3 showed that there are reduced relative errors, $h^{*}$ (which is the error in relation to the fixed optimal bandwidth value) and $A M I S E^{*}$ in the proposed methods. The proposed methods have faster convergence rates compared to their original versions. That is, the $\mathrm{MICI}_{H}$ have lower error propagation and faster convergence rates when used to estimates the Little and Rubin (2002) data with fixed optimal H, MCKDE and the MMCKDE approaches respectively.

The estimated bandwidth selection errors and convergence rates from the data set with missing observation in Little and Rubin (2002, Pg 310) data, via the various methods favour the use of the MICI approach over the other approaches. This is because its bandwidth errors are smaller as well as having higher convergence rate. The MMCKDE has some improvement over the MCKDE approach. These can be seen in Tables 2 and 3. Generally, the AMISE shows the difference between the "true density" and the estimated density. The AMISE for $\mathrm{MICI}_{H}$ is smaller than that of MMCKDE and MCKDE approaches. The graphical densities displays of the data are given below (Figures 1 and 2). 
Figure 1. Density for Race using the Fixed $H, M C K D E, M M C K D E$ and $M I C I_{H}$ Approaches

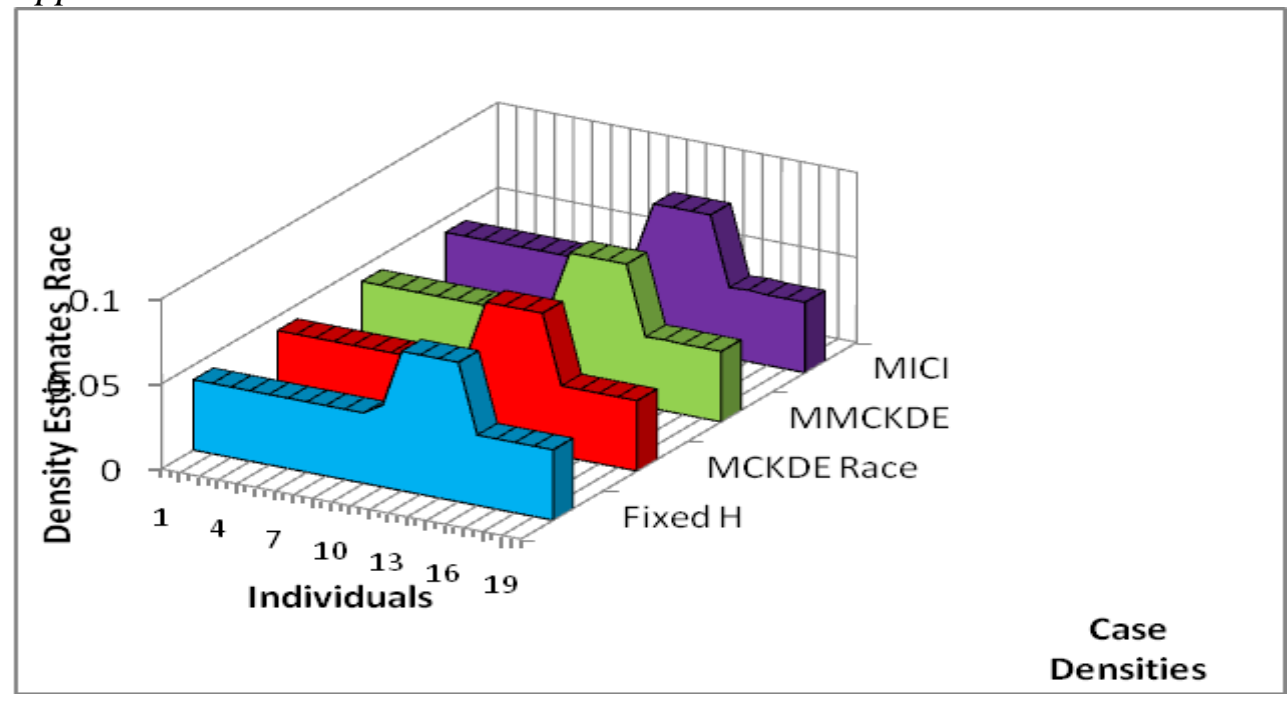

Figure 2. Density for Income using the Fixed $H, M C K D E, M M C K D E$ and $M I C I_{H}$ Approaches

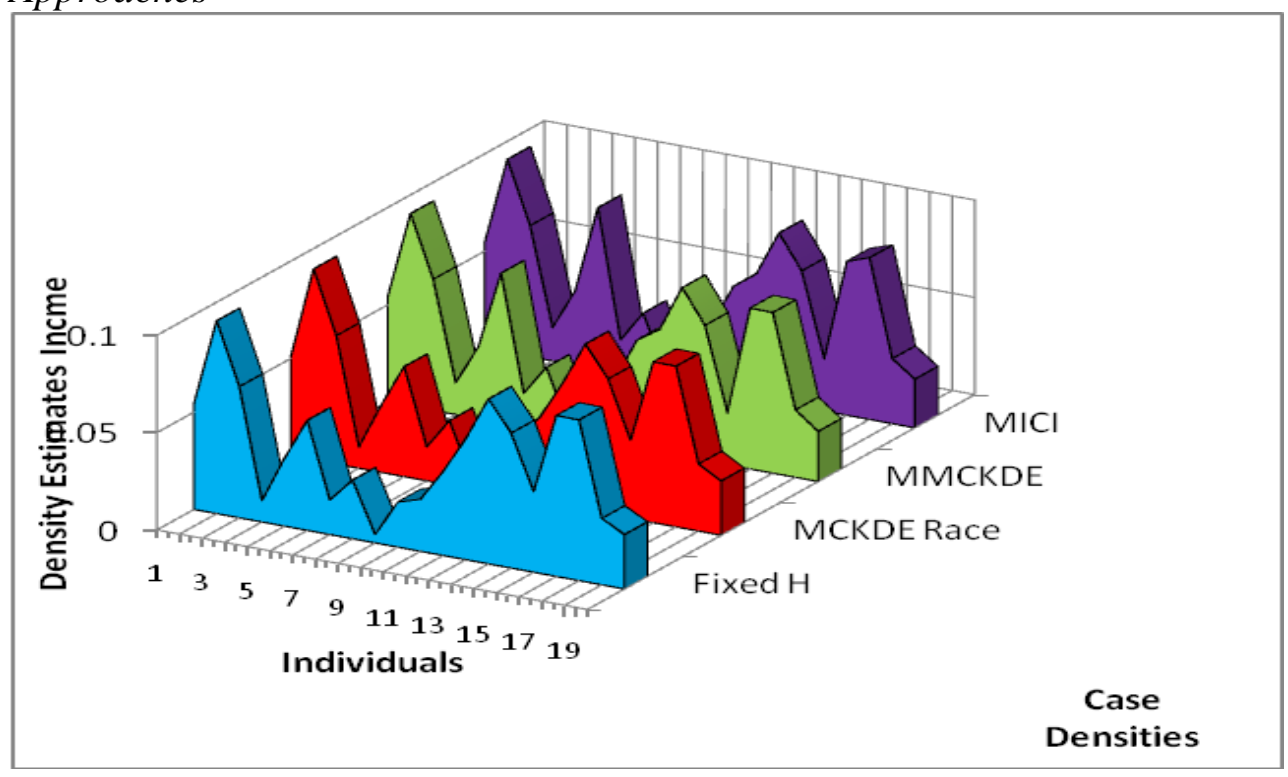

The surface plots are given below. 
Figure 3a. Graphical Density Estimates for Race Data using the Fixed $H$ Approach

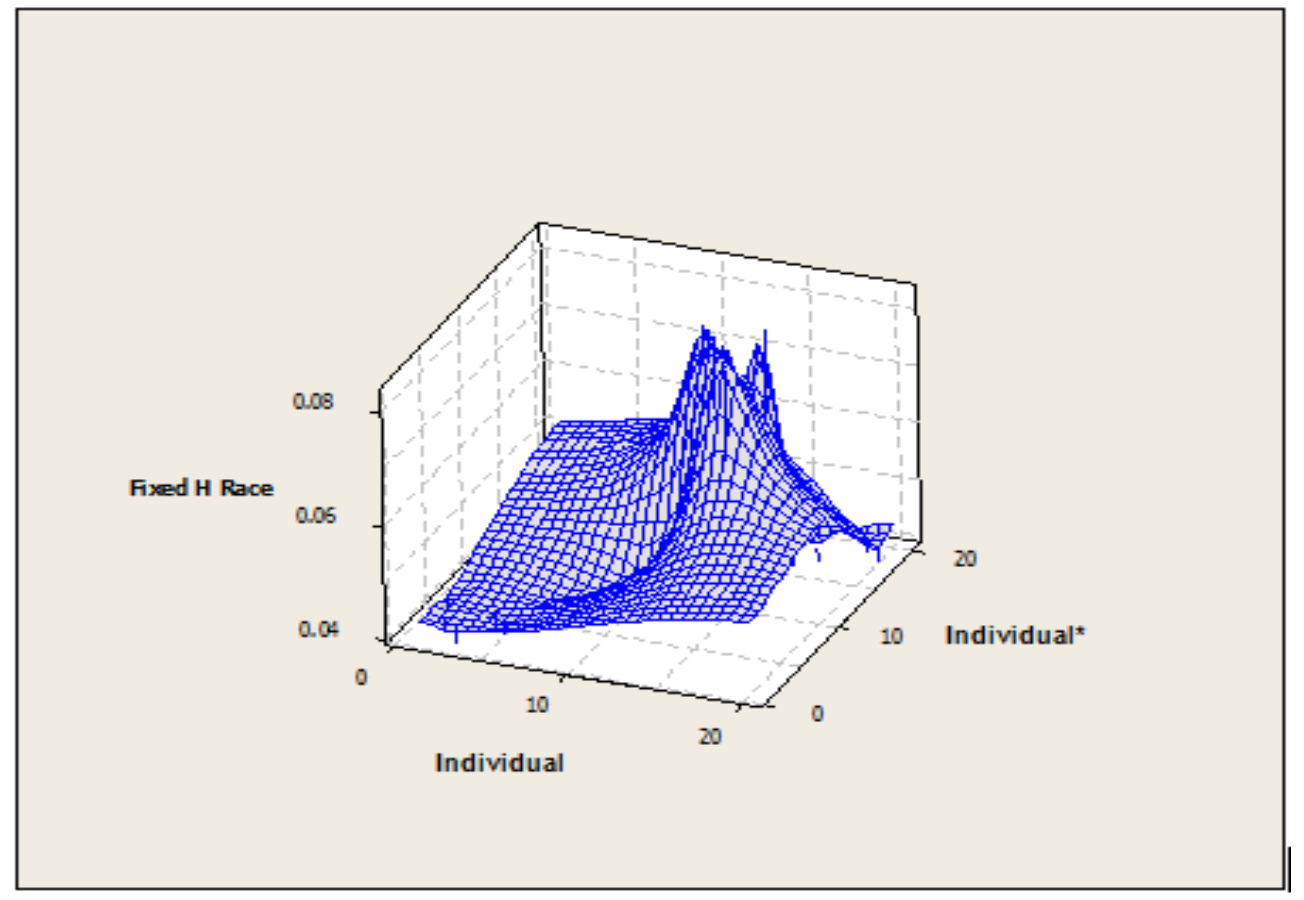

Figure 3b. Graphical Density Estimates for Race Data using the MCKDE Approach

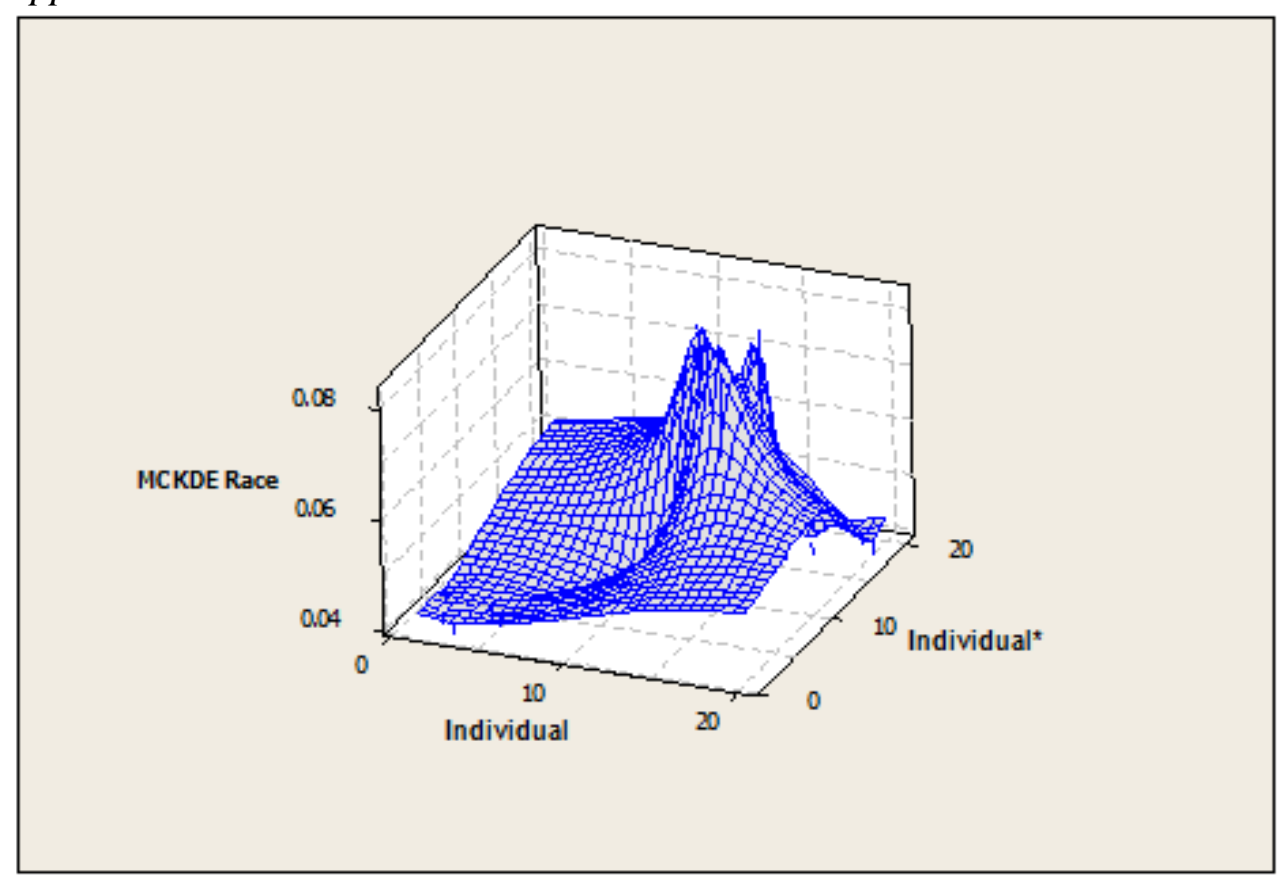


Figure 3c. Graphical Density Estimates for Race Data using the MMCKDE Approach

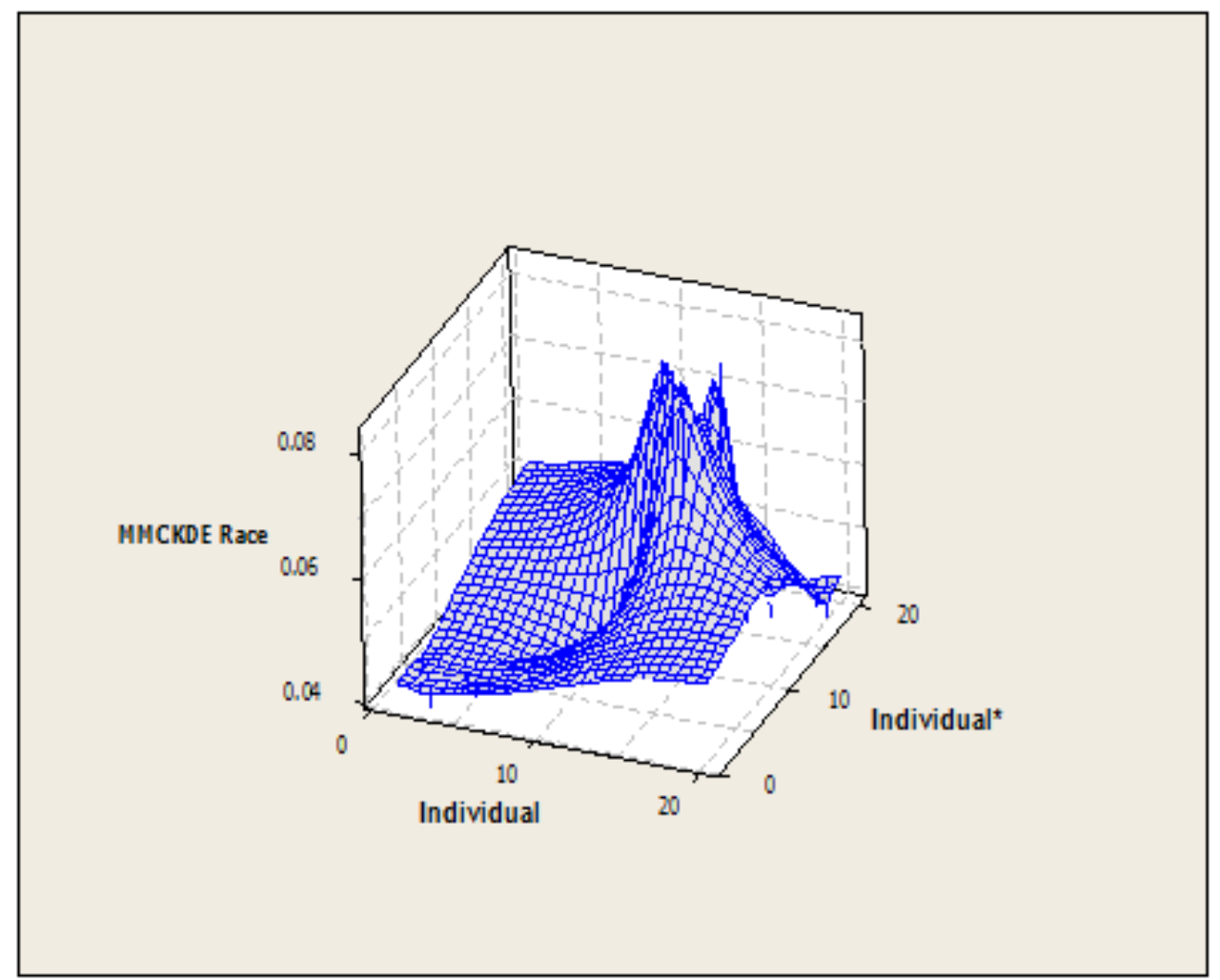

Figure 3d. Graphical Density Estimates for Race Data using the $\mathrm{MICI}_{H}$ Approach

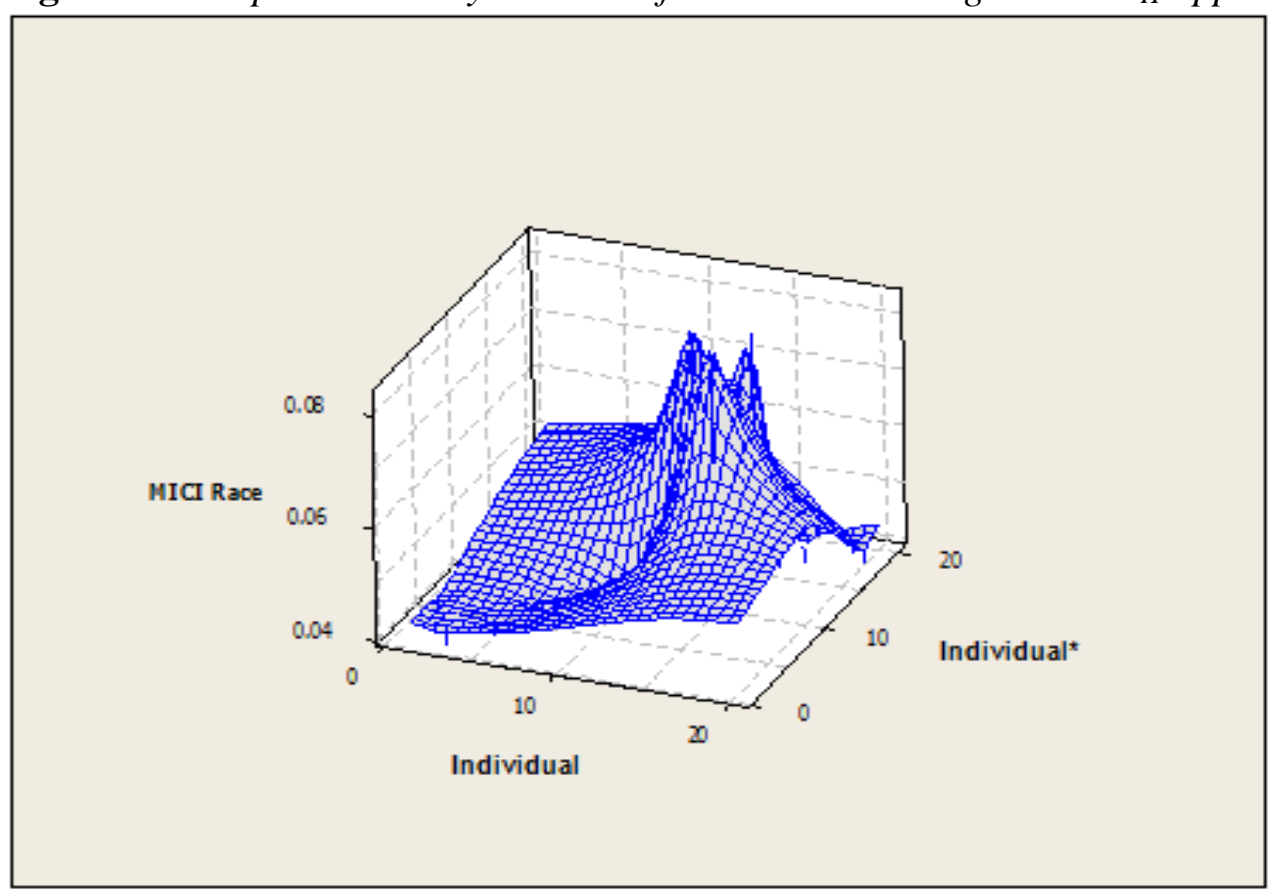


Figure 4a. Graphical Density Estimates for Income using the Fixed H Approach

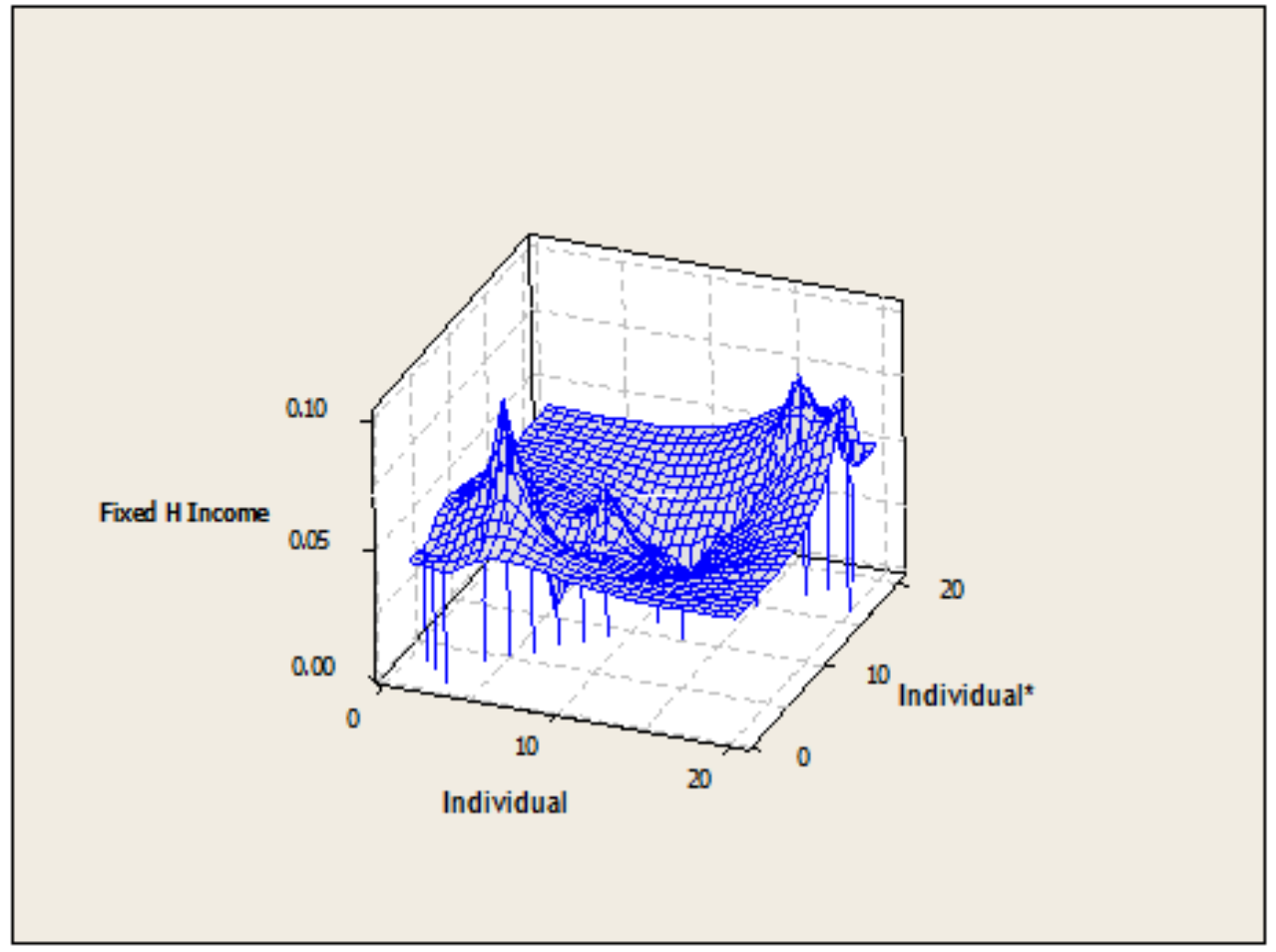

Figure 4b. Graphical Density Estimates for Income using the MCKDE Approach

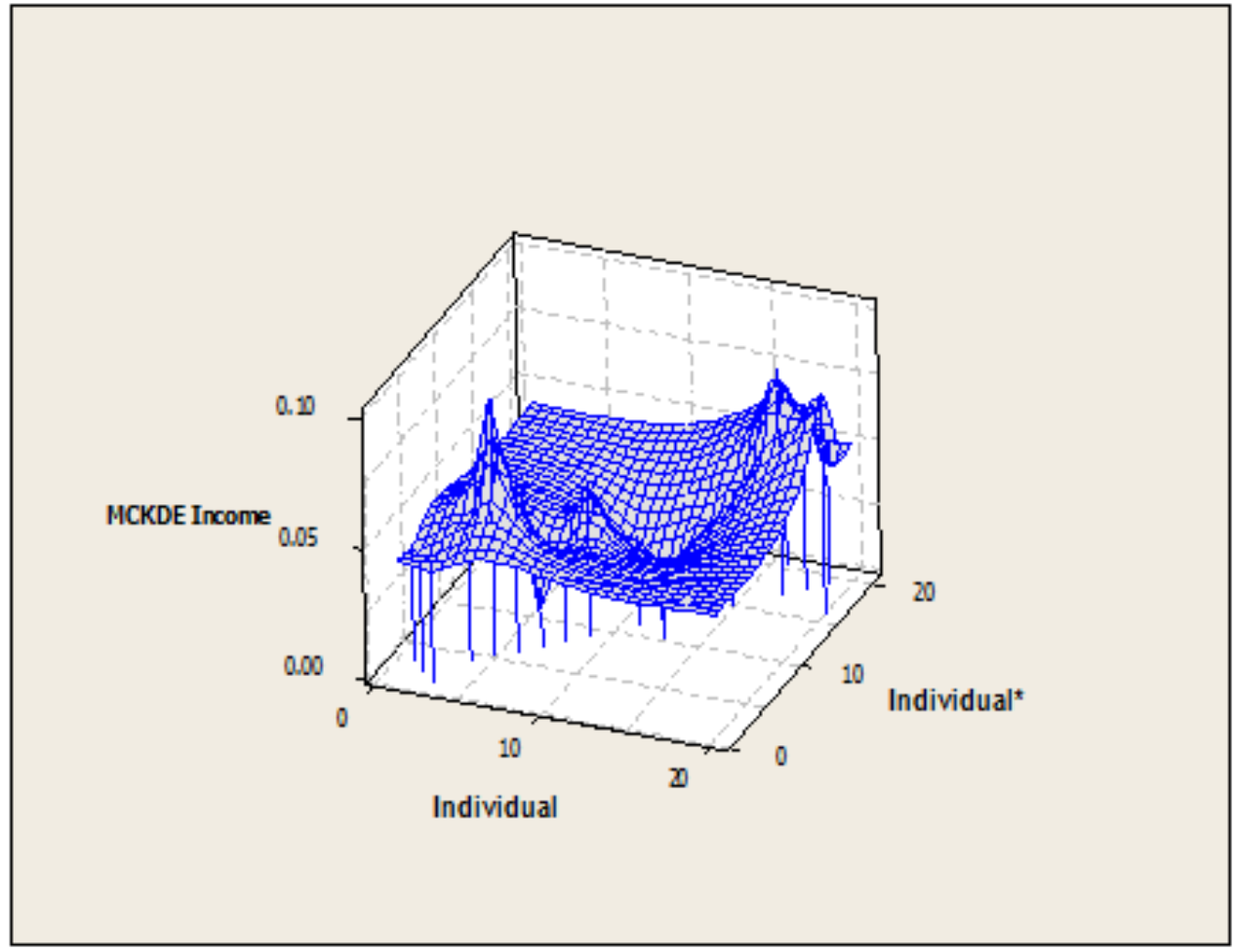


Figure 4c. Graphical Density Estimates for Income using the NMCKDE Approach

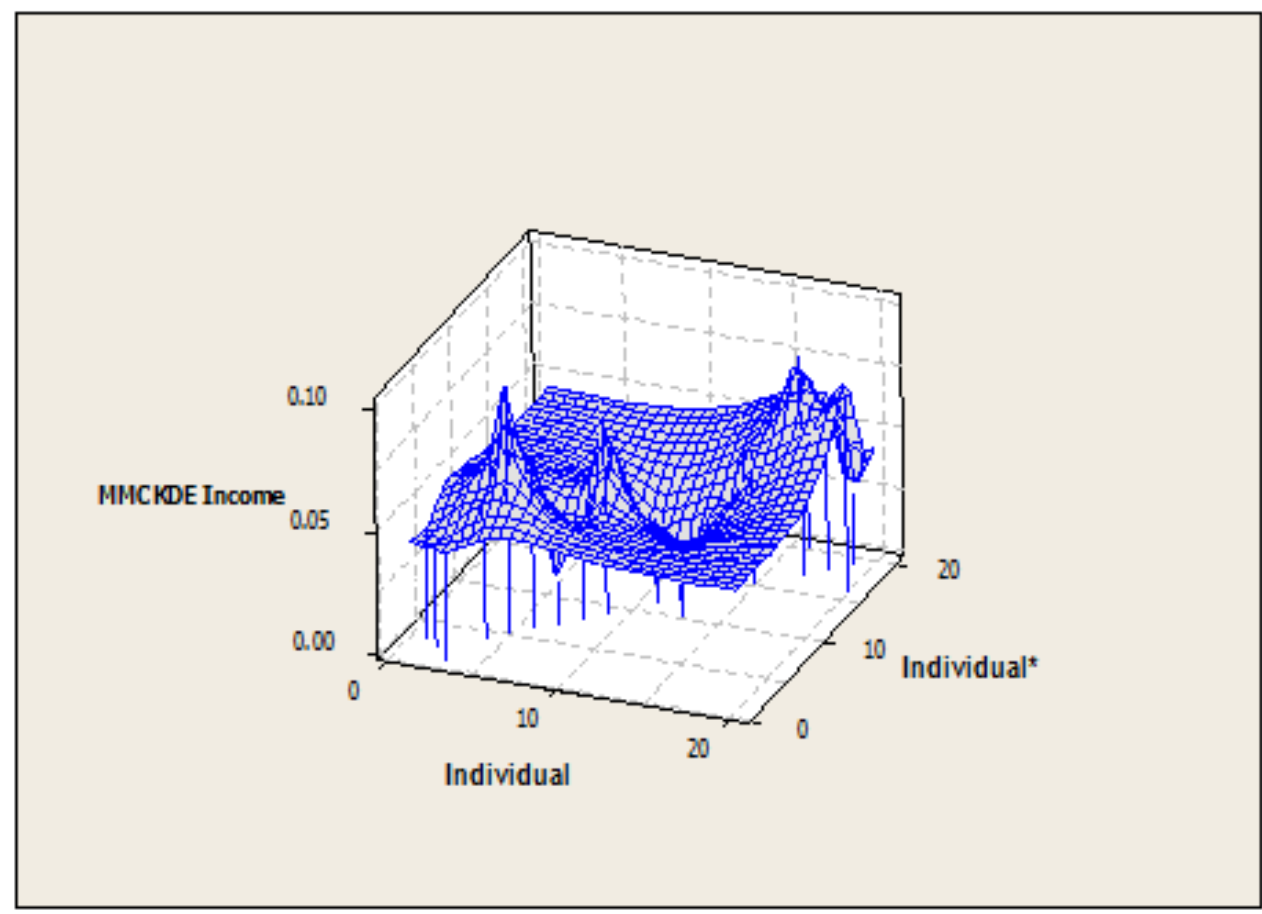

Figure 4d. Graphical Density Estimates for Income using the $\mathrm{MICI}_{H}$ Approach

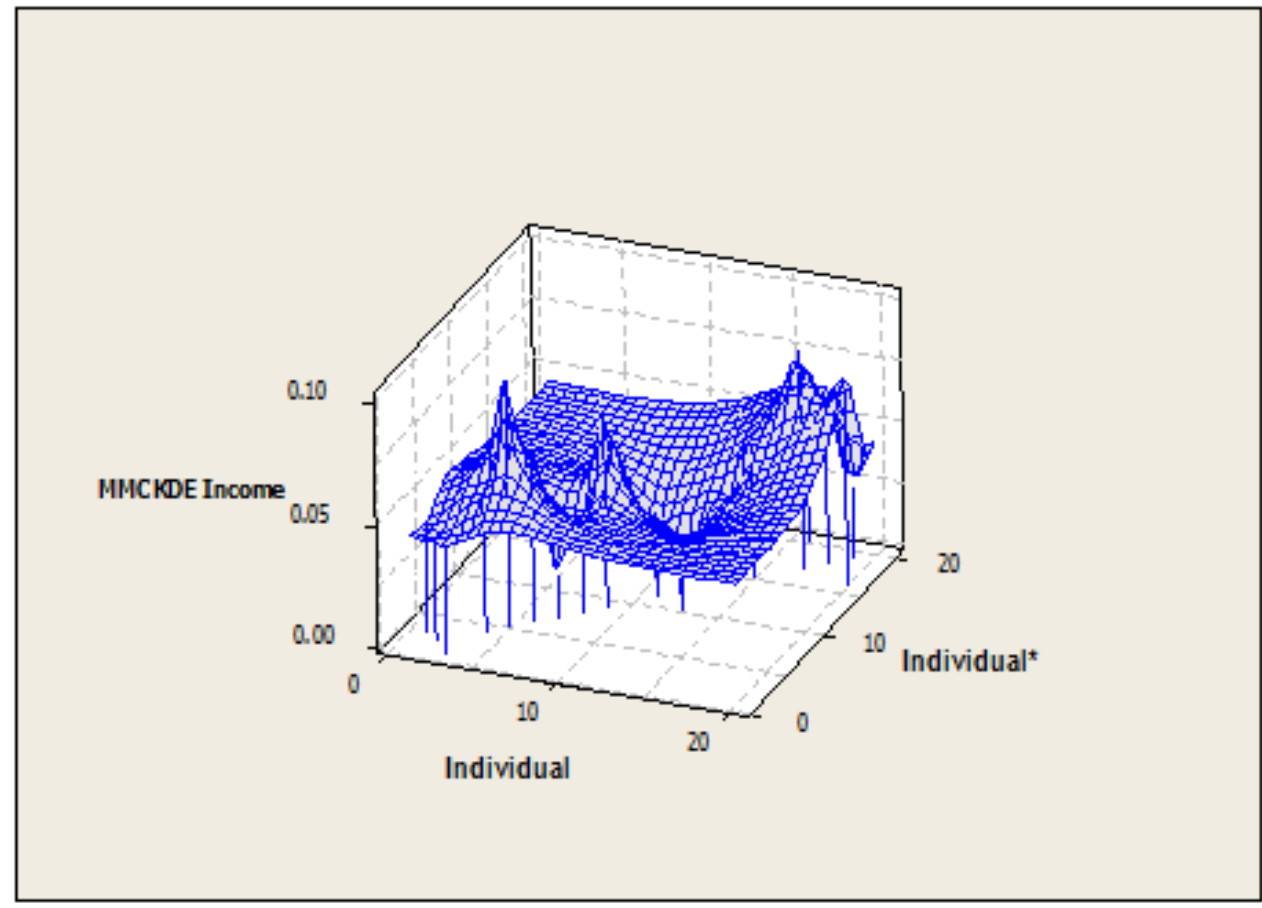

The various approaches have identifiable differences from Figures $3 \mathrm{a}-4 \mathrm{~d}$, using the fixed $\mathrm{H}, \mathrm{MCKDE}, \mathrm{MMCKDE}$ and $\mathrm{MICI}_{H}$ for the dataset in Little and Rubin (2002). 
The MMCKDE corrects identified cluster sampling points of discontinuities in the multivariate kernel nearest neighbourhood density estimate. The $\mathrm{MICI}_{H}$ method which is based on the ICI rule, produces smaller but optimal smoothing parameters extended to the multivariate data set. This is an attempt to achieve reduced error and show more hidden features of the density (see Marrion and Tsybakov 1996).

The modified Intersection of confidence interval $\left(\mathrm{MICI}_{H}\right)$ approach in estimating density show better improvements over the other approaches presented. These are seen in the quality of the density estimates assessed by comparing them with the density obtained using the mean-squared error criterion in Table 3 and in Figures $3 \mathrm{a}-4 \mathrm{~d}$.

In practise, the smaller the variance of the estimate, the better will its contribution to the overall density estimation, as we do not know the true density $f(x)$-Silverman (1986), Wand and Jones (1995), Katkovnik and Shmulevich (2002). We have reduced variances and bias (from AMISE) in our proposed approaches (see Table 2 and Table 3).

According to Silverman (1986), Scott (1992), Cao et al. (1994), Wand and Jones (1995), Katkovnik and Shmulevich (2002) one way of evaluating the method of adaptive window size selection is to compare it to the optimal fixed window size (this is a pilot plot). Our new approaches behave in quite a similar manner. The other approaches are to aim at reducing the AMISE rate in the bandwidth selection method and better convergence rate these were also achieved as seen in Table 3.

\section{Conclusions}

We propose two new varying bandwidths approaches in order to achieve adaptive multivariate kernel density estimation. The quality of the proposed approaches estimates have shown some improvements when assessed and compared with the estimates obtained using existing approaches. These are seen in the errors generated via the AMISE using these proposed approaches, and the convergence rates compared to some other known approaches when applied to some data sets. The MMCKDE and the $\mathrm{MICI}_{H}$ methods are adaptive approaches to data distribution. The MMCKDE corrects identified points of discontinuities in the MCKDE. The $\mathrm{MICI}_{H}$ is based on the intersection of adaptive confidence intervals. Like in every other improved methods, $\mathrm{MICI}_{H}$ requires only simple two additional steps when compared to the ICI approach. These additional procedures are in the choice and application of the smoothing parameters in the multivariate density estimation. The $\mathrm{MICI}_{H}$ and $\mathrm{MMCKDE}$ generate full bandwidth matrices. The cost of these steps brings about the adaptive density constructed. The performance of these approaches with this available data shows that these approaches will perform significantly well for very large size dataset. 


\section{References}

Abramson IS (1982) Arbitrariness of the Pilot Estimate in Adaptive Kernel Methods. Journal of Multivariate Analysis 12(4): 562 -567.

Alan JI (1991) Recent Developments in Nonparametric Density Estimation. Journal of the American Statistical Association 86(413): 205-221.

Bowman AW, Azzalini A (1997) Applied Smoothing Techniques for Data Analysis. Oxford: Clarendon Press.

Breiman L, Meisel W, Purcell E (1977) Variable Kernel Estimates of Multivariate Density. Technometrics 19(2): 135-144.

Cao R, Cuevas A, Manteiga WG (1994) A Comparative Study of Several Smoothing Methods in Density Estimation. Computational Statistics and Data Analysis 17(2): 153-176.

Cencov NN (1962) Evaluation of an Unknown Distribution from Observations. Soviet Math 3: 1559-62.

Duong T, Hazelton ML (2003) Plug-In Bandwidth Matrix for Bivariate Kernel Density Estimation. Nonparametric Statistics 15(1): 17-30.

Duong T, Hazelton ML (2005) Convergence Rates for Unconditional Bandwidth Matrix Selector for Multivariate Kernel Density Estimation. Journal of Multivariate Analysis 93(2005): 417-433.

Elio L, Edgar A (2003) Parallel Computation of Kernel Density Estimates Classifiers and their Ensembles. Proceedings of International Conference on Computer Communications and Control Tecnnologies.

Fukunaga K (1990) Statistical Pattern Recognition (2 ${ }^{\text {nd }}$ Edition). New York: Academic Press.

Friedman JH, Stuetlzle W (1982) Projection Pursuit Regression Analysis. Journal of the American Statistical Association 76(376): 817-823.

Friedman JH, Stuetlzle W, Schneider T (1984) Tool for Viewing Multi-Dimension Surfaces. SIAM Journal of Science and Statistical Computing.

Gray A (1997) The Intuitive Idea of Distance on Surfaces in Modern Geometry of Curves and Surfsces with Mathemtica. ( ${ }^{\text {nd }}$ Edition). Boca Raton, FL: CLC Press, 341-345.

Hall P (1990) On the Bias Variable Bandwidth Curve Estimation. Biometrika 77(3): 527-536.

Hall P (1992) On the Global Properties of Variable Band Width Density Estimator. The Annals of Statistics 20(2): 762-78.

Hall P, Park BU (1987) Extend to which Least-Squares Cross-Validation Minimises Integrated Squared Error in Non-Parametric Density Estimation. Probability Theory and Related Fields 92(1): 1-20.

Hardle W, Scott DW (1992) Smoothing by Weighted Averaging of Rounded Points. Computational Statistics 7: 97-128.

Horova I, Kolacek J, Zelinka J, Vopatova K (2008) Bandwidth Choice for Kernel Density Estimates. Yokohama, Japan: IASC.

Isenman AJ (1991) Recent Developments in Nonparametriuc Density Estimation. Journal of the American Statistical Association 86(413): 205-224.

Jarnicka J (2009) Multivariate Kernel Density Estimation with Parameter Support. Opuscula Matmtica 29(1): 41-55.

Jones MC (1990) Variable Kernel Density Estimates and Variable Kernel Density Estimators. Australian Journal of Statistics 32(3): 36-71.

Jones MC, Mckay IJ, Hu TU (1994) Variable Location and Scale Density Estimation. Annals of the Institute of Statistical Mathematics 46(3): 521-535. 
Katkovnik V (1999) A New Method for Varying Bandwidth Selection. IEEE Transaction in Signal Process 47(9): 2567-2571.

Katkovnik V, Shmulevich I (2002) Kernel Density Estimation with Adaptive Varying Window Size. Pattern Recognition Letters 23(14): 1641-1076.

Little RJA, Rubin DB (2002) Statistical Analysis with Missing Data (2 ${ }^{\text {nd }}$ Edition). New Jersey. USA: Wiley and Sons Publisher.

Marrion JS, Tsybakov A (1996) Visual Error for Qualitative Smoothing. Journal of American Statistical Association 90(43): 499-507.

Muller HG (1985) Empirical Bandwidth Choice for Non-Parametric Kernel Regression by means of Pilot Estimators. Statistical Decisions Supplement 2: 193-206.

Ogbeide EM (2018) A New Iterative Imputation Method based on Adaptive Expectation Maximization. SAU Science-Tech Journal 3(1): 133-142.

Ogbeide EM, Osemwenkhae JE, Oyegue FO (2016) On a Modified Multivariate Cluster Sampling Kernel Approach to Multivariate Density Estimation. Journal of Nigerian Association of Mathematical Physics 34: 123-132.

Osemwenkhae JE (2003) Higher Order Forms in Kernel Density Estimation. PhD Thesis. Nigeria: Department of Mathematics, University of Benin.

Rudemo M (1982) Empirical Choice of Histograms and Kernel Density Estimators. Scandinavian Journal of Statistics 9(2): 65-78.

Sain RR (2002) Muiltivariate Locally Adaptive Density Estimation. Computational Statistics \& Data Analysis 39(2): 165-186.

Salgado-Ugarte IH, Perez-Hernandez MA (2003) Exploring the Use of Variable Bandwidth Kernel Density Estimators. Stata Journal 3(2): 1-15.

Scott DW (1992) Multivariate Density Estimation. New York: John Wiley.

Scott DW, Thompson JR (1983) Probability Density Estimation in Higher Dimensions. In JE Gentle (Ed.), Computer Science and Statistics Proceedings of the Fifteen Symposium on Interface, Amsterdam, Holland, 173-179.

Silverman BW (1986) Density Estimation for Statistics and Data Analysis. London: Chapman and Hall.

Simonoff JS (1996) Smoothing Methods in Statistics. New York: Springer-Verlag.

Tower S (2002) Kernel Probability Density Estimation Method. State University of New York at Stony Book: Seminar Reports on Particular Physics.

Tukey JW (1947) Non Parametric Estimations II. Statistically Equivalent Blocks and Tolerances - The Continuous Case. AMS 18: 29-539.

Victor N (1976) Nonparametric Allocation Rules. In FT Dombai, F Gremy (Eds.), Decision Making and Medical Care: Can Information Help? North-Holland, Amsterdam, 515-529.

Wand MP, Jones MC (1995) Kernel Smoothing London: Chapman and Hall/CRC.

Wu TJ, Tsai MH (2004) Root $n$ Bandwidths Selectors in Multivariate Kernel Density Estimation. Probability Theory and Related Fields 129(4): 537-558.

Wu TJ, Chen CF, Chen HY (2006) A Variable Bandwidths Selectors in Multivariate Kernel Density Estimation. Statistics and Probability Letters 77(4): 462-467.

Wu KL, Shan K., Yung K, Miin-Shen Y, Yuan C (2007) Mean Shift-based Clustering to KDE. Journal of Pattern Recognition 40(11): 3035-3052.

Wu D, Tian Y, Datt A. (2008) Analysis of the Stochastic Interplay between Object Maintenance and Churn. Computer Communications 31(2): 220-239. 